\title{
Aortic valve geometry during the cardiac cycle
}

Citation for published version (APA):

van Renterghem, R. J. (1983). Aortic valve geometry during the cardiac cycle. [Doctoral Thesis, Maastricht University]. Rijksuniversiteit Limburg. https://doi.org/10.26481/dis.19830211rr

Document status and date:

Published: 01/01/1983

DOI:

10.26481/dis.19830211rr

Document Version:

Publisher's PDF, also known as Version of record

\section{Please check the document version of this publication:}

- A submitted manuscript is the version of the article upon submission and before peer-review. There can be important differences between the submitted version and the official published version of record.

People interested in the research are advised to contact the author for the final version of the publication, or visit the DOI to the publisher's website.

- The final author version and the galley proof are versions of the publication after peer review.

- The final published version features the final layout of the paper including the volume, issue and page numbers.

Link to publication

\footnotetext{
General rights rights.

- You may freely distribute the URL identifying the publication in the public portal. please follow below link for the End User Agreement:

www.umlib.nl/taverne-license

Take down policy

If you believe that this document breaches copyright please contact us at:

repository@maastrichtuniversity.nl

providing details and we will investigate your claim.
}

Copyright and moral rights for the publications made accessible in the public portal are retained by the authors and/or other copyright owners and it is a condition of accessing publications that users recognise and abide by the legal requirements associated with these

- Users may download and print one copy of any publication from the public portal for the purpose of private study or research.

- You may not further distribute the material or use it for any profit-making activity or commercial gain

If the publication is distributed under the terms of Article $25 \mathrm{fa}$ of the Dutch Copyright Act, indicated by the "Taverne" license above, 
Aortic valve geometry during the cardiac cycle 


$$
\text { . }
$$




\section{Aortic valve geometry during the cardiac cycle}

\section{Proefschrift}

ter werkrijging van de graad van Doctor in de

Geneeskunde aan de Rijksuniversiteit Limburg

te Maastricht op gezag van de Rector Magnificus

Prof. Dr. H.C. Hemker volgens het besluit

van het College van Dekanen in het openbaar te

verdedigen in de Aula van de Universiteit op

vrijdag 11 februari 1983

des namiddags te 16.00 uur

door

Robert Johannes van Renterghem

geboren te Eindhoven 
Promotores : Prof. Dr. R.S. Reneman, Rijksuniversiteit Limburg, Maastricht Prof. Dr. P.C. Veenstra, Technische Hogeschool, Eindhoven

Co-promotores : Dr. Ir. M.G.J. Arts, Rijksuniversiteit Limburg, Maastricht Dr. Ir. A.A. x. Steenhowen, Technische Hageschool, Eindhoven.

Referenten : Prof. Dr. H.A.J. Struyker Boudier, Rijksuniversiteit Limburg, Maastricht Prof. Dr. Ir. J.D. Janssen, Technische Hogeschool, Eindhoven.

Deze onderzoekingen werden uitgevoerd in thet kader van een samenwerkingsproject tussen de Rijksuniversiteit Limburg te Maastricht en de Technische Hogeschool te Eindhoven.

Het verschijnen van dit proefschrift werd mede moge lijk gemaakt door steun van de Nederlandse Hartstichting.

Financial support by the Netherlands Heart Foundation for the publication of this thesis is gratefully acknowledged.

Typewerk : Mevr. R.M. Borgman-Hanssen

Tekeningen : G.A.P. v.d. Akker en J.H. Onink, Audio-visuele Dienst, Technische Hogeschool Eindhoven

Druk : Schrijen-Lippertz bv, Voerendaal 
Aan Maarten

Voor Janet

Rlnske en Daan 



\section{CONTENTS}

1. GENERAL INTRODUCTION

1.1. Purpose and scope of the present investigation

1.2. Contents of the study

2. THE HEART AND THE AORTIC VALVE

2.1. Introduction

2. 2. Anatomy and functioning of the heart

2.2.2. Functioning of the heart

2.3. Anatomy and functioning of the aortic value

2.3.1. Introduction

2.3.2. Leaflets

2.3 .3 . Sinuses of Valsalva

2.3.4. Aortic ring, interleaflet trigones, intersinus trügones

2.3.5. Functioning of the artic valve during the cardiac cycle

3. THE INDUCTIVE MEASURING TECHN IQUE

3.1. Introduction

3.2. Choice of the technique for strain measurements in the aortic ring

3.3. Strain measurements by the inductive measuring technique

3.3.1. Theory

3.3.2. Analysis of the inductive technique in the experimental situation

3.4. Instrumentation

3.4.2. The design of the coil

3.4.3. Electronic circuitry for strain measurements by two coils 
3.4.4. Electronic circuitry for simultaneous measurement of six strains by six coils

3.4.5. Calibration and specifications of the strain measurement in vitro

3.5. Discussion

4. ANTMAI EXPERIMENTS

4.1. Introduction

4.2. Experimental set-up

4.2.1. Animal preparation

4.2.2. Instrumentation

4.2.3. Cardiopulmonary bypass technique

4.2.4. Experimental protocol

4.3. Data processing

4.3.1. Introduction

4.3.2. Analog-digital conversion of the experimental data

4.3.3. Data processing using interactive computer techniques

4.3.4. Evaluation of strains in the aortic ring

4.4.1. General results

4.4.2. Strain between commissure points

4.4.3. Strain in the base plane of the valve

4.4.4. Strain between base and commissure points

4.5. Discussion

4.5.1. General discussion

4.5.2. Discussion of commissure strain

4.5.3. Discussion of strain in the base plane of the valve

4.5.4. Discussion of strain between commissure and base points

4.5.5. Summary on strain in the aortic ring

5. A MATHEMATICAL MODEL OF COMMISSURE DISPLACEMENT AS A FUNCT"ION OF NORMALIZED TRANSVALVULAR PRESSURE. 
5.2. Simplifications concerning the aortic valve and its adjacent structures

5.3. Design of the mathematical model of aotic valve mechanics

5.3.1. Introduction

5.3.2. Mathematical formulation of the model

5.3.3. Calculation of $h_{c}$ and $d h_{c} / d R_{c}$ from the commissure radius $R_{c}$

5.3.4. Calculation of $d V_{1} / d R_{c}$ and $d v_{2} / d R_{c}$

5.3.5. Calculation of $\mathrm{dV}_{3} / \mathrm{dr}$

5.4. Relation between normalized transvalvular pressure and commissure radius as predicted by the model

5.5. Discussion

6. SUMMARY AND CONCLUSIONS

7. SAMENVATTING

APPENDICES

A1.1. The purpose and the scope of the Eindhoven-Maastricht heart valve research project

A3.1. Derivation of the induced voltage in a receiver coil

A3.2. Analysis of the accuracy of the strain measurement applying the inductive technigue

A5.1. Calculation of volume $V_{3}$ taking into account the non-circular shape of the valve cross-section at the level of the commissures

A5.2. Analysis of the forces exerted by the leaflet upon its commissure points

A5.3. Calculation of $d V_{1} / d R_{c}$ and $d V_{2} / d R_{C}$ : determination of surface areas $A_{1}$ and $A_{2}$

REFERENCES 



\section{LIST OF SYMBOLS}

$a$ scalar
$\vec{a}$ vector
$\vec{a}$ column of scalars $\left[\begin{array}{l}a_{1} \\ a_{2} \\ a_{3}\end{array}\right]$

$\vec{a}$ column of vectors $\left[\begin{array}{l}\vec{a}_{1} \\ \vec{a}_{2} \\ \vec{a}_{3} \\ \vec{a}_{3}\end{array}\right]$

M matrix of scalars $\left(\begin{array}{ccc}a_{11} & a_{12} & \cdots \\ a_{21} & a_{22} & \\ \ldots & & \end{array}\right)$

a mean of scalar a

stochastic scalar

var(䒧) variance of ${ }^{*}$

sa change of a

$\|\vec{a}\|$ magnitude of the vector $\vec{a}$

$\vec{a} \circ \vec{b}$ scalar product of $\vec{a}$ and $\vec{b}$

$\vec{a} * \vec{b}$ vector product of $\vec{a}$ and $\vec{b}$

$\underline{a}^{T} \quad$ transposed of column $\underline{a}: \underline{a}^{T}=\left[a_{1} a_{2} a_{3}\right\rfloor$

$M^{T} \quad$ transposed of matrix $M$ : refiection of the components of $M$ with respect to the $a_{11^{-a_{n}}}$ diagonal,

$M=\left(\begin{array}{lll}a_{11} & a_{12} & \cdots \\ a_{21} & a_{22} & \\ \ldots & & a_{n n}\end{array}\right) \quad M^{T}=\left(\begin{array}{ll}a_{11} & a_{21} \\ a_{12} & a_{22} \\ \ldots & \end{array}\right.$

Definitions:

$\vec{e}_{i} \quad$ orthonormal vector base $\underset{\rightarrow}{i t h} \vec{e}_{i}^{T}=\left[\vec{e}_{i_{j}} \vec{e}_{i_{k}} \vec{e}_{i_{j}}\right]$ orthonormal: the vectors $\vec{e}_{i_{j}}, \vec{e}_{i_{k}}, \vec{e}_{i_{l}}$ are perpendicular to each other and have unit length

$M_{i, j}$ rotation matrix which relates the orientation of $\vec{e}_{i}$ to $\vec{e}_{j}$ :

$$
\overrightarrow{\underline{e}}_{\mathbf{i}}=\underline{M}_{i}, j \cdot \overrightarrow{\underline{e}}_{j}
$$





\section{GENERAL INTRODUCTION}

\subsection{PURPOSE AND SCOPE OF THE PRESENT INVESTIGATION}

The investigations dealt with in the present thesis have been performed within the framework of the Eindhoven-Maastricht heartvalve research project, which is described in appendix Al, 1 . It is the aim of the project to obtain specifications for the design and the implantation of an artificial triple-leaflet-valve prosthesis which has a longer 1 ife than the ones nowadays in use. For this purpose the behavior of the natural as well as the artificial valves presently availabe is investigated with respect to hydrodynamical and mechanical performance.

One of the topics of the project concerns the determinants of the stresses in the leaflets of the natural aortic valve. These stresses are mainly determined by instantaneous forces exerted by the blood on the leaflets, by instantaneous changes in the threedimensional geometry of the suspension of the leaflets (aortic ring) and by material properties of the leaflets. The aim of the present study is to get insight into changes of the three-dimensional geometry of the aortic ring during the cardiac cycle and the mechanism which controls this geometry.

In literature only little information could be found about changes in the three-dimensional geometry of the aortic ring during the cardiac cycle. Thubrikar and co-investigators (1977, 1979, 1980, 1981) studied by means of angiography the changes in perimeter of two triangles, one determined by the three commissure points and the other determined by the three base points (figure 1.1), in the intact canine aortic valve. The dynamic relation between leaflet motion and distension of the aortic root was studied by Brewer and co-investigators (1977). Akgün and Layton (1977) and Ambrose and co-investigators (1980) studied motion of the anterior and posterior wall of the 'aortic root' by m-mode echo-cardiography. Mercer investigated the motion of two points at the base of the aortic ring (1969) as well as the 


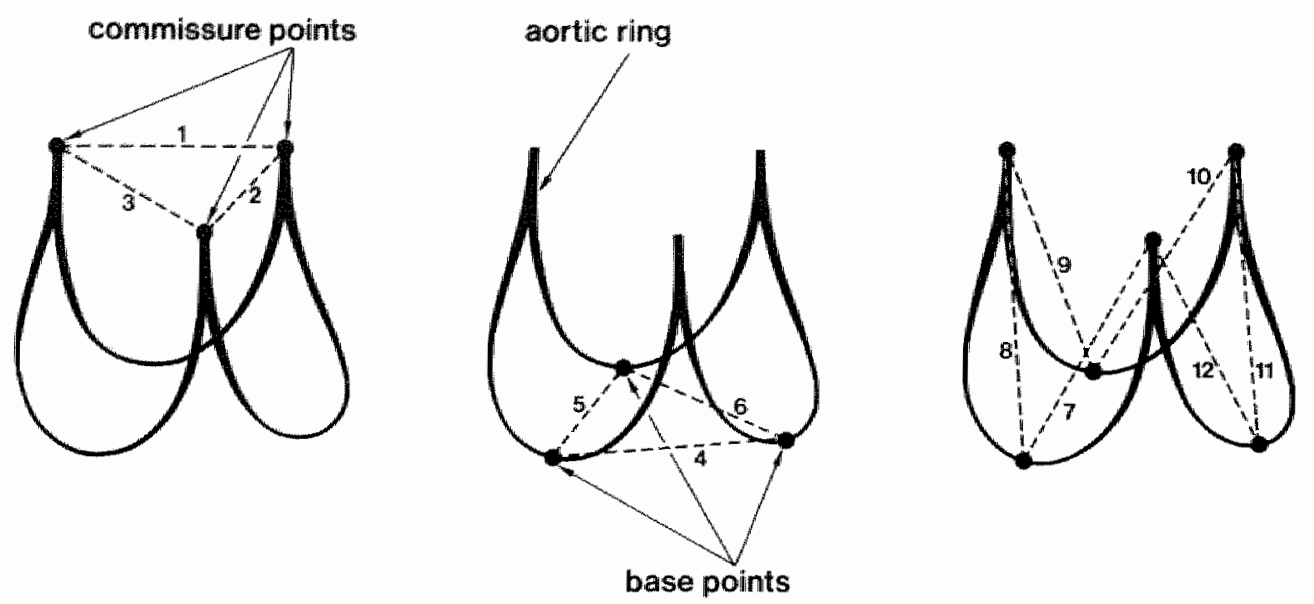

FIGURE: 1.1

strain between commissure points $(1,2,3)$, between base points $(4,5,6)$, and between comissure points and base points (7-12).

movement of the leaflets (1973) by cine-angiography. The instantaneous position of the right coronary leaflet during the cardiac cycle was determined by Heckman and co-investigators (1972), using high speed angiography. From this literature no detailed information could be obtained about the relation of instantaneous changes in geometry of the aortic ring and hemodynamic variables such as aortic and left ventricular pressure during the entire cardiac cycle.

In the investigations of the present work, the three-dimensional geometry of the aortic ring has been studied both in vivo in the canine aortic valve and in a mathematical model. only movements of those parts of the aortic ring were studied which are assumed to be of major importance for the state of stress in the leaflet: In histological preparations of the pig aortic leaflet sauren (1980) observed that this structure is attached to the aortic ring mainly by collagen bundles which run from commissure to commissure parallel to the free edge of the leaflet. From the centerpart of the leaflet, however, some collagen bundles run towards the aortic ring to penetrate the latter almost perpendicularly close to the base points. It is assumed that these collagen bundles suspend the leaflet to the aortic ring. Hence 
changes in the mutual positions of the commissure points and the base points are likely of main interest for the investigation of stresses in the leaflet.

In the present study changes in the natural strains between the commissure points, between the base points, and between the commissure points and the base points (figure 1.1) were determined in the dog aortic valve during the cardiac cycle. Natural strain is defined as the natural logarithm of the ratio of the instantaneous distance between two points and the original distance between these points. Hence, change of natural strain is found as the logarithm of the ratio of instantaneous distances between two points, whereas the original distance between these points is insignificant. Changes in natural strain were chosen to be determined because variations in distance between two points can easily be compared with these variations at any other site, whereas it is not necessary to know the absolute magnitude of instantaneous distances. Consequently, comparison of strain behavior of different valves of different size becomes readily feasible. Changes in the natural strains in the canine aortic ring were determined with a specially designed and developed measuring system, which is based on an electromagnetic induction technique. The measuring system delivers an output signal proportional to the natural strain. From this output signal change of strain can be determined. Thus, in order to measure natural strain, it is not necessary to know the instantaneous distances in the aortic ring. This is a major advantage because these distances cannot be determined accurately in the intact dog aortic valve. By the measuring system changes of six natural strains in the aortic ring can be determined simultaneously and continuously during the cardiac cycle. The frequency response of the system (up to $150 \mathrm{~Hz}-3 \mathrm{~dB}$ ) permits the measurement of fast changes in natural strain during the isovolumic phases of the cardiac cycle as well as during valve opening and valve closing.

Changes in aortic valve geometry may result from elastic deformation of materials involved as well as from change in shape due to redistribution of forces at the attachments of the leaflets to the sinuses of Valsalva. The latter change of geometry is 
deroted as non-elastic deformation. The change of natural strain in the aortic ring was evaluated with respect to the change in three quantities:

- the pressure in the ascending aorta.

- the pressure in the left ventricle.

- the nomalized transvalvular pressure, defined as the ratio of the pressure difference between ascending aorta and left ventricle and the pressure in the ascending aorta.

These quantities are chosen because they describe the pressure load of the valve completely - assuming that the pressure in the thoracic cavity is that low it can be neglected - and hence detemine the geometry of the aortic ring. The aortic pressure and the left ventricular pressure determine the elastic deformation of the aortic ring: the aortic pressure mainly determines the deformation of all valve parts except for the leaflets; the difference between aortic and left ventricular pressure mainly determines the elastic deformation of the leaflets when the valve is closed. The normalized transvalvular pressure is assumed to determine the mon-elastic deformation of the aortic valve (chapter 5).

The relation of the change of the natural strain between the commissure points and change of normalized transvalvular pressure at constant aortic pressure was analyzed in a mathematical model. The relevancy of this investigation follows from the fact that during the isovolumic phases of the cardiac cycle normalized transvalvular pressure changes rapialy. As a consequence, rapid changes in the state of stress in the leaflets are to be expected, followed by a change in geometry. First attempts were made to extend the finite element model as proposed by sauren (1981) by introducing as constitutive components both a flexible aortic ring and a sinus of Valsalva. However, this extended model is not available yet. Therefore, a new much simpler mathematical model. has been developed based on the principle of minimum energy and simplification of the geometry and material properties of the aortic valve. The prediction of the latter model of change of strain between commissure points as a function of normalized transvalvular pressure, has been compared with in vivo results. 


\subsection{CONTENTS OF THE STUDY}

In chapter 2 the anatomy and the function of the heart and the aortic valve are described. "The different parts of the artic valve are denoted for use throughout the thesis.

In chapter 3 the problems encountered in measuring natural strains in the canine aortic ring in vivo are discussed keeping in view the specific feasibility of different techniques available to measure these strains. Next, the principle of the electromagnetic measuring technique used, is described. The accuracy of determination of strains in the aortic ring by this technique is estimated. Consequently a description of the electronics of the measuring system is given. Finally, the performance of the measuring system is evaluated in an in vitro experimental set-up.

In chapter 4 the measurement of strains in the canine aortic ring in vivo is described. The experimental set-up is presented and a description is given of the data processing used to evaluate the movements of the commissure points and the base points. The chapter ends with a presentation and discussion of the results of the data processing.

In chapter 5 a mathematical model which relates the normalized transvalvular pressure to the strain between the commissures is described. The assumptions about the material properties and the geometry of the aortic valve are presented. It is followed by the description of the mathematical model. The predictions of the model are compared to the experimental results as presented in chapter four.

Chapter six contains the summary and conclusions of the present study. 


\section{THE HEART AND THE AORTIC VALVE}

\subsection{INTRODUCTION}

In the first part of the present chapter some anatomical and functional aspects of the heart are reviewed. The information, as taken from textbooks (McAlpine 1975, Guyton 1976, caro et al. 1978) is basic and may be omitted by the reader who is familiar with it. In the second part of the chapter the anatomy and the histology of the aortic valve and its function throughout the cardiac cycle are described. As in literature parts of the aortic valve are not defined uniformly, the definitions as used in the present study are also given.

\subsection{ANATOMY AND EUNCTIONING OF THE HEART}

\subsubsection{Anatomy}

Figure 2.1 diagrammatically shows a sagittal cross-section of the heart. The heart consists of four cavities, a left and a right ventricle and a left and a right atrium. The left ventricle and the left atrium as a whole are called the left side of the heart, whereas the right ventricle and the right atrium are named the right side of the heart. The left and the right atrium are separated by the atrial septum, whereas the left and the right ventricle are separated by the ventricular septum. The remaining parts of the ventricular walls are the free walls of the ventricles. The free wall of the left ventricle is much thicker than the one of the right ventricle because the pressure is much higher in the left than in the right ventricle. The inner and outer surface of a ventricular wall are called endocardium and epicardium respectively, the tissue in between is the myocardium.

Four heart valves are situated in the base plane of the heart; two on the left side of the heart and two on the right side of it. The valves in between the atria and the ventricles are called 


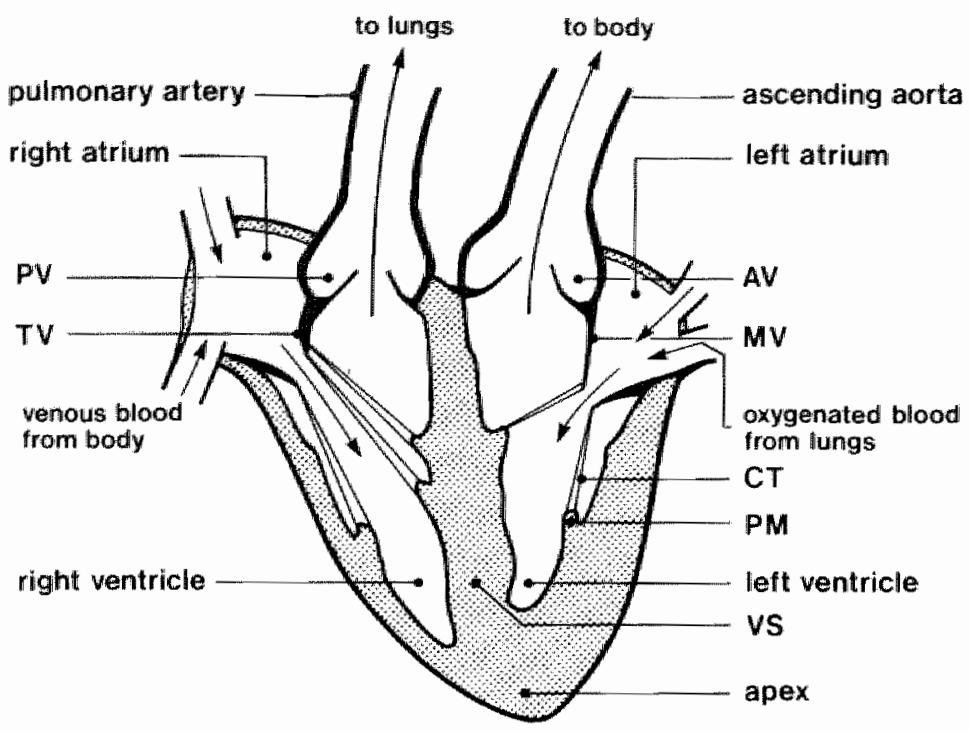

FIGURE 2.1

Schematic sagittal cross-section of the heart. $A V=$ aortic valve; $C I^{\prime}$ chordae tendineae; $M V=$ mitral valve; $P M=$ papillary muscle; $P V=$ pulmonary valve; TV = tricuspid valve; VS = ventricular septum (after Caro et al. 1978).

atrio-ventricular valves. The ather two - one in between the right ventricle and the pulmonary trunk and another one in between the left ventricle and the aorta - are called semilunar valves. Opposite to the base plane is the apex of the heart. At this site the free ventricular walls are relatively thin.

From the endocardium of both ventricles papillary muscles project into the ventricular cavities. These muscles are connected to the atrio-ventricular valves by fine fibrous bands (chordae tendineae). The combination of papillary muscles and chordae prevents the atrio-ventricular valves from bulging into the atria when both ventricles pump blood into the arterial systems.

The veins which collect the blood from the systemic arterial circulation empty into the right atrium, whereas the blood from the lungs drains into the left atrium via the pulmonary veins. From the left atrium the blood drains into the left ventricle through one of the atrio-ventricular valves, the mitral valve. 
The left ventricle empties into the ascending aorta through a semilunar valve, the aortic valve. Analogously, the right ventricle receives blood from the right atrium through the tricuspid valve whereas it empties into the pulmonary trunk through the pulmonary valve. In the dog the first large side branches of the aorta are the brachiocephalic artery and the left subclavian artery, which supply the head and the upper extremities with blood. In humans three aorta branches have this function. The pulmonary trunk bifurcates after a short distance into the left and right pulmonary arteries.

2.2.2. Functioning of the heart

Under normal circumstances the human heart contracts about once a second. The periad from the beginning of one heart contraction to the beginning of the next one is called the cardiac cycle. The contraction cycle starts with the spontaneous generation of an action potential in the sino-atrial node, which is situated in the wall of the right atrium. This action potential travels through both atrial walls (causing atrial contraction) and conseguently. via the atrio-ventricular node and the atrio-ventricular bundle (bundle of His) to the wall of both ventricles. This conduction system has the ability to initiate atrial contraction about 0.1 sec prior to ventricular contraction, which enables the atria to empty into the ventricles.

During the cardiac cycle the following phenomena occur. At the end of the contraction period and during the relaxation period of the ventricles blood flows into the right atrium from the systemic veins and into the left atrium from the pulmonary veins, which results in an increase in pressure in both atria. Because of this pressure increase and the relaxation of the ventricles the atrioventricular valves open and the ventricles are filled. This filling is completed by the contraction of both atria which is initiated by the action potential from the sino-atrial node. Then ventricular contraction starts and the atrio-ventricular valves close, partly as a result of the increase in pressure in the ventricles. As long as the pressure in the arteries laorta and 
pulmonary trunk) exceeds the pressure in the ventricles the semilunar valves remain closed and the ventricular volumes are constant. As soon as the pressure in the ventricles exceeds the arterial pressures the semilunar valves open. Now the ventricles empty into the arteries. A steep rise in ventricular outflow is Eollowed by a slower decline due to relaxation of the ventricles. During the decline of the ventricular outflow the semilunar valves close gradually. When finally a small backflow towards the ventricles occurs the valves clase completely. For normal man the volume ejected from the ventricle during one cardiac cycle ranges in between 70 and $100 \mathrm{~cm}^{3}$, which is about 60-70 percent of the ventricular contents (Caro et al. 1978). As ventricular muscle continues to celaxe the pressure in the ventricles drops further. During this relaxation both ventricular volumes again are constant because all valves are closed. When pressure in the ventricles falls below the pressure in the atria the atrio-ventricular valves, open again.

By the moment of closure and opening of the semilunar and atrio-ventricular valves the cardiac cycle is divided into four phases:

- isovolumic contraction phase: starts at the moment of closing of the atrio-ventricular valves and ends when the semilunar valves open.

- ventricular ejection phase: starts at the moment of opening of the semilunar valves and ends when they close.

- isovolumic relaxation phase: starts at the moment of closing of the semilunar valves and ends at the moment of opening of the atrio-ventricular valves.

- ventricular filling phase: starts at the moment of opening of the atrio-ventricular valves and ends when they close.

The isovolumic contraction phase and the ventricular ejection phase together are called the ventricular systole. The isovolumic relaxation phase and the ventricular filling phase together are called the ventricular diastole. At low heart rates (about 60 beats.min ${ }^{-1}$, systole occupies about one third of the cardiac cycle. At increasing heart rates this interval increases relative to the duration of the diastolic phase. The pressure curves as 


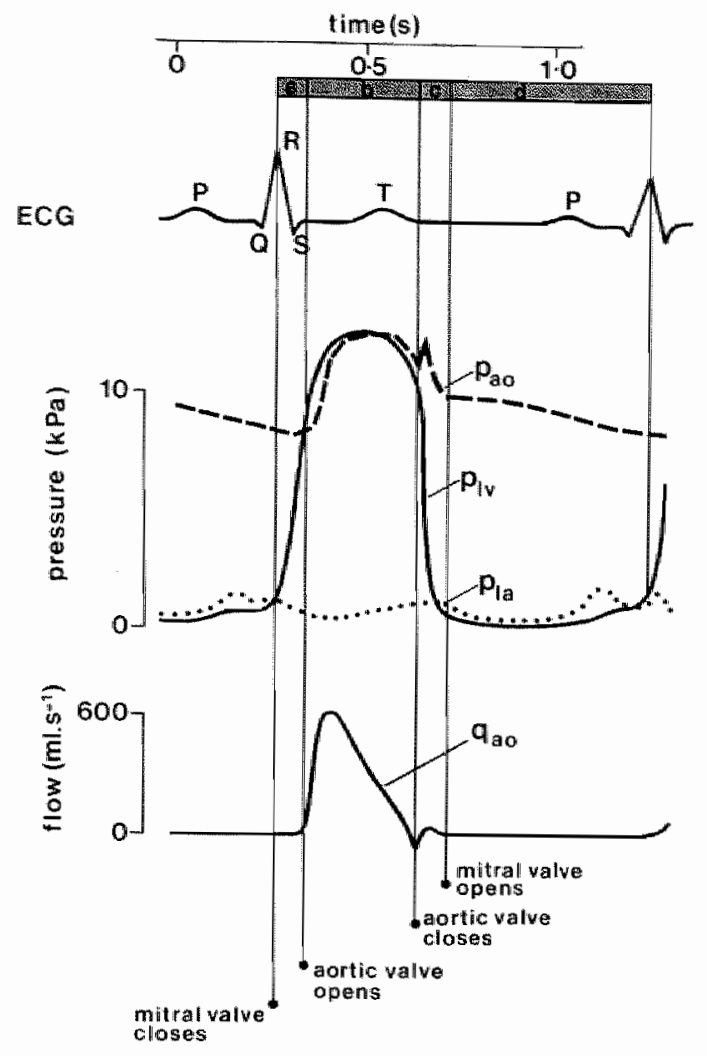

FIGURE 2.2

Diagrammatic representation of pressures in the left ventricle $\left(p_{1 v}\right)$. the aorta $\left(\mathrm{P}_{\mathrm{aO}}\right)$, and the left atrium $\left(p_{1 a}\right)$ as well as volume flow in the ascending aorta ( $9 a{ })$ and the elecm tracardiagram (ECG) during one cardiac cycle, $a=$ isovolumic contraction phase; $b=$ ventricular ejection phase, $c=$ isovolumic relaxation phase; $d=$ ventricular filling phase (after Caro et al. 1978).

recorded as a function of time in the ascending aorta as well as in the left atrial and left ventricular cavities, together with the instantaneous aortic flow curve are shown in figure 2.2. In the accompanying electracardiogram the "P-wave" represents the contraction of the atria, the "ORS-complex' the depolarization of both ventricles and the 'T-wave' the repolarization of the ventricles.

\subsection{ANATOMY ANE FUNCTIONING OF THE AORTIC VALVE}

\subsubsection{Introduction}

The aortic valve is situated between the outflow orifice of the 


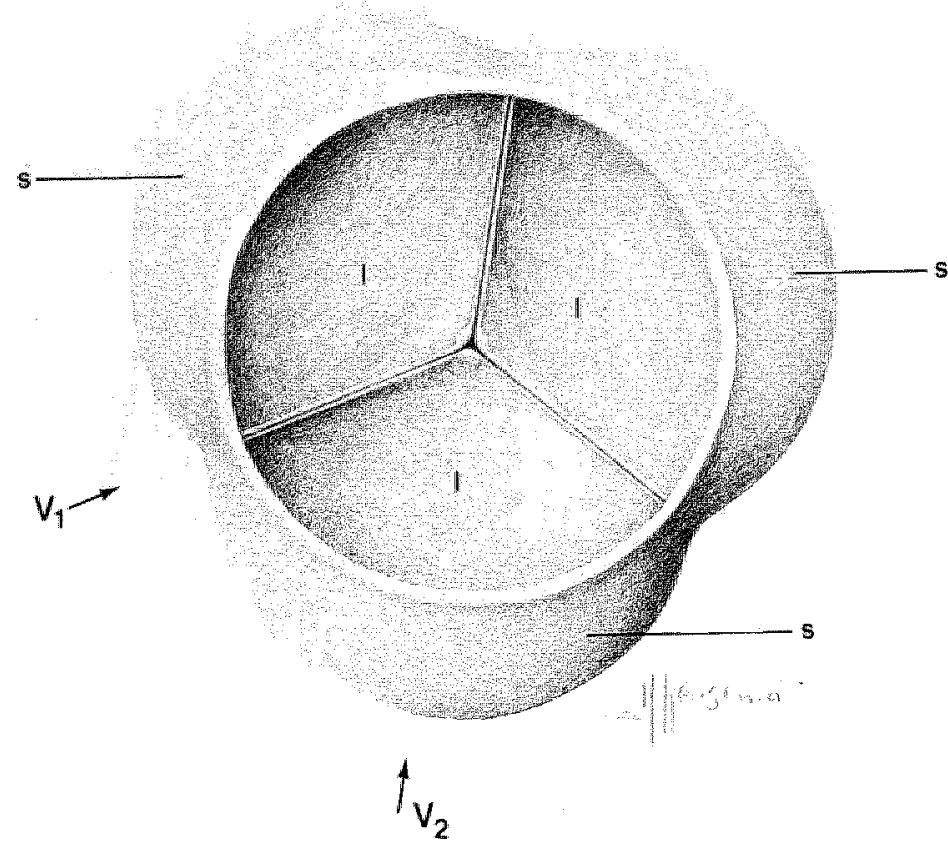

A

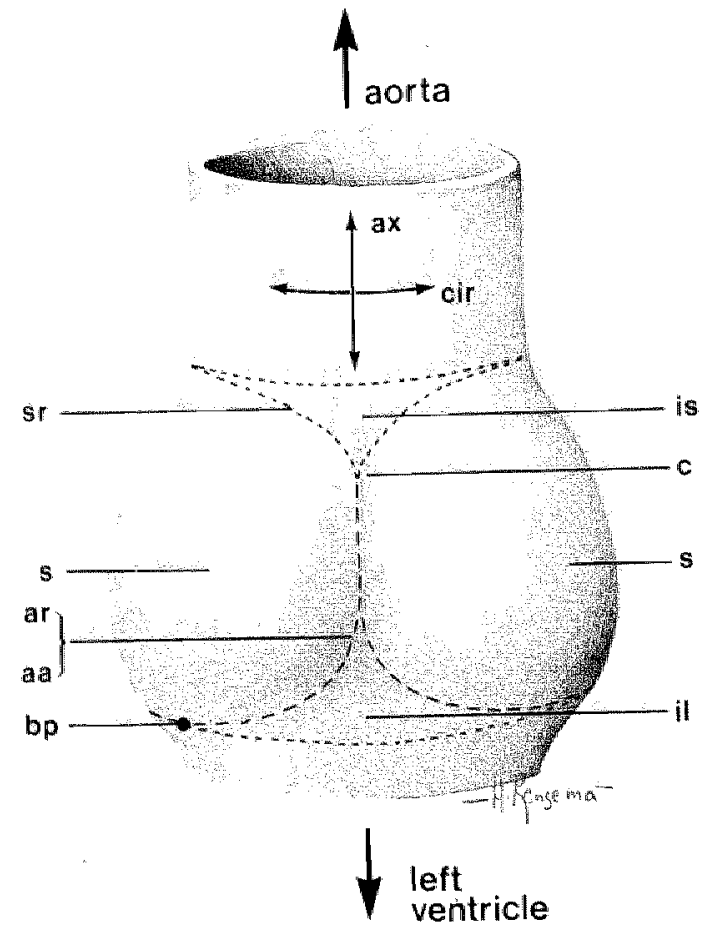

B 


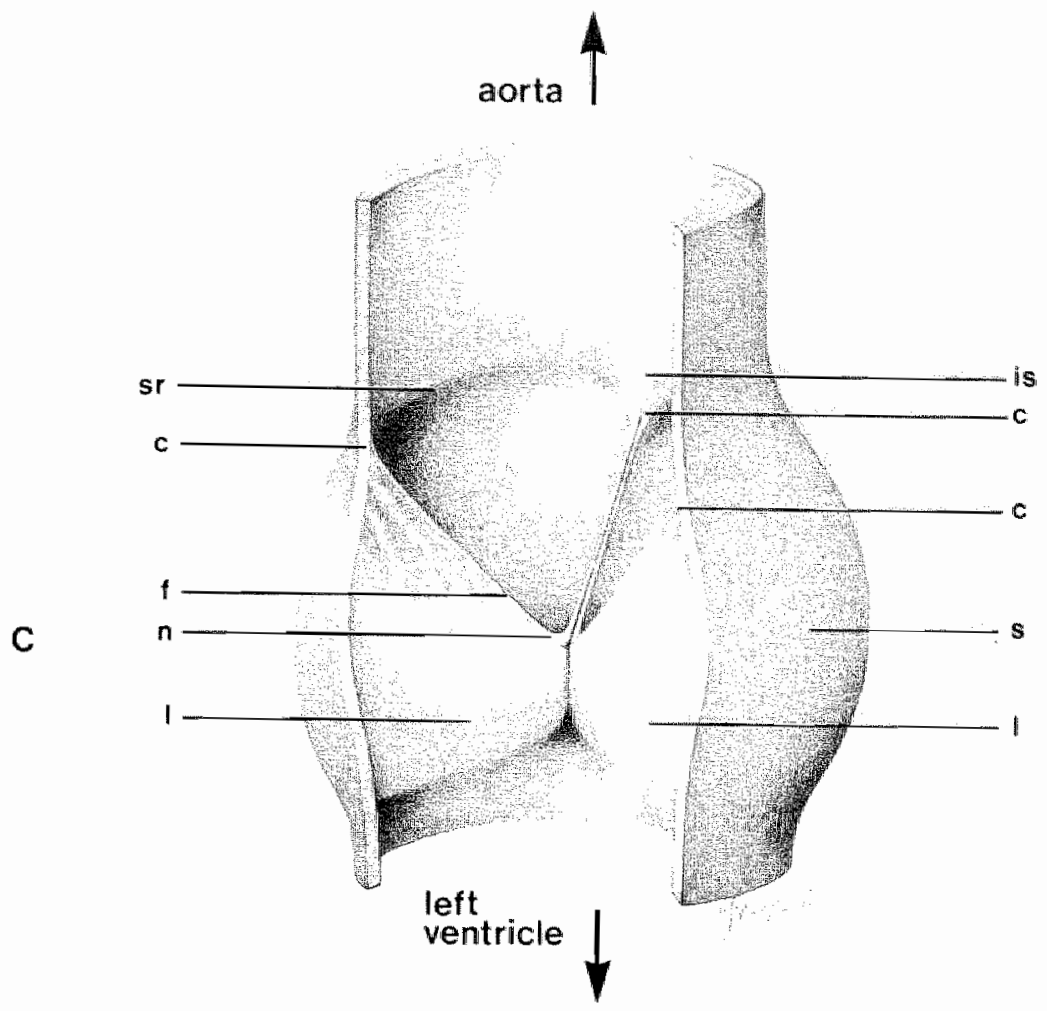

FIGURE $2 * 3$

Eiagramatic representation of the actic valve (comonary arteries are not shown)

A: the aortic valve in the closed configuration as seen from the ascending aorta.

E: side view of the value (according to $v_{1}$ in figure 2.3A).

$C$ : the aortic valve in the cllosed configuration after alssection of one leaflet and the corresponding sinus wall (according to $\mathrm{v}_{2}$ in fligure 2.3A). $a a=$ aortic annulus; $a r=a o r t i c$ ring; $b p=b a s e$ point; $c=$ compissure; $f=$ free edge of the leaflet; il = interleatlet trigone; is = intersinus trigone; 1 = leaflet; $n=$ node of Arantius; $s=s$ inus of Valsalva; sr = sinus rim. (Drawings made by H. Rensema). 


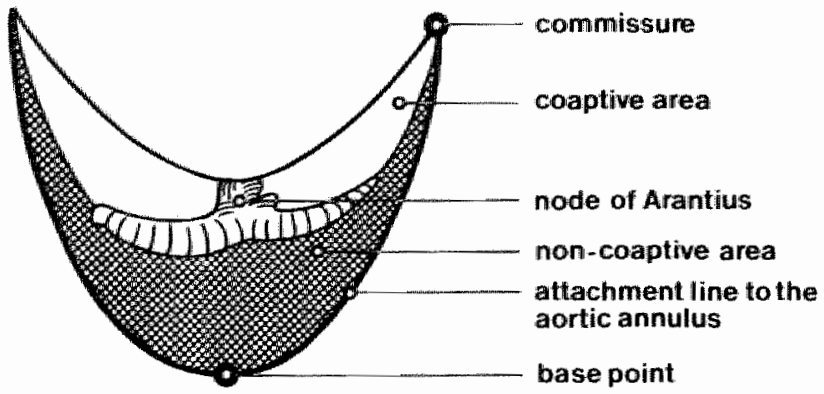

FIGURE 2.4

Diagramatic representation of an aortic valve leaflet after McAlpine 1975 ).

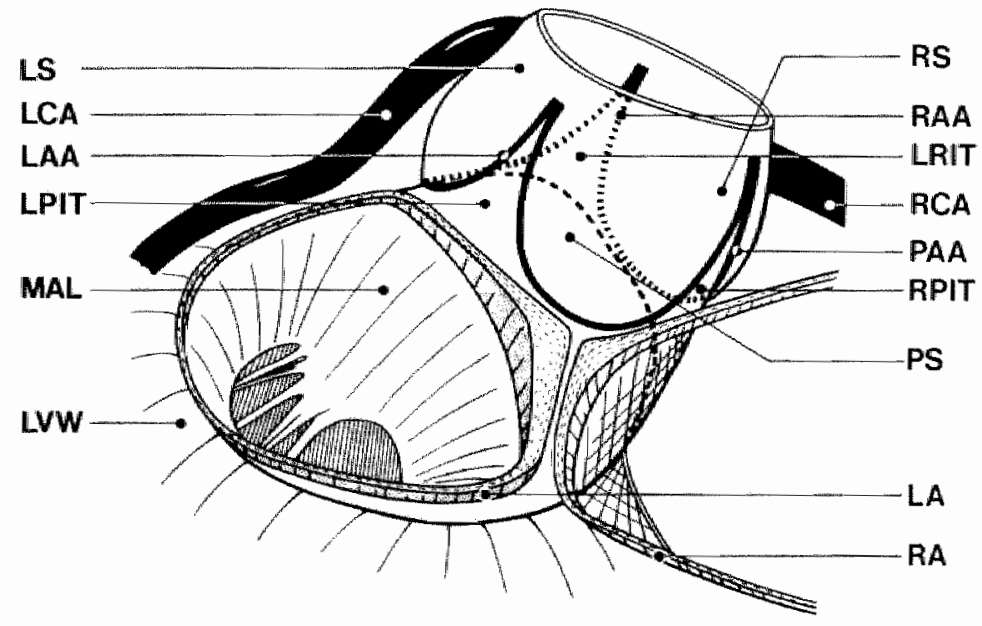

FIGURE 2.5

Schematic representation of the attachment of the actic valve to the left ventricle. LA = left atrium; LAA = left aortic annulus, LCA = left coronary artery, LPIT = left-posterior interleaflet trigone; LRIT = left-right interleaflet trigone; $\mathrm{LS}=$ left sinus, LVW = left ventricular wall; MAL = mitral arterior leaflet; PAA = posterior aortic annulus; $P S=$ posterior sinus; RA = right atrium; $R A A=$ right aortic annulus; $R C A=$ right coconary artery; $R P I T=$ right-posterior interleaflet trigone; $R S=$ right sinus (figure after McAlpine 1975). 
left ventricle and the ascending aorta. Through this valve the left ventricle pumps blood into the systemic arterial circulation. In figure 2.3 the aortic valve is represented diagramatically. In terms of functional morphology the aortic valve is composed of three identical units (Zimmerman 1969). Each of these units consists of a leaflet (or cusp), a sinus of Valsalva and a hemi-elliptical aortic annulus (McAlpine 1975). The latter" is situated along the line of attachment of a leaflet to its belonging sinus of Valsalva. When the three leaflets join, the outflow orifice of the left ventricle is obstructed.

The three hemi-elliptical aortic annuli together form a crownlike formation which is defined as the aortic ring (figure 2.5). The places where two adjacent aortic annuli meet are called comissures. The points of the aortic annuli which are closest to the left ventricle are called base points. The plane through these points is the base plane of the aortic valve.

Each pair of aortic annuli forms with the base plane of the valve a trigomal segment of wall which is called the interleaflet trigone. Similarly, three intersinus trigones are formed by the edge of each two sinuses of Valsalva and the plane through the point of each sinus which is closest to the ascending aorta (figure 2.3).

In the present study the term 'aortic valve' will be used to denote the entity of leaflets, sinuses of Valsalva, aortic ring, interleaflet trigones and intersinus trigones. To distinguish between the different sinuses, leaflets and aortic annuli the following additions are used throughout this thesis (figure 2.4): - as the left and right coronary artery originate each from a sinus of Valsalva, the corresponding sinus, leaflet and aortic annulus are specified by "left" and "right" "The remaining sinus of Valsalva, leaflet and aortic annulus are referred to as "posterior".

- the trigones (interleaflet and intersinus) are distinguished by the addition 'left-right', 'right-posterior' and 'left-posterior".

In figure 2.3b two directions are defined for reference purposes: the circumferential direction and the axial direction. In the 
following sections the properties of the different parts of the artic valve are discussed in more detail.

\subsubsection{Leaflets}

Each of the three aortic leaflets consists of a coaptive area (1unula) and a non-coaptive area (figures 2.3 and 2.4 ). When the coaptive areas of the lealets join, the outiet orifice of the left ventricle is obstructed. In the midale of the free edge of each lunula the 'node of Arantius' is located (McAlpine 1975 ). According to zimmerman (1969), it is a 'triangular shaped concretion' which structurally permits a significant reduction in the height of the lunula without causing central regurgitation when the valve is closed (Clark and Finke 1974).

Both the actic and the left ventricular side of the leaflet are covered with endothelium (Clark and Finke 1974, sauren 1980). The latter investigator showed that in the non-coaptive area four different layers can be distinguished between both endothelial layers of the pig leaflet. The same layers are present in the coaptive area, but their arrangement may be very irregular. From the left ventricular side towards the aortic side of the leaflet the following layers can be recognized:

- a subendothelial layer composed of elastic fibers which run in various directions. This layer is continuous with the subendothelial layer of the left ventricle.

- a layer of loose connective tissue, containing sparse nuclei and a few elastic fibers.

- a layer of macroscopically visible, collageneous bundles which run from commissure to commissure parallel to the free edge of the lunula. In the middle of the non-coaptive area these bundles have many ramifications, resulting in a dense collageneous network. From this network bundies penetrate perpendicularly into the aortic annulus. They anchor the mid-part of the leaflet to the aortic annulus.

- a thin subendothelial layer of elastic fibers.

other investigators found similar layers in the buman (Gross and Kugel 1931, clark and Finke 1974) and dog (Lyons 1976, Brewer et 
a1. 1977) aortic leaflets. The thickness of the leaflets may differ from site to site (Clark and Finke 1974). The average thickness of the human leaflet was found to be about $0.6 \mathrm{~mm}$ (Sands 1969).

\subsubsection{Sinuses of Valsalva}

The three sinuses form the major part of the wall of the aortic valve. Each adjoins an aortic annulus and two intersinus trigones. The part of the boundary line adjacent to the intersinus trigones is called the sinus rim (Reid 1970, McAlpine 1975).

The shape of the sinus of Valsalva was investigated by Reid (1970) and Swanson and Clark (1974). According to Reid (1970), the human sinus has a hemi-spherical shape when no pressure difference is present across the sinus wall. However, under similar conditions Swanson and Clark (1974) found that the sinus height relative to the truncated cone through the base points and the commissures was smaller than to be expected when assuming a hemispherical shape. Even at a pressure difference across the sinus wall of $13.3 \mathrm{kPa}$ no hemi-spherical shape was found. A reason for this discrepancy cannot been given. The axial length of the sinus of Valsalva is about 1.75 times the radius of the circle through the base points (Swanson and Clark 1974). From this length about $80 \%$ is taken up by the distance between the commissures and the baseplane of the valve (Reid 1970, Swanson and Clark 1974, MCA1pine 1975).

The tissue of the sinus wall mainly consists of a network of arbitrarily oriented elastic fibers in which smooth muscle fibers are inbedded (Boucek 1964, Sauren 1980, Thubrikar et al. 1980). Sauren (1980) found that in the sinus of valsalva of the pig the muscle fibers were mainly circumferentially oriented. Moreover. small collagen fibers were scattered throughout the tissue. Boucek (1964) observed that in the canine sinuses of valvalva three layers of muscle fibers could be distinguished. The inner layer (side of the sinus in contact with blood) consists of circularly arranged musculo-elastic fibers. The middle layer is composed of muscle fibers which do have a right-spiral orienta- 
tion in axial direction. The outer muscle layer is formed by larger muscle fibers. The latter fibers, mostly originating from the aortic annulus, also have a right-spiral orientation in the axial direction, but the spiral is less steep in the circumferential direction. In the left sinus, part of the muscle fibers from the middle and outer layers are continuous with the muscle fibers in the wall of the proximal part of the left coronary artery. Collagen deposits are also to be found present in the dog sinus wall (Boucek, 1964). Near the coronary arteries small collagen areas (septa) were found to which fibers of the middle muscle layer of the sinus were attached.

The thickness of the sinus wall is considerably less than that of the wall of the ascending aorta (Boucek 1964, sauren 1980). According to Reid (1970) the human ascending aorta may have a wall thickness 4 to 5 times that of the sinus wall. The coronary arteries are mainly located in the region of the sinus cavity determined by the segment between the commissures and the sinus rim (McAlpine 1975).

2.3.4. Acrtic ring, interleaflet trigones, intersinus trigones

The aortic ring consists of three hemi-elliptical (McAlpine 1975) or U-shaped (Zimmerman 1969) aortic annuli. The place where two aortic annuli meet is defined as a commissure. Leaflets are anchored to the aortic ring by collagen bundles (Sauren 1980) and the sinuses of valsalva are attached to it by musculo-elastic fibers (Boucek 1964, Thubrikar et al. 1980).

The ring consists of a dense collageneous and/or cartilagenous structure (Boucek 1964, Zimmerman 1969, Sauren 1980). The three annuli of the aortic ring are, apart from the commissures, mutually connected by the interleaflet trigones. Although it has been suggested that these trigones merely consist of dense collagenous tissue (Zimmerman 1969, MCAlpine 1975), Thubrikar and co-investigators (1980) found that in the canine aortic value this only holds for the left-posterior interleaflet trigone. On its left ventricular side this trigone continues into the anterior mitral leaflet (figure 2.5). Sands (1969) showed that about half of the 
left and half of the posterior aortic annulus are connected to the left-posterior interleaflet trigone. The left-right interleaflet trigone consists of circumerentially oriented muscle fibers. This also holds for the right-posterior interleatlet trigone, however to a lesser extent. Both muscular trigones can considered to be extensions of the ventricular septum (Thubrikar et al. 1977bl. The presence of ventricular muscle in the tissue of the left-right and right-posterior interleaflet trigone was confirmed by Reid (1970) for the buman and by Boucek (1964) for the canine aortic valve. Thubrikar et al. (1980) found that the collagen tissue in these trigones is limited to a thin layer on the side which is in contact with the blood.

Distal to the commissures the intersinus trigones are present. They are much smaller than the interleaflet trigones as the axial length of the sinus rim is small relative to the axial length of the aortic valve (section 2.3.3). Many collagen deposits are present in the musculo-elastic tissue of the intersinus trigones. The collagen deposits of the three intersinus trigones together form a ringlike structure along the sinus rims (Boucek 1964). BY these collagen deposits the muscular tissue of the sinuses of Valsalva is connected to that of the ascending aorta. The latter has the same three layer muscular structure as the sinus (Boucek 1964 ).

2.3.5. Functioning of the aortic valve during the cardiac cycle

As discussed in section 2.2 .2 the aortic valve opens and closes once during each cardiac cycle. The opening and closure of the canine aortic valve has been studied in vivo by several investigators (Heckman 1972a,b, Mercer 1973, Thubrikar et al. 1977a, Van Steenhoven 1979b, 1981). Just prior to left ventricular ejection the leaflets start bulging towards the ascending aorta. Next valve opening takes place in a short period of time. Thubrikar and colleagues (1977a) found that the valve opened completely in about $28 \mathrm{~ms}$. Mercer (1973) distinguished a period in which the valve opened to a great extent (14 msec) and a period in which gradual completion of valve opening occurs $(14 \mathrm{msec})$. At the 
moment of maximum valve opening the volume flow in the ascending aorta has reached about $75 \%$ of its maximum value during systole (Van Steenhoven 1979b, Van Steerhoven et al. 1981). After complete valve opening the area of the orifice between the leaflets tends to diminish gradually as was observed by Heckman (1972b), Mercer (1973), Thubrikar et al. (1977a), Van Steenhoven (1979b) and Van steenhoven et al. (1981). Van Steenhoven and his colleagues (1982b) showed that under specific experimental conditions (high systolic pressure level) $10 \%$ of valve closure had already been accomplished at the moment of maximum volume flow in the ascending aorta. Bellhouse and Talbot (1969) concluded from their model-experiments that the gradual closure of the valve takes place during the deceleration phase of ascending aortic blood flow. At the moment of zero flow in the ascending aorta about 80 of the closure is completed. A small volume flow from the ascending aorta towards the left ventricle, caused by the deceleration still present, completes valve closure. Similar results were obtained by van steenhoven (1979b) and van Steenhoven et al. (1981) in vivo measurements on the dog aortic valve. Coinciding with the occurrence of maximum reversed flow the valve closes completely (Van Steenhoven et al. 1981). The final closure of the valve appears to be slightly slower than the initial opening $(17.3 \mathrm{~ms}$ Mercer $1973,17.0 \mathrm{~ms}$ Thubrikar et al. 1977a). During approximately the next $34 \mathrm{~ms}$ the joined cusps move towards their diastolic position. During diastole little changes take place in the bulgy shape of the cusps until the next valve opening starts. 


\section{THE INDUCTIVE MEASURING TECHNIQUE}

\subsection{INTRODUCTION}

The present chapter deals with the description of an inductive technique for the measurement of aortic ring motion during the cardiac cycle. To this purpose change of natural strain is determined measured between different commissure points, different base points, and between commissure and base points (figure 1.1; chapter 1). With the measuring equipment used natural strains related to 6 distances can be measured simultaneously.

In section 3.2 several techniques to measure strains in the aortic ring are discussed. Section 3.3 deals with the theoretical background of the inductive distance measuring technique and its application to the measurement of the changes of the above mentioned strains in the aortic ring. The electronic circuitry of the device and its specifications are presented in section 3.4 . The applicability of the inductive system to animal experiments is discussed in section 3.5 .

3.2. CHOICE OF THE TECHNIQUE FOR STRAIN MEASUREMENTS IN THE AORTIC RING

To determine strains within the aortic valve, different techniques can be used. Problems and difficulties in the measurement originate from the following aspects:

- the strains have to be measured between base points and commissure points which are well defined in the three-dimensional geometry of the aortic valve.

- the base points are spatially separated from the commissure points by the aortic valve leaflets during part of the cardiac cycle.

- the base points are not accessible from the outside of the valve without damage of the atrial and the left ventricular tissues. 
- for proper measurement of the motion of the aortic $x$ ing as a whole, various strains have to be measured simultaneously.

- East varlations of strain, occurring during valve opening and valve closure, must to be cecorded accurately $(0<f<100 \mathrm{~Hz})$.

- the measuring technique should not noticeably influence the normal behavior of the aortic valve.

With these points in mind, a survey of the literature on measuring techniques for distances or strains in heart valves, the beart or the ascending aorta was performed. Generally the techniques are based on one of the following principles:
a. $x-$ ray
b. echocardiography
c. optical visualization
d. Iinear aisplacement
e. pulsed transit-time sonomicrometry
f. electromagnetic induction

a. X-ray

By this technique movements of an object with an opacity to $x-$ rays bigher than the surrounding tissue can be detected using cinematography or video. Variations in distances can be taken from distances on the recordings. For the determination of movements in three-dimensional space, two recordings of the object are needed, both made under known different angles of view.

In one method small opaque markers were attached to the inner wall of the valve (Rushmer et al 1956, Davis and Kinmonth 1963 , Tsakiris et al. 1971 and 1975, Thubrikar et al. 1977). During the cardiac cycle their movements could be followed using angiographic projections of the locations of the markers. The length of the segments between the markers was determined off-line.

For our purpose disadvantages of this method are:

- the accuracy in the determination of the distance between two markers is no better than $0.15 \mathrm{~mm}$ (Ferton et al. 1978).

- measurement of distances can only be performed off-line after analyzing the two-dimensional frames. The inaccuracy in determining a spatial distance may increase because of the computation of distance from two two-dimensional frames and moreover 
movement of the aortic valve as a whole relative to the measuring apparatus.

- off-line analysis of the frames is rather time consuming, especially when high frequency recordings are made.

In other techniques blood is made opaque (Tsioulias 1965, Mercer 1969 and 1973) or valve tissue is coated with an opaque medium (Heckman et al. 1972). Apart from the disadvantages of the marker technique these techniques have additional limitations. In the angiographic projections of the blood within the valve the commissures and the base points cannot be localized, whereas coating with the opaque medium keeps only for about twenty heart beats. Rushmer and coinvestigators (1956) tried to inject an opague medium into the tissue of the mitral valve. This technique, however, was abandoned because the opaque medium did not disperse uniformly, which resulted in a poorly outlinea valve structure on the angiogram. Moreover, the geometry of the valve became abnormal because of the reaction of the tissue to the opaque medium.

\section{b. Echocardiography}

In echocardiographic techniques ultrasound is transmitted into the tissue with one or more ultrasonic crystals. Differences in tissue properties along the ultrasonic beam result in the reflection of ultrasound. Cardiac valve motion can be detected by one-dimensional echocardiography (M-mode echocardiography; Pratt et al. 1976, Akgün and Layton 1977, Ambrose et al. 1980) or by two-dimensional echocardiography (Green and Popp 1981, ormiston et a1. 1981). The feature of being non-invasive is an advantage of this technique. However, for our purpose the limited resolution $(\approx 1 \mathrm{~mm})$ and the variations in reflection intensity aue to changing valve geometry are major drawbacks. Moreover, a threedimensional reconstruction based on two-dimensional information is quite inaccurate when resolution is limited.

\section{c. Optical visualization}

The movement of heart valves can also be determined by optical. visualization of the valve. In this technique the valve 1 s visualized by a fiberscope placed in front of the valve or by an 
optical window in the tissue surrounding the valve. The opaque blood is either replaced by a clear fluid like saline or Ringers solution (Hider et al. 1966, Padula et al. 1968, Brooks et al. 1968, Van Steenhoven 1979b, Van Steenhoven et al. 1981) or pushed away by inflating a tramsparent balloon around the tip of the fiberscope (Gamble and Innis 1967). An alternative possibility is the injection of a clear fluid between the fiberscope and the object of investigation (Dee and crosby 1977).

Ihis technique has also the disadvantage of three-dimensional reconstruction from two-dimensional projections. Moreover, because the valve closes during part of the cardiac cycle two fiberscopes are needed for the simultaneous recording of strains between the base points and between the commissure points. This complicates the localization of the fiberscopes and the illumination of the valve.

\section{d. Linear displacement transducer}

In the linear asplacement technique the object of investigation is brought in (rigid) contact with the movable part of a linear displacement transducer. The position of the object relative to the stationary part of the transducer thus can be determined electronically. Brewer et al. (1977) studied the length of the right coronary leaflet by attaching four Dacron sutures to appropriate parts of the leaflets and comissures and connecting these sutures to linear displacement transducers outside the valve. For our purpose this technique has the following disadvantages:

- it is restricted to those points of the valve which can be easily reached.

- movement of the object of investigation may be hampered by the mechanical loading of the object due to the transducer and its connections. Especially at high frequencies (valve opening or valve closure) this may be a problem due to inertances of transducer and connection.

- measurement of several distances between clearly defined points in the three-dimensional geometry of the valve is difficult because each transducer gives only one-dimensional information. 
e. Pulse transit-time sonomicrometry

The pulse transit-time sonomicrometry as applied to the heart by Rushmer et al. (1956), Van Tright et al. (1981) and olson et al. (1981) and to arteries by Sabbah and stein (1981), uses two ultrasonic transulucers placed opposite to each other. A sound pulse transmitted by the one transducer is received by the other. The delay time of the sound pulse through the medium is equal to the ratio of the distance between the two transducers and the velocity of wave propagation.

Advantages of pulse transit-time sonomicrometry are the accuracy and the sensitivity (stegall 1974). A disadvantage is the transducer directionality. Misalignment of the two transducers results in decreased accuracy and sensitivity (Van Tright et al. 1981). These effects can be reduced by the use of acoustic lenses, but this addition makes the transducer too bulky for measurements on small structures (Stegall 1974). Moreover, when several transducers are used simultaneously cross-talk may occur resulting in additional noise. Considering the three-dimensional 120-degrees rotational symmetric geometry of the aortic valve, transducer directionality becomes a serious problem indeed. An additional limitation is that a sound pulse transmitted from a commissure point to a base point passes through the aortic valve leaflet, which might result in additional noise, especilally because the valve leaflet is moving during part of the cardiac cycle.

\section{E. Electromagnetic induction}

Inductive coils have also been used for distance measurements (Hinds et al. 1969, Remington et al. 1967 and Arts and Reneman 1980). In this method changes in mutual inductance between two coils correspond to changes in mutual position of these coils. Generally this method has highly non-linear characteristics, but this cam be overcome by logarithmic conversion of the induced voltage (Arts and Reneman 1980). A disadvantage is the directional sensitivity of the coils. So for accurate measurement the mutual orientation of the coils has to be taken into account. An advantage, however, is that the mutual induction is not affected 
by the blood and/or the tissues around the coils. Moreover, the technique is sensitive and stable and can be designed to have a high frequency response $(100 \mathrm{~Hz}$ f $-3 \mathrm{~dB}$ ) (Arts and Reneman 1980).

Choice of the measuring technique

A common disadvantage of echocardiography, $x$-ray and optical $v$ isualization techniques is that they are indirect techniques: a distance between well defined points in the three-dimensional geometry of the valve has to be reconstructed mathematically from two two-dimensional video or cine frames. In this reconstruction inaccuracies in the two-dimensional recordings will contribute to the inaccuracy of the computed distance. The latter inaccuracy may be increased by movement of the valve as a whole relative to the measuring system (e.g. X-ray tube). To obtain variations in distance with a bandwidth of $0 \leq$ frequency $s F$, at least $2 \times 2 \mathrm{~F}$ frames have to be analyzed. This analysis to obtain spatial distance is time consuming and only can be performed off-line. Moreover, increasing the number of frames per second can result in decrease of accuracy of the computed distance because of decreased contrast of the frames at shorter exposure times. These disadvantages which have echocardiography, $x$-ray and optical visualization techniques in common and moreover their specific disadvantages make these techniques less suitable for strain measurements in the aortic valve.

The pulse transit-time sonomicrometry and the inductive measurement technique have the advantage that spatial distances are measured directly and on-line. Disadvantages in common are the necessity of using wires for crystals or coils, which complicates the experimental situation. Besides both techniques are directional sensitive. The directional sensitivity of the pulse transit-time sonomicrometry technique is a serious problem when applying the technique to strain measurements in the aortic ring as was discussed before. The directional sensitivity of the inductive measurement technique is also a problem. However this technique may be advantagecus because coils can be positioned in the aortic valve in such a way that directional sensitivity is 
minor (see section 3.3). Moreover, with this technique natural strain can be measured directly and with a high frequency response. Besides, the technique is stable and sensitive (Arts and Reneman 1980).

considering the disadvantages of the indirect techniques ( $\mathrm{x}$-ray, echocaraiography and optical visualization) we have chosen for a direct approach. The linear displacement transducer technique and the pulse transit-time sonomicrometry technique are less suitable (see above), so we developed an inductive measuring technique. In the following sections this technique will be discussed in detail.

\subsection{STRAIN MEASUREMENT BY THE INDUCTIVE MEASURING TECHNIQUE}

\subsubsection{Theory}

The inductive technique is based on the detection of changes in the mutual induction between two coils caused by changes in the mutual position of these coils. Let us make the following assumptions to define the mutual position and the mutual orientation of a transmitter coil and a receiver coil:

- in the three-dimensional space a cartesian coordinate system $\left(x_{\mathrm{T}}, \mathrm{y}_{\mathrm{T}}, \mathrm{z}_{\mathrm{T}}\right)$ is positioned in point $\mathrm{P}_{\mathrm{T}}$ with an orthonormal vector base $\overrightarrow{\underline{e}}_{\mathrm{T}}=\left[\overrightarrow{\mathrm{e}}_{\mathrm{T}_{\mathrm{X}}} \overrightarrow{\mathrm{e}}_{\mathrm{T}_{\mathrm{Y}}} \overrightarrow{\mathrm{e}}_{\mathrm{T}_{\mathrm{z}}}\right]$ as shown in figure 3.1

- spherical coordinates $\left(\rho_{R}^{Y}, k_{R}, \theta_{R}\right)$ are defined by $x_{T}=\rho_{R} \cdot \sin \left(\theta_{R}\right) \cdot \cos \left(k_{R}\right), y_{\mathbb{T}}=\rho_{\mathbb{R}} \cdot \sin \left(\theta_{R}\right) \cdot \sin \left(k_{R}\right)$, $z_{T}=\rho_{R} \cdot \cos \left(\theta_{R}\right)$, and vector base $\vec{e}_{s R}=\left[\vec{e}_{s R_{\rho}} \vec{e}_{s R_{K}} \vec{e}_{s R \theta}\right\rfloor$.

- In the point $\mathrm{P}_{\mathrm{T}}$ a transmitter coil $\mathrm{TC}$ is located. The orientation of the coil with respect to $\vec{e}_{\mathrm{T}}$ is given by the unit vector $\vec{n}_{T}$ which is located in the center of the coil and which is parallel to the axis of the coil. The coil is assumed to be rotational symmetric around $\vec{n}_{\mathrm{T}}$. The direction of $\vec{n}_{\mathrm{T}}$ is $e x-$ pressed as $\vec{n}_{T}=1 \cdot \vec{e}_{T_{Z}}$.

- In the point $P_{R}$ with spherical coordinates $\left(\rho_{R},{ }_{R}{ }^{\prime} \theta_{R}\right)$ a receiver coil $R C$ is located. The orientation of this coil is expressed by the unit vector $\vec{n}_{R}$ in the point $\vec{P}_{R}$ where 


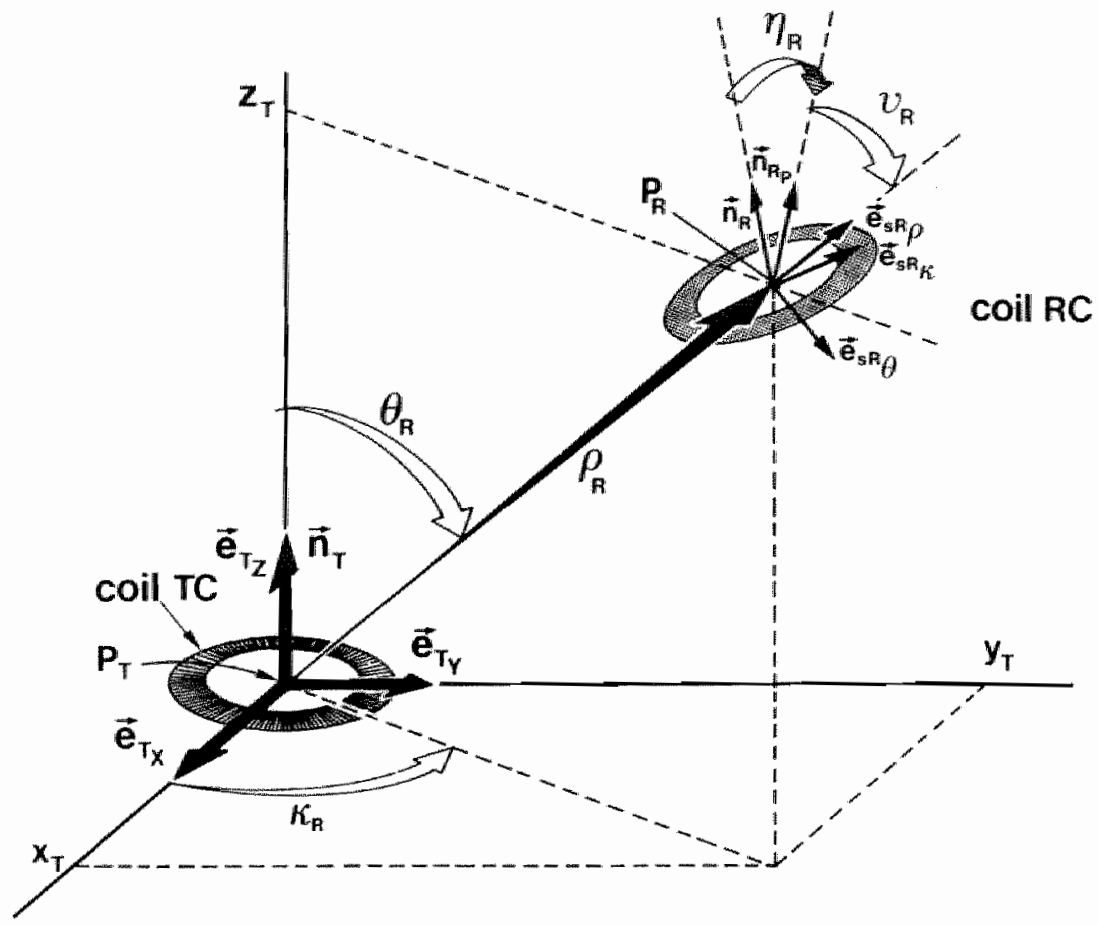

\section{FIGURE 3.1}

Schematic representation of the mutual position and the mutual orientation of a transmitter coil $\mathrm{TC}$ and a receiver coil $\mathrm{RC} . \vec{e}_{\mathrm{T}_{\mathrm{X}}}, \vec{e}_{\mathrm{F}_{\mathrm{P}}}, \vec{e}_{\mathrm{T}_{Z}}$ define cartesian

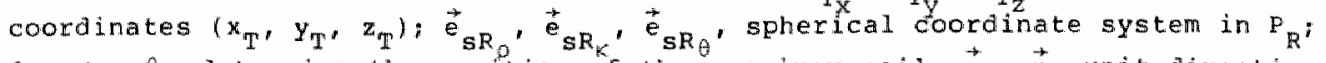
$P_{R^{\prime}} k_{R^{\prime}}$ determine the position of the receiver coil; $\vec{n}_{T}, \vec{n}_{R}$ unit direction vectors of transmitter and receiver coil resp.; ${ }_{R}$, " $R=$ angles which define the orientation of the receiver coil; $\vec{n}_{\mathrm{np}}$ = projection of $\vec{n}_{\mathrm{R}}$ an the plane determined by $\vec{e}_{\mathrm{r}_{\mathrm{Z}}}$ and the line $\mathbb{P}_{\mathrm{T}} \mathrm{P}_{\mathrm{R}}$.

$$
\vec{m}_{R}=\cos \left(\eta_{R}\right) \cdot \cos \left(v_{R}\right) \cdot \vec{e}_{s R}+\sin \left(\eta_{R}\right) \cdot \vec{e}_{s R}+\cos \left(\eta_{R}\right) \cdot \sin \left(v_{R}\right) \cdot \vec{e}_{s R_{\theta}}
$$

The angle $\eta_{R}$ is defined as the angle between $\vec{n}_{R}$ and $\vec{n}_{R p}$, which is the projection of $\vec{n}_{R}$ on the plane that is determined by the line $P_{T} P_{R}$ and $e_{T_{Z}}$. The angle $v_{R}$ is defined by the angle between the same projection of $\vec{n}_{R}$ and the 1 ine ${ }{ }_{T} P_{R}$. This angle is taken positive when it is measured from ${ }_{P}{ }_{T}{ }_{R}$ towards the projection of $\vec{n}_{R}$ in the same direction as $\theta_{R}$. 
When the turns on coil TC carry a current $j=5 \cdot \exp \left(i \cdot \mathrm{c}_{\mathrm{T}} \mathrm{t}\right.$ ) $\mathrm{a}$ magnetic dipole field is induced at distances $\rho>\mathrm{R}_{\mathrm{T}}\left(\mathrm{R}_{\mathrm{T}}\right.$ is the radius of one turn of wire of $T C)$. In the point $P_{R}$ the direction and the magnitude of this field are given by (E1liott 1966)

$$
\vec{B}\left(P_{R} \cdot{ }^{k}{ }^{\prime} \theta_{R}\right)=B_{1} \cdot \vec{e}_{S R}+B_{2} \cdot \vec{e}_{S R}+B_{3} \cdot \vec{e}_{s R_{\theta}}
$$

where

$$
\begin{aligned}
& \mathrm{B}_{1}=C_{0} \cdot \rho_{R}^{-3} \cdot 2 \cdot \cos \left(\theta_{R}\right) \cdot \exp \left(i \cdot \omega_{T} \cdot t\right) \\
& B_{2}=0 \\
& B_{3}=C_{0} \cdot \rho_{R}^{-3} \cdot \sin \left(\theta_{R}\right) \cdot \exp \left(i \cdot \omega_{T} \cdot t\right)
\end{aligned}
$$

and

$$
C_{O}=k_{M} \cdot \hat{J} \cdot A_{T} \cdot \mu_{O} \mu_{r}
$$

In these expressions $k_{T}$ is the number of turns on the transmitter coil, $A_{T}$ the surface area of one turn of the transmitter coil and $H_{0} H_{r}$ the magnetic permeability of the medium in which both coils are situated. In the receiver coil $R C$ the magnetic field induces a voltage $V_{R C}$ which is dependent on the position of the point $P_{R}$ and proportional to both the time derivative of the magnetic flux through coil $\mathbb{R C}$ and its number of turns $k_{\mathbb{R}^{\prime}}$ as expressed by

$$
V_{R C}\left(P_{R} \cdot k_{R} \cdot \theta_{R}\right)=k_{R} \cdot \frac{\partial \psi}{\partial t}
$$

The magnetic flux through the coil RC is given by

$$
\psi=A_{R} \cdot \vec{B}\left(\rho_{R}, k_{R}, \theta_{R}\right) \circ \vec{n}_{R}
$$

where $A_{R}$ is the surface area of one turn of the receiver coil. When the equations $(3.3),(3.4)$ and $(3.1)$ are combined, $V_{R C}$ can be rewritten under certain conditions (appendix A3.1) as 


$$
v_{R C}\left(\rho_{R}, \kappa_{R}, \theta_{R}\right)=1 \cdot \hat{v}_{R C}\left(\rho_{R}, k_{R}, \theta_{R}\right) \cdot \exp \left(i \cdot \omega_{T} \cdot t\right)
$$

where

$$
\begin{aligned}
\hat{\theta}_{R C}\left(\rho_{R}, k_{R}, \theta_{R}\right)= & c_{1} \cdot \theta_{R}^{-3} \cdot \cos \left(n_{R}\right) \cdot\left(2 \cdot \cos \left(\theta_{R}\right) \cdot \cos \left(\nu_{R}\right)+\right. \\
& \left.+\sin \left(\theta_{R}\right) \cdot \sin \left(\nu_{R}\right)\right\}
\end{aligned}
$$

and

$$
c_{1}=\omega_{T} \cdot C_{0} \cdot A_{R} \cdot k_{R}
$$

The natural strain between the transmitter coil and the receiver coil with respect to an original distance between the coils alref can be expressed by taking the natural logarithm of $\mathrm{V}_{\mathrm{RC}}$ in expression ( $3.5 b)$ and rewriting the equation as:

$$
\ln \left[\frac{\rho_{R}}{d_{\text {ref }}}\right]=-\frac{1}{3} \cdot \ln \left[\frac{\hat{v}_{R C}\left(\rho_{R}, k_{R}, \theta_{R}\right)}{a_{\text {ref }}^{3} \cdot c_{1}}\right]+f
$$

where

$$
f=\frac{1}{3} \cdot \ln \left[\cos \left(\eta_{R}\right) \cdot\left(2 \cdot \cos \left(\theta_{R}\right) \cdot \cos \left(v_{R}\right)+\sin \left(\theta_{R}\right) \cdot \sin \left(v_{R}\right)\right)\right](3 \cdot 6 b)
$$

Measurement of natural strain by the inductive technique is based on equations (3.6a) and (3.6b). Natural strain can be derived from $\hat{v}_{R C}$ if $f, c_{1}$ and $d_{\text {ref }}$ are known. Change of natural strain can be measured if $f$ and $C_{1}$ remain constant, as expressed by

$$
\ln \left\{\frac{\rho_{\mathrm{R}, 1}}{\rho_{\mathrm{R}, 2}}\right\}=\ln \left\{\frac{\rho_{\mathrm{R}, 1}}{\mathrm{~d}_{\text {ref }}}\right\}-\ln \left\{\frac{\rho_{\mathrm{R}, 2}}{\mathrm{~d}_{\text {ref }}}\right\}=-\frac{1}{3} \cdot \ln \left(\frac{\hat{v}_{\mathrm{RC}}\left(\rho_{\mathrm{R}, 2}, \kappa_{\mathrm{R}}, \theta_{\mathrm{R}}\right)}{\hat{v}_{\mathrm{RC}}\left(\rho_{\mathrm{R}, 1}, \kappa_{\mathrm{R}}, \theta_{\mathrm{R}}\right)}\right\}
$$

We assume that no variations occur in $C_{1}$. From equation (3.6b) it can be concluded that $f$ may change due to mutually independent changes in $\theta_{R}$, ${ }_{R}$ and $\nu_{R}$. The joint changes in $\theta_{R}$ " ${ }^{n} R$ and ${ }_{R}$ determine the change in the mutual orientation of the two coils. 
It should be noted that by the inductive technique strain apparently can be measured although there is no variation in the distance between the two coils. Only a change in the mutual coil orientation occurs. In the next section the strain measurement in the aortic ring by the inductive technique is evaluated with respect to the influence of $f$ on this measurement.

3.3.2. Analysis of the inductive technique in the experimental situation

In order to determine experimentally the changes of natural strain between the commissure points, between the base points and between the commissure points and the base points respectively, coils are placed at each base point as well. as at each commissure point (figure 3.2). The coils are attached to the wall in such a way that the unit vector of the coil is perpendicular to the wall at each point. The coils at the base points are attached to the aortic ring at the left ventricular side of the leaflets. As each coil both can transmit and receive a magnetic field, the inductive technique can be used to measure the strains as mentioned in the aortic ring. The relation between the induced voltage in a receiver coil and the strain between transmitter and receiver coil is derived in the previous section (equation $(3.6)$. For each strain in the aortic ring $f$ in equation (3.6a) may change during the cardiac cycle since changes in the geometry of the aortic ring may result in changes in the mutual orientation of the coils and consequently in changes in ${ }^{\theta} R^{\prime}{ }^{n}{ }_{K}$ and ${ }_{R}$. The change of $f$ can be calculated according to the general mathematical procedure presented in appendix A3.2, if the changes in local position and local orientation of each coil were known. Evidently this is not possible, since change of geometry of the aortic ring during the cardiac cycle in relation to strain itself is subject to investigation. However, to gain some insight into the accuracy of strain measurement, change of $f$ due to assumed changes in the mutual position and mutual orientation of the coils is calculated. 


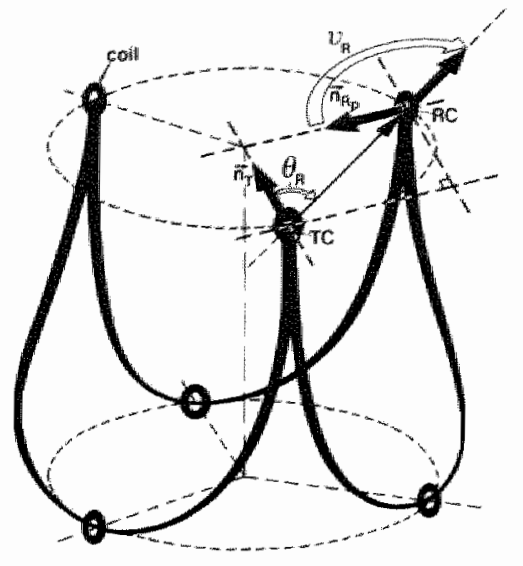

a

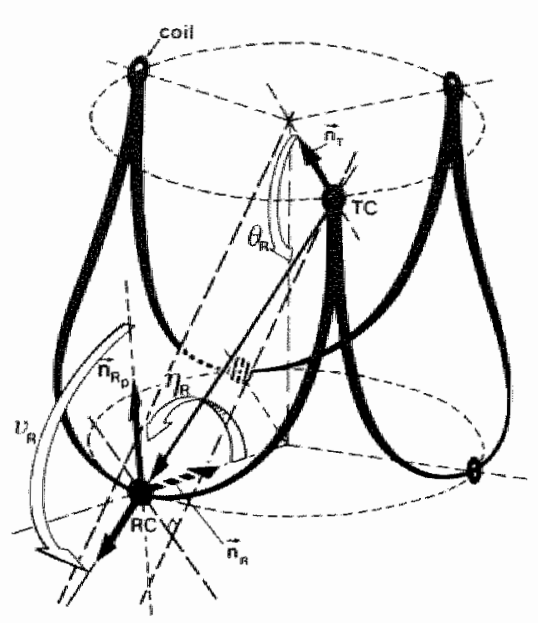

b

FIGURE 3.2

The position and the orientation of the colls on the aortic ring showing the angles $\theta_{R}, n_{R}$ and ${ }_{R}$.

a: strain measurement between comissure points $\left(\eta_{R} \approx 90^{\circ}\right)$.

b: strain measurement between comissure and base point. other symbols are explained in figure 3.1.

The following assumptions are being introduced to hold before any change in position and orientation of the coils occurs:

- the aortic ring is 120-degrees rotational symmetric around the value axis.

- the coils are located at the commissure points and at the base points (Eigure 3.2$)$.

- the unit vector of each coil is perpendicular to the wall at the point of attachment.

- the mutual position of the coils is given by the data of Swanson and Clark (1974) for a closed aortic valve which is loaded with a transvalvullar pressure of $13.3 \mathrm{kPa}$.

- only small changes of $\theta_{R}$ ' ${ }^{n} R$ and $v_{R}$ occur. These changes may be stochastic as well as non-stochastic.

The contribution of small changes in ${ }^{\theta} R^{\prime}{ }^{\prime}{ }_{R}$, and ${ }_{R}$ to a change of is expressed in a way analogous to appendix A3.2. For non-stochastic changes in $\theta_{R}$ " ${ }^{n}{ }_{R}$, ${ }^{\prime}$ it holds that 


$$
\Delta f \cong \Delta n_{R} \cdot\left(\frac{\partial f}{\partial n_{R}}\right)+\Delta \theta_{R} \cdot\left(\frac{\partial f}{\partial \theta_{R}}\right)+\Delta v_{R} \cdot\left(\frac{\partial f}{\partial v_{R}}\right)
$$

For stochastic changes in $\theta_{R} \cdot{ }^{n}{ }_{R},{ }^{\nu_{R}}$ and assuming a $95 \%$ reliability interval, it holds that

$$
-2 \cdot \sqrt{\operatorname{var}(\stackrel{*}{\mathrm{E}})}<\Delta f<2 \cdot \sqrt{\operatorname{var}(\stackrel{*}{\mathrm{E}})}
$$

where

$$
\operatorname{var}(\stackrel{*}{f}) \cong \operatorname{var}\left(\stackrel{\eta}{\eta}_{R}\right) \cdot\left(\frac{\partial f}{\partial \eta_{R}}\right)^{2}+\operatorname{var}\left(\hat{\theta}_{R}^{*}\right) \cdot\left(\frac{\partial f}{\partial \theta_{R}}\right)^{2}+\operatorname{var}\left(v_{R}^{*}\right) \cdot\left(\frac{\partial f}{\partial v_{R}}\right)^{2}
$$

The partial derivatives of $f$ in the equations (3.8) and (3.9b) are found to be

$$
\begin{aligned}
& \left(\frac{\partial f}{\partial \eta_{R}}\right)=\frac{1}{3} \cdot \tan \left(n_{R}\right) \\
& \left(\frac{\partial f}{\partial \theta_{R}}\right)=-\frac{1}{3} \cdot\left[\frac{-2 \cdot \tan \left(\theta_{R}\right)+\tan \left(v_{R}\right)}{2+\tan \left(\theta_{R}\right) \cdot \tan \left(v_{R}\right)}\right) \\
& \left(\frac{\partial f}{\partial v_{R}}\right)=-\frac{1}{3} \cdot\left(\frac{-2 \cdot \tan \left(v_{R}\right)+\tan \left(\theta_{R}\right)}{2+\tan \left(\theta_{R}\right) \cdot \tan \left(v_{R}\right)}\right)
\end{aligned}
$$

The equations (3.8) up to (3.12) included were evaluated for strains between two commissure points and strains between a commissure point and a base point. The evaluation of strain between two base points is analogous to that of strains between two commissure points. To begin with, the partial derivatives (3.10) -(3.12) were calculated. The results are shown in table 3.1 .

TABLE 3.1

\begin{tabular}{lccc}
\hline strain & $\frac{\partial f}{\partial n_{R}}$ & $\frac{\partial f}{\partial \theta}$ & $\frac{\partial f}{\partial V_{R}}$ \\
\hline cominissure strain & 0.01 & 0.08 & 0.08 \\
commissure-base strain & 0.30 & 0.20 & 0.01 \\
\hline
\end{tabular}


Next, the equations (3.8) and (3.9) were evaluated for assumed changes of $\theta_{R}$ " " $R$ " " ${ }_{R}$ "

If non-stochastic changes $\Delta \theta_{R}=\Delta n_{R}=\Delta u_{R}=\pi / 36$ are assumed, for the commissure strain $\Delta \mathbb{E} \cong 0.01$. As to the commissure-base strain $\Delta x \cong 0.04$.

If stochastic variations in $\theta_{R} n_{R}$ and $v_{R}$ are assumed to fit a gaussian distribution function with a standard deviation of $\pi / 72$ for each, the change of $f$ is found to be:

$$
\begin{aligned}
& \text { commissure strain : }-0.01<\Delta f<0.01 \\
& \text { commissure-base strain: }-0.03<\Delta f<0.03
\end{aligned}
$$

The changes of Af also show a gaussian distribution.

In conclusion, under the assumptions made it is to be expected that the inductive technique can be used to determine change of natural strain between the commissure points or base points over 0.01 . For the change of strain between commissure points and base points inaccuracy is less than 0.04 .

\subsection{INSTRUMENTATION}

3.4.1. Introduction

The choice of the inductive measurement technique implicates that coils have to be attached to the base points and to the comissure points of the aortic ring. As not all these points are accessible from the outside, the coils have to be mounted inside the valve. Thus the coils must be tiny and light and their connection wires must be flexible to prevent disturbances in the natural behavior of the aortic valve. The design of the coils, following these requirements, is explained in section 3.4.2. The cardiopulmonary bypass technique which is required to mount the coils within the valve is described in chapter 4 .

Because of the small dimensions of the coil, the number of turns and the surface area of one turn must be smaIl. As this holds for both the transmitter coil and the receiver coil, the 
voltage induced in the receiver coil is small and additional electronic processing is necessary to obtain an output signal. proportional to the natural strain. The electronic circuitry for processing the induced voltage is described in section 3.4.3. Since fast variations in strain during opening and closure of the aortic valve are also subject of investigation, the electronic circuitry has been designed for measurement of strain with a frequency content of $0<f<150 \mathrm{~Hz}$. For appropriate description of aortic ring motion as many strains as feasible have to be recorded simultaneously. We have chosen to measure six strains at the same time: three between the commissure points and three between the base points. The related electronic circuitry - which is based on the one described in section 3.4 .3 - is discussed in section 3.4.4. By this device can in separate measurements also a strain between twa commissure points and two strains between these commissure points and the corresponding base point simultaneously be determined. The final in vitro specifications of the measuring device are presented in section 3.4.5.

\subsubsection{The design of the coil}

The coil consists of approximately 230 turns enamelled copper wire (O.D. $=0.03 \mathrm{~mm}$ ) on a core of magnetically inert synthetic material with an inner diameter of $0.8 \mathrm{~mm}$ (figure 3.3 and figure 3.4). The outer diameter is approximately $1.3 \mathrm{~mm}$. On one side, the base plane of the coil, the core of the coil ends in a disc which has a diameter of $3.0 \mathrm{~mm}$ in order to permit a stable mounting of the coil to the tissue of the valve. The leads of the coils are connected to two flexible wires llength $250 \mathrm{~mm}$; 0.0 . = $0.25 \mathrm{~mm}$ ) which are twisted to reduce magnetic interference to a minimum. The wires are connected to a shielded two pole plug. The coil, leads and soldering contacts and part of the flexible wires are casted in epoxy resin. The total height of the coil is approximately $1.3 \mathrm{~mm}$. In the base plane of the coil, two holes (points $A$ and $B$ in figure $3.3 ; \mathrm{D}=0.25 \mathrm{~mm}$ ) are drilled for fixation of the sutures which serve to attach the coil to the valve wall. The weight of a coil is about $12 \mathrm{mg}$. 


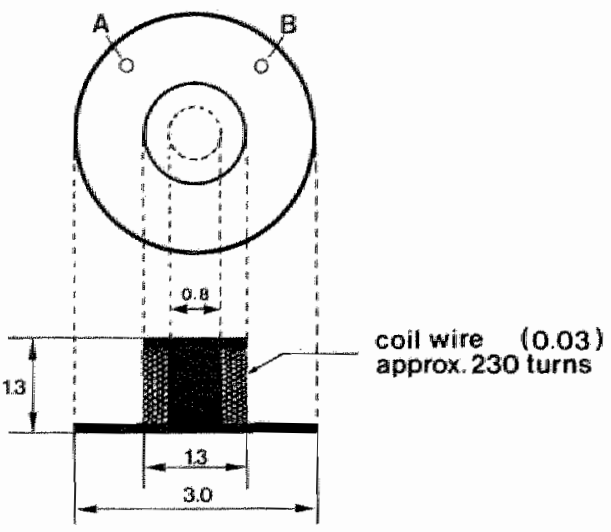

FTURE 3.3

Schematic drawing of a coid used in the inductive measuring technique (dimensions in mm). $A, B=$ attachment sites of the sutures.

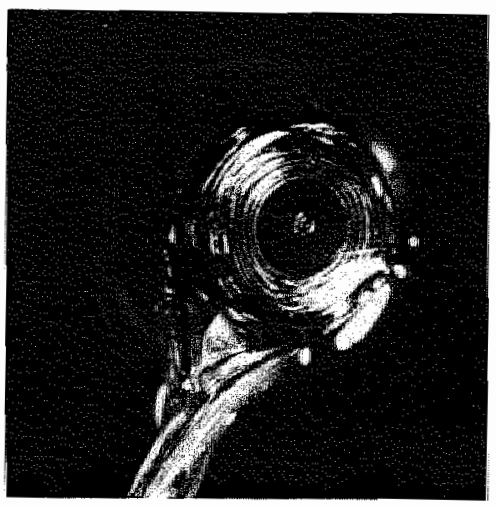

FIGURE 3.4

Photograph of a coil used in the inductive measuring technique.

3.4.3. Electronic circuitry for strain measurements by two coils

In a basic set-up the electronic circuitry for strain measurements by means of two coils has been designed. The circultry is presented diagrammatically in figure 3.5. A current source (70 $m A, 99 \mathrm{kHz}$ ) supplies the field generating coil TC. The high frequency transformer $T$ is used to prevent leakage of current to the transmitter coil. The small voltage induced in the sensor coil ( $\approx 0.5 \mathrm{mV}$ ) passes a high frequency transformer $T$ and is amplified by a voltage controlled amplifier (gain $40 \mathrm{~dB}-90 \mathrm{~dB}$ ). After this the signal is band pass filtered $(97.5-100.5 \mathrm{kHz} f$ $-3 d B$ ) to reduce noise. Next the signal is single phase rectified, filtered by a first order low pass filter $(400 \mathrm{~Hz} f-3 \mathrm{~dB})$ and fed into a logarithmic amplifier which delivers a signal proportional to the natural logarithm of the amplitude of the induced voltage and, therefore, to natural strain lequation (3.6a)). To connect the current source and the receiver to the coils, double shielded co-axial cables (length $1.75 \mathrm{~m}$ ) are used 

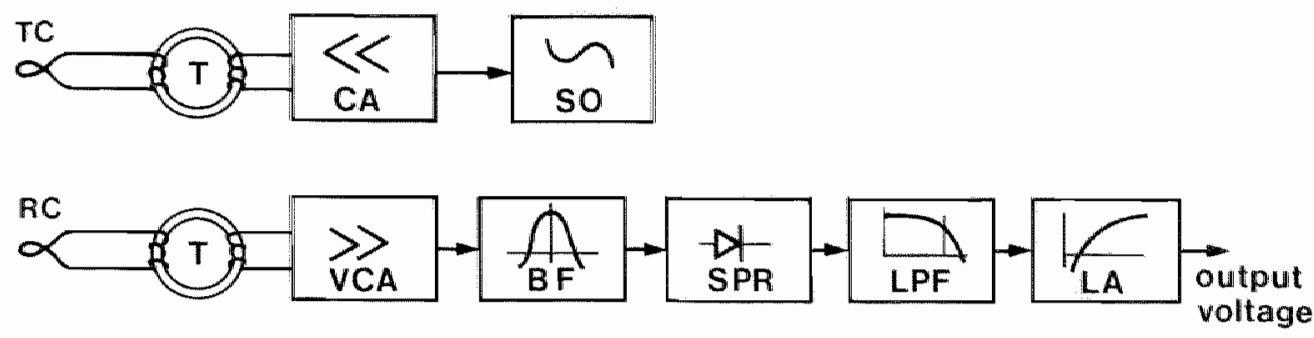

FIGURE 3.5

Diagramatic representation of electronic circuitry for strain measurement with two coils in a basic set-up. $B F=$ band pass filter: $C$ = current amplifier; LA = logarithmic amplifier; LPE = low pass filter; $\mathrm{RC}=$ receiver coil; $S P R=$ single phase rectifier; $S O=$ sinus oscillator; $T$ = high frequency transformer: $T C=$ transmitter coil; $V C A=$ voltage controlled anplifier.

to prevent disturbances of the induced voltage by magnetic or electric fields.

3.4.4. Electronic circuitry for simultaneous measurement of six strains by six coils

The present section deals with the electronic ciccuitry to measure six strains simultaneously by applying two identical systems. Each system measures three strains by means of three coils. The systems operate with different magnetic field frequencies to prevent crosstalk. Only one system is described in detail.

Simultaneous measurement of three strains using three coils is performed by multiplexing the measurement of strain with a period of $0.8 \mathrm{~ms}$ and a repetition frequency of approximately $416 \mathrm{~Hz}$ (figure 3.6). The voltage proportional to the strain is sampled once during the period and next held by a sample and hold circuit until the subsequent sampling period.

The electronic circuitry of the multiplexing system is presented diagrammatically in figure 3.7. During a period of $0.8 \mathrm{~ms}$ and with a repetition rate of about $416 \mathrm{~Hz}$ the current source ( $140 \mathrm{~mA}, 99 \mathrm{kHz}$ or $70 \mathrm{kHz}$ ) generating the magnetic field is alternately connected to each of the three coils, using multiplexers. Each coil is permanently connected to its corresponding 
measurement of strain 1
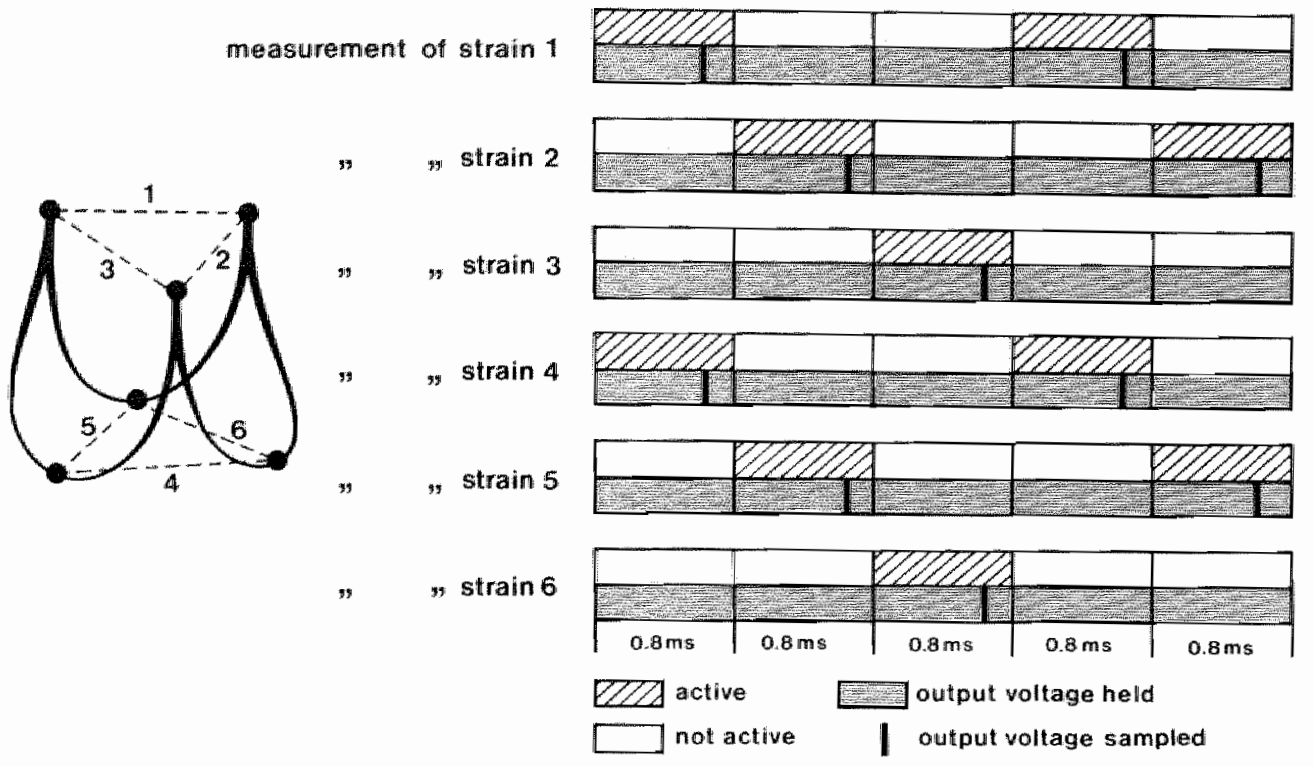

FIGURE 3.6

Schematic representation of simultaneous measurement of six strains by six coils and subsequent multiplexing of strain signals.

receiving circuit. However, during each period of $0.8 \mathrm{~ms}$ only one receiver is activated by voltage control of the amplifier. Approximately $0.7 \mathrm{~ms}$ after onset of activation of the receiver a sample is taken of the output signal of the logarithmic amplifier and stored during the next $2.4 \mathrm{msec}$, using a sample and hold circuit. The electronic circuitry of the receiver is virtually the same as described in the previous section. A few minor modifications are:

1. a first order high pass filter $(10 \mathrm{kHz} f-3 \mathrm{~dB})$ is added between the voltage controlled amplifier and the band pass filter to suppress switching artefacts in the amplifier section.

2. the bandwidth of the band pass filter is increased 196.5 $101.5 \mathrm{kHz}$ and $68.3-71.7 \mathrm{kHz} \mathrm{f}-3 \mathrm{~dB}$ ) to obtain a response that is fast enough to follow the stepwise activation of the amplifier section within the period of $0.8 \mathrm{~ms}$.

3. a sample and hold circuit is added. 


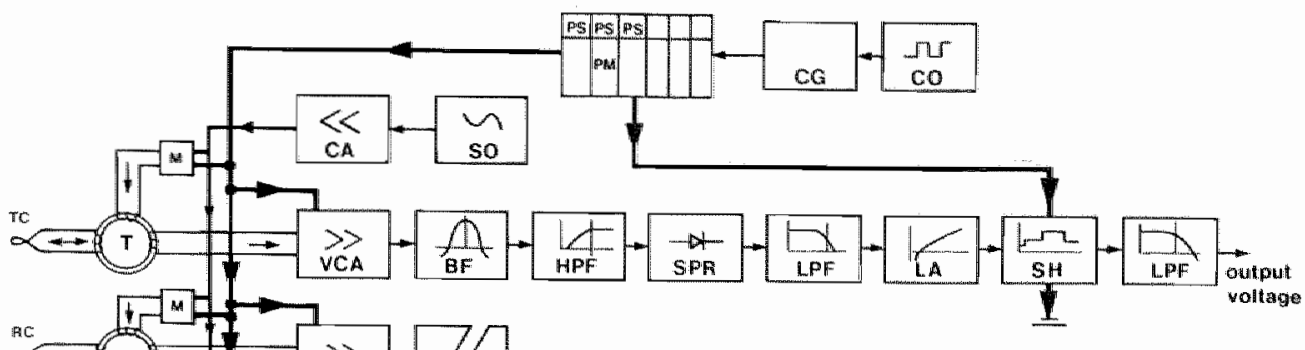

$99 \mathrm{kHz}$ : system

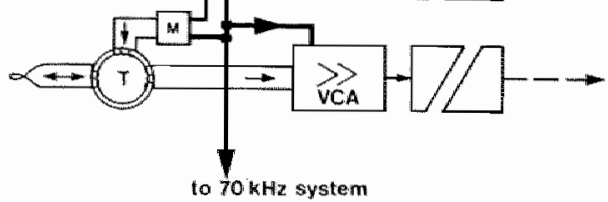

FIGURE 3.7

Schematic representation of the electronic circuitry for simultaneous measurement of six strains by six coils, only detalls of the $99 \mathrm{kHz}$ system are given. The $70 \mathrm{kHz}$ system is fully analogous (see text); $B F$ = band pass filter; $C A=$ current amplifier; $C O=$ crystal oscillator; $C G=$ code generator; $H P F=$ high pass filter; $L A=$ logarithmic amplifier; LPF = low pass filter; $M=$ multiplexer: $\mathrm{PS}=$ pragram switch; $\mathrm{PM}$ = programable memory; $\mathrm{RC}$ = receiver COII $\mathrm{SH}=$ sample and hold; $\mathrm{SO}=$ sinus oscillator; $\mathrm{SPR}=$ single phase rectifier; $T=$ high frequency transformer; $T C=$ transmitter coil; $V C A=$ voltage controlled amplifier.

4. the low pass filter is placed between the rectifier and the logarithmic amplifier following the sample and hold circuit, in order to permit stepwise activation of the logarithmic amplifier during multiplexing. To adjust the Erequency content of the rectifier signal to the bandwidth of the logarithmic amplifier, a low pass filter $(10 \mathrm{kHz} f-3 \mathrm{~dB})$ is fitted in between the rectifier and the logaritbmic amplifier.

For controlling the multiplexers and the repeated activation of the receivers a device is used in which a crystal oscillator ( $1250 \mathrm{~Hz}$ ) drives a code generator delivering three different consecutive codes with a repetition frequency of $1250 / 3 \approx 416 \mathrm{~Hz}$. The code generator is connected to six memories. Each memory, with some additional electronic circuitry to create the specific control signals, controls the multiplexer and receiver of each coil. In order to realize the multiplexing of the six strain 
signals as described earlier, each memory is programmable with two thumbweel switches.

3.4.5. Calibration and specifications of the strain measurement in $i$ itro

The single channel transmitter-receiver combination described in section 3.4 .2 was tested in vitro with respect to linearity, frequency response and stability. The experimental set-up is shown schematically in figure 3.8 . The transmitter coil was placed on a mechanical vibrator (Ling 201, Ling TP 021) which allows sinusodial displacement of the transmitter coil along its

FIGURE 3.8

Schematic representation of the experimental set-up for testing the one-channel transmitter-receiver combination on linearity, frequency response and stability, $C=$ carriage; $C A=$ current amplifier, $C M S$ = capacitive measuring system; IMs = inductive measuring system; MV = mechanical vibrator ; No = non fading oscilloscope; $\mathrm{RC}=$ teceiver coil; SO = sinus oscillator; $\mathrm{TC}=$ transmitter coil; $d=$ distance between transmitter and receiver coil.

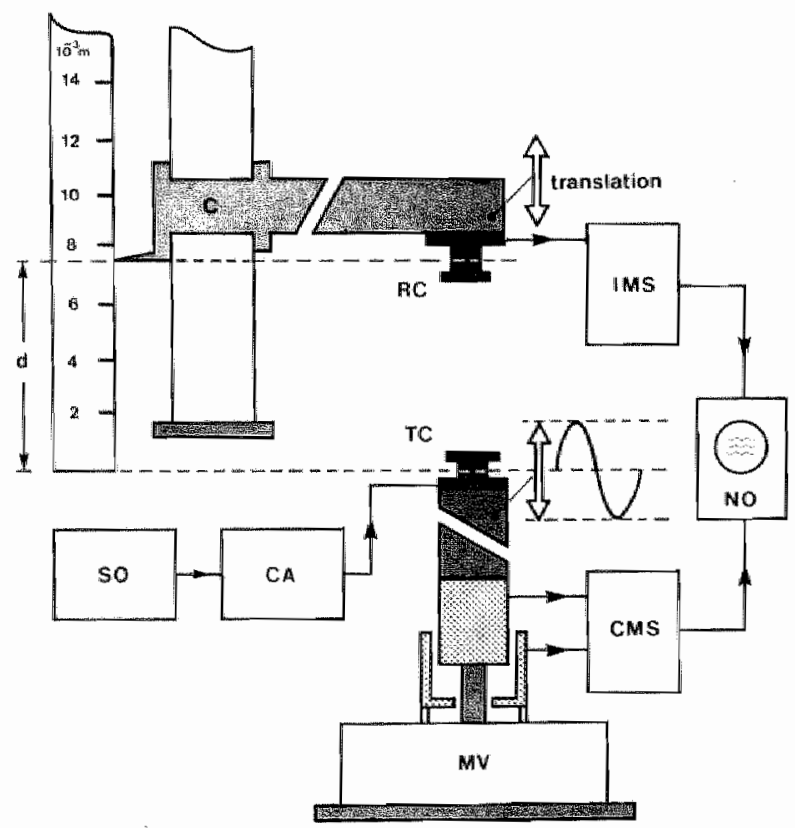


axis with an amplitude of $0.8 \mathrm{~mm}$ over a frequency range of $0<\mathrm{f}<150 \mathrm{~Hz}$. The position of the transmitter coil could be determined by a capacitive distance measuring system (Boersma CVM VI, inaccuracy $<0.002 \mathrm{~mm})$. The sensor coil was placed on a carriage, enabling change of distance between the coils up to 50 $\mathrm{mm}$, with an inaccuracy $<0.002 \mathrm{~mm}$.

Taking care the axes being in line the coils were mounted on magnetically inert synthetic material to prevent disturbance of the magnetic field. The linearity of the strain measurement system was tested by changing the distance between the coils (by translation of the carriage) and recording the output voltage of the receiver. Figure 3.9 shows the results in terms of natural strain between the coils. Assuming distance of reference $d_{\text {ref }}$ between the coils ranging in between $5 \mathrm{~mm}$ and $25 \mathrm{~mm}$, the maximum deviation of the strain measurement due to non-linearity is 0.006 when natural strain is in the range of \pm 0.20 . The inaccuracy increases to 0.009 if strain is in the range of \pm 0.30 .

FIGURE 3.9

output voltage of the inductive measurement system as a function of natural strain (reference distance $a_{\text {ref }}=15 \mathrm{~mm}$ ).

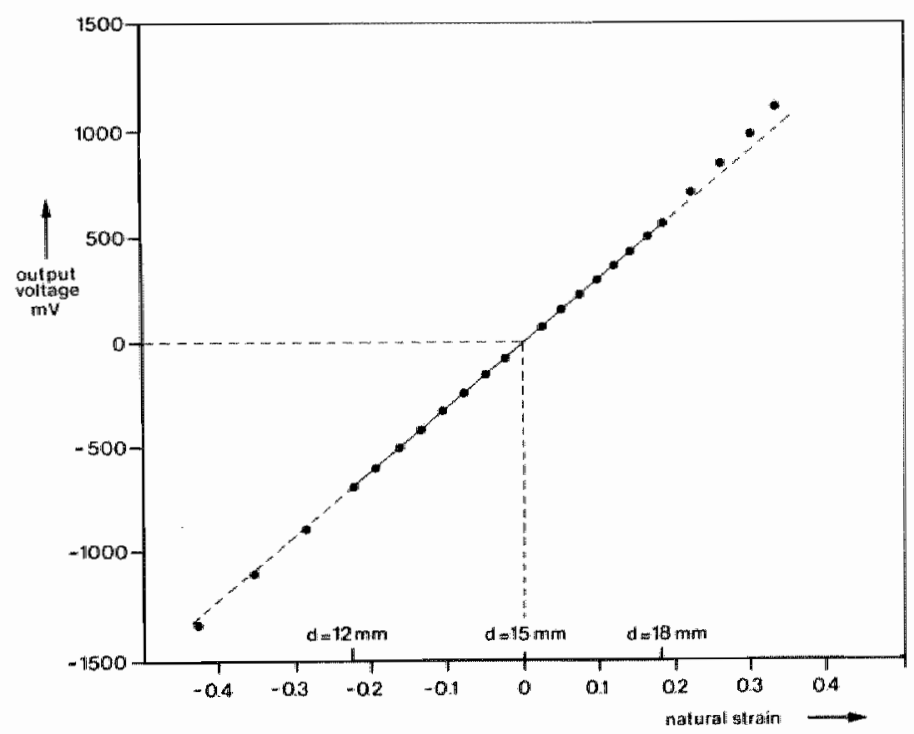


To determine the frequency response of the measuring system the coils were placed at a distance between them of $d=7.7 \mathrm{~mm}$. The transmitter coil was vibrating sinusodially with an amplitude of $0.8 \mathrm{~mm}$. Both the signals of the capacitive displacement measuring system and the inductive measuring system were recorded on a dual-channel memory oscilloscoop (Tektronix TM7313). The frequency response of the transmitter-receiver combination was found to be linear within 0,5 aB over a frequency range $0<E<150 \mathrm{~Hz}$.

The zero drift of the inductive measuring system was determined over a period of four hours and in terms of natural strain proved to be less than 0.006 .

The inductive strain measuring system was also tested in whole blood. No significant changes in the characteristics were observed. The performance of the sixfold multiplexing strain measuring system is the same as that of the tested single-channel transmitter-receiver combination, except for the maximum absolute inaccuracy amounting to 0.008 . This may be caused both by the increase of the noise in the output signal due to increased bandwidth of the band pass filter and the application of the sample and hold circuit.

\subsection{DISCUSSION}

The performance of the inductive measuring system as described in the previous sections will be discussed in relation to the experimental duficulties mentioned in section 3.2 .

- The strains between points, which are clearly defined in the three-dimensional geometry of the aortic valve, were to be measured. These strains can be measured with the inductive technique if small coils (height $1.3 \mathrm{~mm}$, width $1.3 \mathrm{~mm}$ ) are attached to the points mentioned which requires cardiopulmonary bypass surgery.

- The base points are hidden from the commissure points by the aortic valve leaflets during part of the cycle. This is no problem in the inductive measurement technique as neither tissue nor blood does affect the magnetic field. 
- To determine the motion of the aortic ring as many strains as feasible were to be measured simultaneously. Moreover fast variations in strain at the monents of valve opening and valve closure needed to be recorded accurately $(0<f<100 \mathrm{~Hz})$. The measuring system presented enables the simultaneous measurement of three strains between the base points of the leaflets and three strains between the commissure points. Besides it is also possible to measure the two strains between a base point and two commissure points simultaneously with the strain between the two commissure points involved. Combination of these measurements for different cardiac cycles results in information about the motion of the aortic ring as a whole.

In order to obtain "simultaneous" measurements the strain signals were multiplexed. In spite of this a sufficient bigh frequency response could be attained to measure strain during valve closure and valve opening $(0<\mathrm{f}<150 \mathrm{~Hz})$. Technically, $i$ would be feasible to measure all strains in the aortic ring simultaneously by increasing the number of consecutive measuring periods to five and consequently substantial extension of the electronic circuitry. However, the frequency response of the measuring device then would be reduced to about $0<f<50$ $\mathrm{Hz}$, which will be too poor to measure strain during valve closure and valve opening.

- Application of the measuring technique should not influence noticeably the normal geometrical behavior of the aortic valve. Therefore the coils were made tiny and as light as possible (12 mg), and connected to flexible wires (section 3.4.2). A disadvantage of miniaturization is that the number of turns on the coil and the surface area of one turn are small. This limits the magnetic field strength and hence the amplitude of the induced voltage (section 3.2) and consequently the distance over which strain can be measured. To get a reasonable number of turns the thinnest coilwire that could be handled was used $(0.003 \mathrm{~mm})$. Eecause the induced voltage is proportional to the frequency of the magnetic field a specification of design is to apply the highest frequency that not noticeably affects the measurements. A frequency of $100 \mathrm{kFz}$ appeared to be appropri- 
ate. The magnetic Eield strength is proportional to the cucrent through the transmitter coil. As the curcent through the coils causes generation of heat the maximum current is 1 imited. A dissipation of about $0.15 \mathrm{mw}$ proved to be acceptable, corresponding to a maximum continuous current of $80 \mathrm{~mA}$. However, since as in multiplexing the strain signals dissipation takes place during only one third of time of measuring, the current could be increased to twice this value.

By means of the measuring system developed, strain can be measured over a distance between coils of $5 \mathrm{~mm}<\mathrm{d}<25 \mathrm{~mm}$. This range is sufficient for the measurement of strains in the canine aortic valve. For distances less than 5 mm the dimensions of the coils become a problem. Moreover, at a distance in the order of the diameter of the transmitter coil ( $\cong 1 \mathrm{~mm})$ the magnetic field is no more a dipole field (Elliott 1966), which results in inaccuracy of strain measurement. For distances over $5 \mathrm{~mm}$, the inaccuracy of strain due to the finite dimensions of the coils is less than 0.002 (e.g. distance of $10 \mathrm{~mm}$, inaccuracy $<0.0004$ ). Hence, the dimensions of the coils do not significantly affect the accuracy of the measuring technique. At distances over $25 \mathrm{~mm}$ the signal to noise ratio of the induced voltage becomes too small to measure strain accurately. In this case coils must be redesigned.

The accuracy of the measuring system (inaccuracy $<0.006$ at strains \pm 0.20 ) proves to be sufficient, particularly when having in mind the possible inaccuracy caused by incidental misalignment of the coil axes during the cardiac cycle (section 3.3.2). In the in vitro calibration of the measuring system (section 3.4.5), the position of one coil was changed. The results of calibration hold also when the change of distance between the two coils originates from displacements of both coils, because the relatively slow dynamics of coil displacement $(<150 \mathrm{~Hz})$ do not significantly affect the induced voltage ( $>70 \mathrm{kHz}$; appendix A3.I). In conclusion it can be stated that the inductive measuring system meets the experimental requirements mentioned in section 3.2 . 


\section{ANIMAL EXPERIMENTS}

\subsection{INTRODUCTION}

In the aortic valve strain between the 3 comissure points, the 3 base points as well as the base points and comissure points were determined during the cardiac cycle in the anesthetized openchest dog, using the inductive technique as described in detail in chapter 3. Simultaneously the ascending artic pressure at the level of the commissures and the left ventricular pressure were measured. The strains in the aortic ring were off-line related to these pressures.

The experimental set-up is presented in section 4.2. After description of the animal preparation (section 4.2.1), the instrumentation used (section 4.2.2), the cardiopulmonary bypass technique employed to mount coils in the aortic valve (section 4.2.3) and the experimental protocol are presented (section 4. 2. 4).

The way the experimental data were processed, is presented in section 4.3. The data were digitized using an analog-digital converter (section 4.3.2) and next processed using interactive computer techniques (section 4.3.3). Finally, the strains in the aortic ring were evaluated (section 4.3 .4 ).

The results are presented in section 4.4. Successively are presented the general results (section 4.4.1) and the results with respect to strain between commissure points (section 4.4.2), base points (section 4.4.3), and commissure and base points (section 4.4.4). Discussion of the results completes this chapter $(\operatorname{section} 4.5)$.

4.2. EXPERIMENTAL SET-UP

4.2.1. Animal preparation

Healthy adult mongrel dags of either sex, ranging in weight from 
$25 \mathrm{~kg}$ to $60 \mathrm{~kg}$, were used for the experiments. The dogs were premedicated with hypnorm (1 $\mathrm{ml} . \mathrm{kg}^{-1}$ bodyweight $\left.\mathrm{i} . \mathrm{m}.\right)$ as described by Marsboom et al. (1964). One mi hypnorm contains $10 \mathrm{mg}$ fluanisone and $0.315 \mathrm{mg}$ fentanylcitrate. Anesthesia was induced by sodium pentobarbital $\left(10 \mathrm{mg} . \mathrm{kg}^{-1} \mathrm{i} . \mathrm{v}.\right)$. The dog was placed in the supine position. After endotracheal intubation anesthesia was maintained by nitrous oxide in oxygen, combined with a continuous infusion of sodium pentobarbital ( $2 \mathrm{mg} \cdot \mathrm{kg}^{-1}$.hour $\left.{ }^{-1} \mathrm{i} . \mathrm{v}.\right)$. Ventilation was kept constant by a positive pressure ventilator (Pulmomat). Body temperature was controlled by two heating pads placed underneath the dog and heating and humidifying the inhalated air by an air humidifier (Draeger). During thoracotomy muscle contractions were prevented by succinylcholine $\left(2 \mathrm{mg} . \mathrm{kg}^{-1}\right.$ i.m.). Heparine was administered (5000 I.U., i.v.) to prevent clotting. The chest was opened by a median sternotomy. After incision of the pericardium the heart was suspended in a pericardial cradle.

\subsubsection{Instrumentation}

Apart from strains within the aortic ring, ascending aortic (at the level of the commissures) and left ventricular pressure, a number of variables was measured in order to check the hemodynamic functioning of the dog during the experiment. Moreover, it was speculated that some of the variables as listed below, might be useful for further analysis. These variables were:

- left atrial pressure

- pressure in the inferior caval vein

- volume flow in the aorta just proximal to the brachiocephalic tree

- ascending aortic pressure at the site of measurement of aortic volume flow

- first derivative of left ventricular pressure

- ECG $-\mathrm{P}_{\mathrm{O}_{2}}, \mathrm{P}_{\mathrm{CO}_{2}}$, $\mathrm{pH}$, base excess and hemoglobin in the arterial
blood.

Strains within the aortic ring were measured with the inductive 
technique as described in detail in chapter 3 . Blood pressures in the animal were measured by several pressure transducers as described below. Prior to the measurements each pressure transducer was calibrated by using a mercury column. The zero level of pressure was defined by the pressure as recorded by the transducer. connected to a fluid column the level of which was at the level of the center of the left ventricular cavity.

Pressures in the aorta were measured by 2 catheter-tip micromanometers (Millar) which were inserted through the left brachial artery and the left femoral artery, respectively. pressure in the left ventricle was also measured by a catheter-tip micromanometer which was inserted through the apex of the ventricle. Each micromanometer was provided with a lumen to which an external pressure transducer (Ailtech MDS 10 ) could be connected. Phis external pressure transducer was used to calibrate the zero level of the micromanometer after this manometer was inserted into the arterial system. In this calibration procedure end-diastolic pressures as recorded by each pressure transducer system were made equal. The frequency response of the micromanometer ranged from 0 up to $2000 \mathrm{~Hz}$ ( $\mathrm{f}-3 \mathrm{~dB}$ ), whereas the inaccuracy of the transducer due to non-linearity was less than about $0.15 \mathrm{kPa}(\cong 1 \mathrm{mmHg})$.

Pressures in the inferior caval vein and the left atrium were measured by polyethylene water-filled catheters connected to external pressure transaucers (Ailtech MDS 10). The catheter to measure pressure in the caval vein was inserted through the right femoral vein. The catheter to measure left atrial pressure was inserted through the auricle of the left atrium. The freguency response of the measuring systems ranged from 0 up to $25 \mathrm{~Hz}$ (f -3 ab). whereas inaccuracy due to non-linearity was less than 0.15 $\mathrm{kPa}$.

Volume flow in the aorta was measured by a sine-wave electromagnetic flowmeter with a carrier frequency of $600 \mathrm{~Hz}$ (Transflow 601). The frequency response ranged from 0 up to $100 \mathrm{~Hz}$ $(f-3 \mathrm{~d} B)$. The end-diastalic level of the instantaneous flow tracing was used as a zero-reference. The flow probes had been calibrated in vitro, prior to the experiments. 
The first derivative of left ventricular pressure was derived from the output signal of the left ventricular micromanometer by an analog electronic differentiating circuit (frequency response 0-50 $\mathrm{Hz}$; time delay $10 \mathrm{~ms})$. ECG was derived from $1 \mathrm{imb}$ leads. Normally lead $I$ was used. Rectal temperature was measured by a tip-temperature-probe connected to an Ellab DU-3 system. $\mathrm{p}_{\mathrm{O}_{2}}$ ' $\mathrm{PCO}_{2}$ " $\mathrm{pH}, \mathrm{HCO}_{3}$ " base excess and hemoglobin were determined in samples taken from the left femoral artery, using a Radiometer ABL-3 blood analyzing system. The values of these variables were maintained within the following ranges: $100<\mathrm{P}_{2}<150$ (mmHg), $35<\mathrm{P}_{\mathrm{CO}_{2}}<45(\mathrm{mmHg}), 7.350<\mathrm{pH}<7.450, \mathrm{HCO}_{3} \cong 22(\mathrm{mmol} / 1)$, $-4<\mathrm{base}^{2} \operatorname{excess}<4(\operatorname{mol} / 1)$.

During the experiment the hemodynamic variables and strain signals were displayed on two multichannel oscillascopes (Knott GSAB). During the measurement of strain within the aortic ring, the strain signals and the hemodynamic variables, with exception of the venous pressure, were also recorded on two analog tape units. Two tape units were used as the number of signals exceeded

FIGURE 4.1

Schematic representation of the signals recorded on two tape units during a measurement. Data signals as well as two synchronization signals (pulse signal and square wave signal, are recorded on each tape unit.

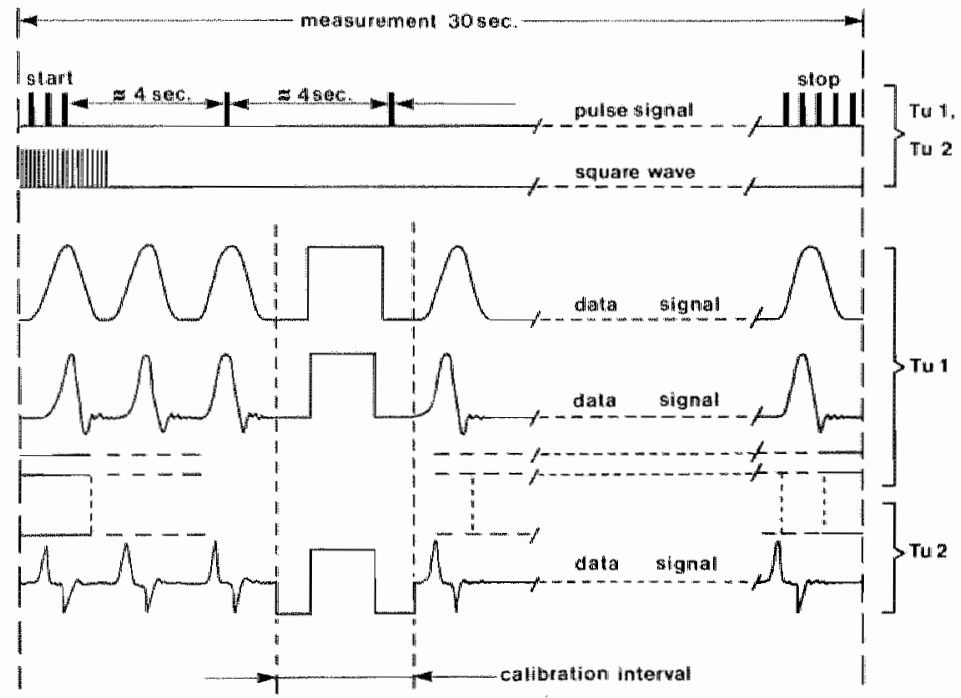


the number of channels available on one tape unit. Left ventricular pressure, both aortic pressures, aortic volume flow and the strains were recorded on an Ampex PR 2200 tape unit $(0-5 \mathrm{kHz}-3$ $d B, S / N=-42 d B$ ) whereas the first derivative of left ventricular pressure, ECG and left atrial pressure were recoraed on a Hewlett Packard $3968 \mathrm{~A}$ tape unit $(0-2.5 \mathrm{kHz}$ f $-3 \mathrm{~dB}, \mathrm{~S} / \mathrm{N}=-40$ $d B)$. For off-line synchronization of the data signals recorded, both a pulse signal and a $400 \mathrm{~Hz}$ square wave signal were recorded on each tape unit (figure 4.1). The pulse signal marked beginning (by 3 consecutive pulses) and ending (by 5 consecutive pulses) of a recording. During the recording the pulse signal showed one pulse after each period of about 4 seconds. The recordings on the 2 tape units were continuously monitored, using 2 multi-channel paper recorders (Schwarzer) and a dual-channel memoryscope (Philips).

\subsubsection{Cardiopulmonary bypass technique}

The heart-lung machine consisted of the following components (see also figure 4.2; in the text letters between parentheses refer to the Eigure):

- a venous tube (VT) which drained blood from the venous system into a bubble oxygenator (ox) by gravitational force.

- a venous clamp (VC) used to control the amount of blood drained from the venous system.

- a bubble oxygenator (OX; Polystan VT 5000), a device in which the venous blood was oxygenated with a mixture of oxygen and five percent carbon dioxide.

- a heat exchanger (HE) by which the temperature of the blood could be controlled. The heat exchanger was incorporated in the oxygenator.

- a rollex-pump (P1) to transport the blood leaving the heat exchanger into the arterial circulation.

- a roller-pump (P2) used to drain blood from the left ventricular cavity into the oxygenator through a cannula in the apex of the heart. 


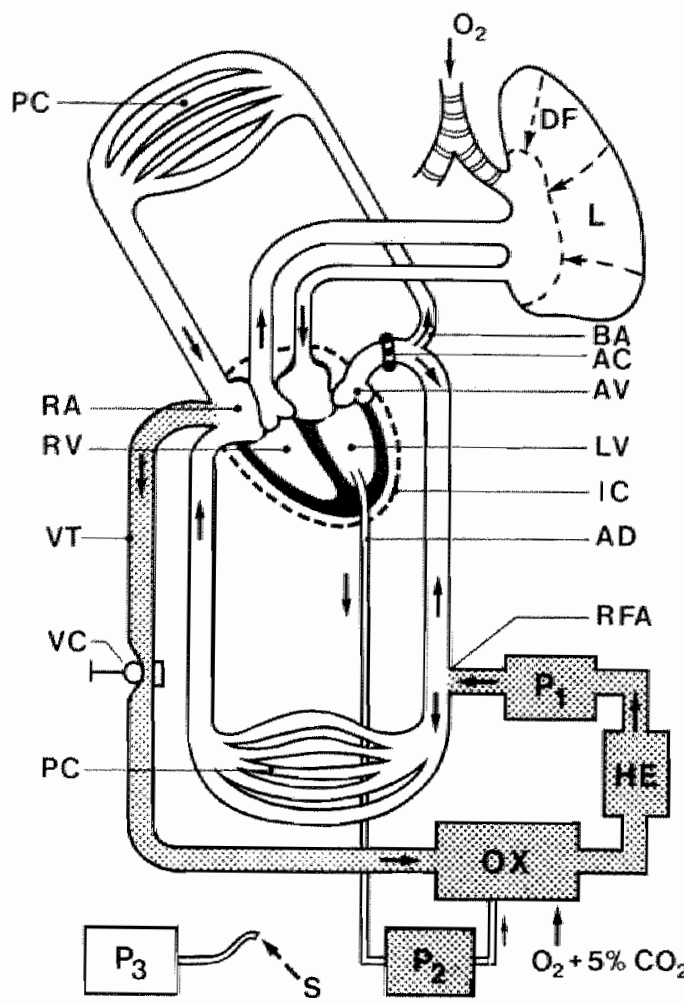

[F. IGURE 4.2

Schematic representation of partial cardiopulmonary bypass. $A C=$ aortic clamp; $\mathbb{A D}=$ ape* drain; $A V=$ aortic valve; $B A=$ brachiocephalic artery" $\mathrm{DF}=$ deflation of the lungs: HE = heat exchanger; IC = embeament of ice and cooled saline $\left(4^{\circ} \mathrm{C}\right) ; L=1$ ung: LV $=$ left ventricle: $O \mathrm{X}=$ oxygenator; P1, $P 2, P 3=$ roller-pump; $P C=$ peripheral circulation; $\mathrm{RA}=$ right atrium; RFA = right femoral artery: $\mathrm{RV}=$ right ventricle; $\mathrm{S}=$ suction; VC = venous clamp; $\mathrm{VT}_{\mathrm{T}}=$ venous tube .

- a roller-pump (P3) used to suck fluid from outside the heart into a reservoir. This fluid was not returned to the oxygenator.

- a temperature measuring device employed to check the temperature of the blad in the arterial line of the machine.

The bypass system was primed with a mixture of fresh donor blood (approximately $1500 \mathrm{ml}$ ) and a glucose solution ( $25 \mathrm{ml} / \mathrm{kg} \mathrm{body-}$ weight of a saline solution containing glucose $5 \mathrm{~g} / \mathrm{l})$. Thirty eight meq sodium hydrocarbonate were added to the mixture. Next, the mixture was saturated with oxygen and heated to approximately $38^{\circ} \mathrm{C}$.

Venous arainage was achieved through a catheter in the right atrium (RA), whereas the oxygenated blood was returned to the arterial system via a cannula in the right femoral artery (RFA). Initially only part of the venous blood was transported to the 
heart-lung machine and returned to the right femoral artery to be able to cool the heart homogeneously down to $25^{\circ} \mathrm{C}$. During the decrease in temperature, partial bypass was gradually extended, controlled by the arterial and wenous pressures. The heart was cooled further with a mixture of ice and cooled saline $\left(4^{\circ} \mathrm{C}\right.$, IC). The left side of the heart and the aortic valve were separated from the blood circulation by clamping the aorta (AC) just proximal to the brachiocephalic artery (BA) and deflating the lungs (DF). The left ventricular cavity was drained through the cannula in the apex (AD). Next, coils were mounted on the aortic ring as described in section 4.2.4. After installment of the coils, the ice, the cooled saline, the apex drain (AD) and the aortic clamp (AC) were removed and the lungs were inflated. Care was taken that all air was removed from the arterial system. Gradually the blood temperature was raised to 38 degrees using the heat exchanger in the heart-1ung machine and the heating pads underneath the dog. During the increase in temperature partial bypass was gradually diminished, controlled by the aortic and venous pressures. Calcium was administered $(0.5 \mathrm{~g})$ and, if necessary, the heart was defibrillated. Finally, the venous and arterial lines of the heart-lung machine were clamped. They remained in place for the purpose of infusing blood and bleeding the animal during the measurements (see section 4.2 .4 ).

\subsubsection{Experimentad protocol}

The dog was anesthetized and prepared according to the procedure described in section 4.2.1. The transducers for the measurement of aortic pressure, venous pressure, rectal temperature and the needles for recording the ECG were placed in position. Then the three cannulas used in the cardiopulmonary bypass procedure, one in the auricle of the right atrium (venous drainage), one in the right femoral artery (arterial return) and one in the apex of the heart (drainage of the left ventricular cavity), were inserted.

Partial cardiopulmonary bypass was installed. The heating pads underneath the dog were switched off and the animal was cooled down to $25^{\circ} \mathrm{C}$ by the heat-exchanger within the heart-lung machine. 
During this cooling procedure the aortic root was dissected so that the aortic valve was accessible down to the ostium of the right coronary artery * Partial bypass was completed at $25^{\circ} \mathrm{C}$ body temperature. Then the coils were mounted in the aortic valve (figure 4.3). An incision (aortotomy) was made across half the circumference of the ascending aorta and about $2 \mathrm{~cm}$ distal to the right coconary astium. The apex drain was removed. A hooked Eorceps was manipulated through the incision in the aorta, the aortic valve, the left ventricular cavity and the drain opening in the apex. With this forceps 6 sutures of 3 coils, to be attached to the base points, were picked up. By withdrawing the forceps the coils were pulled towards the base of the aortic valve, leaving the electrical connection wires of the coils through the opening in the apex. In this procedure care was taken to avoid damage to the chordae tendineae or papillary muscles. The cannula through the apex was repositioned, and the left ventricle and the aortic valve were cleaned from blood by infu-

\section{PIGURE 4.3}

Schematic representation of the procedure of attachment of coils to the commissure and base points during partial cardiopulmonary bypass.

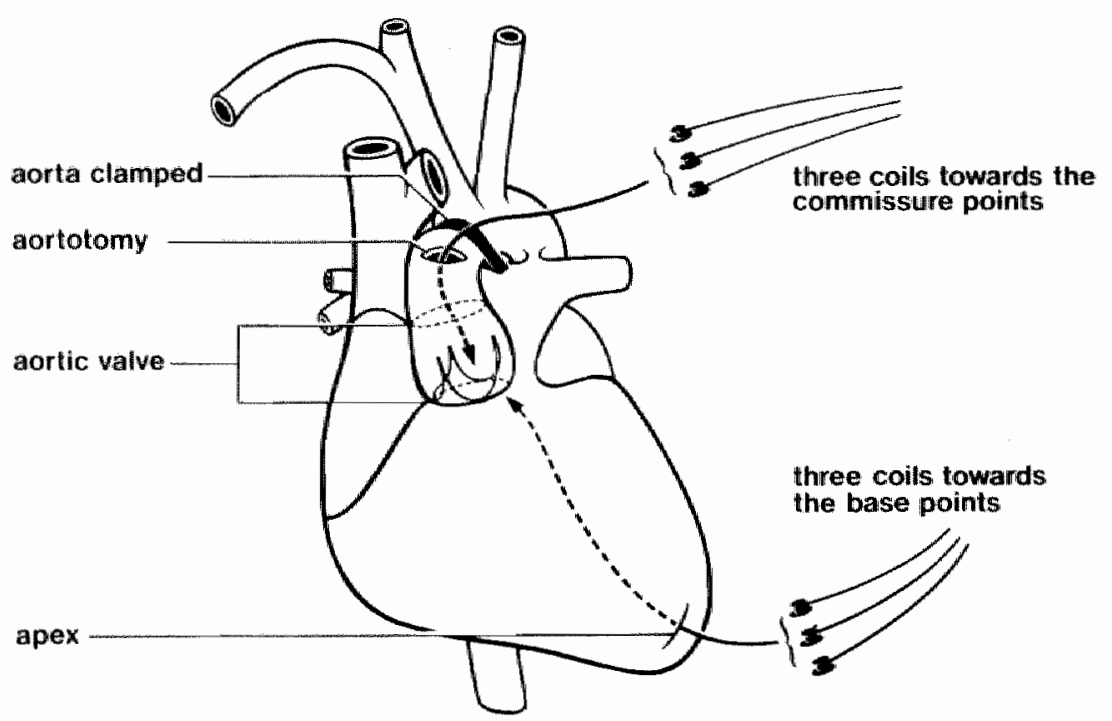


sion of a cooled plasm expander ( $4^{\circ} \mathrm{C}$; haemaccel, Behring). Each of the 3 coils at the base of the valve was sutured to a base point of the aortic ring by manipulation of suturing tools through the opening in the aorta. A fiberscope lamp was used for illuminating the inside of the valve. Next, through the opening in the aorta, a coil was sutured to each of the 3 commissure points of the aortic ring. The electrical connection wires of the 3 coils left the ascending aorta through the aortotomy. After the 6 coils had been attached, the aortotomy was closed by suturing. The blood circulation through the left ventricle and the artic valve was reinstalled. Body temperature was raised to $38^{\circ} \mathrm{C}$ by heating the blood passing the heat exchanger in the heart-lung machine and partial bypass was gradually reduced. In the meantime, the micromanometers for measuring aortic pressure and left ventricular pressure, the aortic flow probe and the polyethylene catheter for measurement of left atrial pressure were placed in position. Finally, partial bypass was terminated.

\section{FIGURE 4.4}

Position of the aortic micromanometer between the commissure points (AOPI). the aortic micromanometer (AOP2) inside the flow probe, the left ventricular micromanometer (LVP), the flow probe $\left(g_{a O}\right)$, and the coils on the aortic $r i n g$.

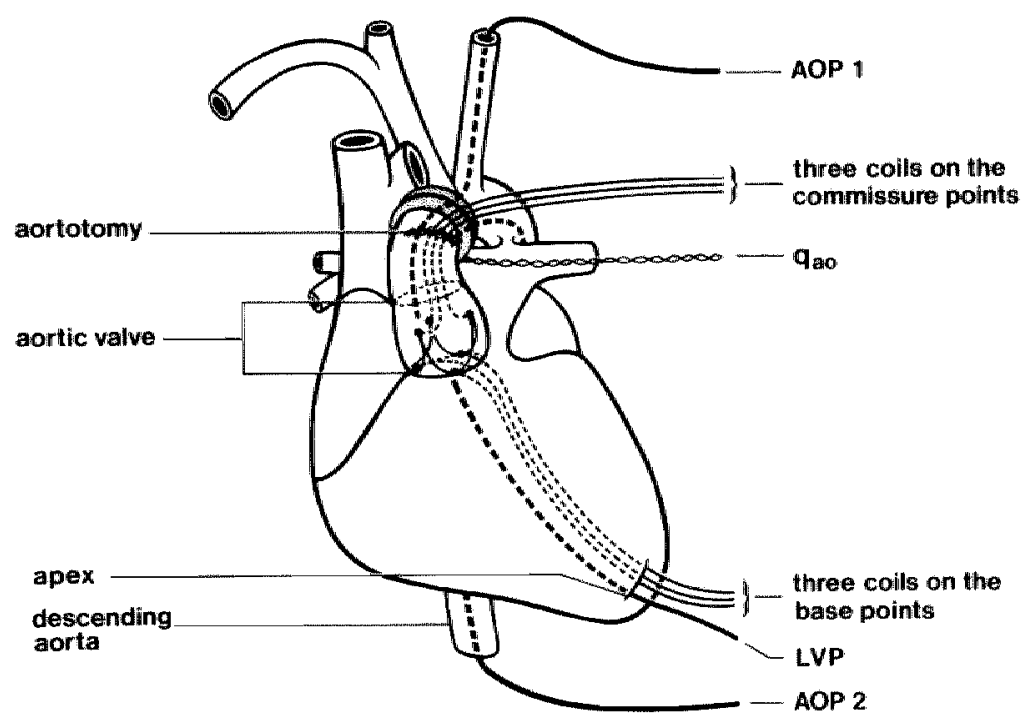


After stabilization of the hemodynamics the positions of the micromanometers and flow probe with respect to the coils were checked and recorded on video using $X-R a y$ fluoroscopy (Siemens). In figure 4.4 these positions are presented schematically. Strains within the aoric ring were measured in the following order.

Firstly the strains between the 3 base points and between the 3 commissure points were simultaneously measured at a mean aortic pressure of about $8 \mathrm{kPa}(60 \mathrm{mmHg})$. Next, the strains between a base point and the 2 nearest commissure points were measured simultaneously. The latter measurement was repeated for other commissure and base points to obtain all 6 strains between commissure points and base points (figure 1.1). At each measurement the strains and the hemodynamic variables (section 4.2.2) were recorded for about 30 seconds. The recording was interrupted for about 4 seconds to record calibration values for each variable (figure 4.1.).

These 4 measurements were repeated at various levels of mean aortic pressure in order to determine strains in the aortic ring at instantaneous aortic pressures ranging in between 4 and 30 $\mathrm{kPa}$. Mean aortic pressure was raised by infusing donor blood. In case mean aortic pressure could not be raised sufficiently, noradrenaline was administered (i.v.). The mean aortic pressure was decreased. stepwise by bleeding the animal.

Due to the complicated character of the experiments, often either not all variables could be measured, or the entire protocol be carried out. For instance, one or nore coils wowld fail or the desired aortic pressures were not reached.

At the end of the experiment the animal was killed with an overdose of pentobarbital. The heart was removed and the inside of the aortic valve was exposed. The location of the coils and their attachment to the commissure points and the base points were examined and several photographs were taken. 


\subsection{DATA PROCESSING}

\subsubsection{Introduction}

In each measurement strains and hemodynamic variables were recorded during a period of 30 seconds (see section 4.2.4). From each period of 30 seconds an interval of 10 seconds was used for data processing.

The data signals being recorded during this interval of 10 seconds, were digitized using an analog-digital converter (section 4.3.2). The digitized data were fed into a digital computer and processed by an interactive program (section 4.3.3; figure 4.5). Finally, the strain measurements were evaluated according to the procedure as described in section 4.3 .4 .

4.3.2. Analog-digital conversion of the experimental data

During the experiments 10 data signals were recorded by one tape

FIGURE 4.5

Schematic representation of the data processing. $A-D=$ analog-digital; LPF = low pass filter; TU1, TU2 = tape units 1 and 2 .
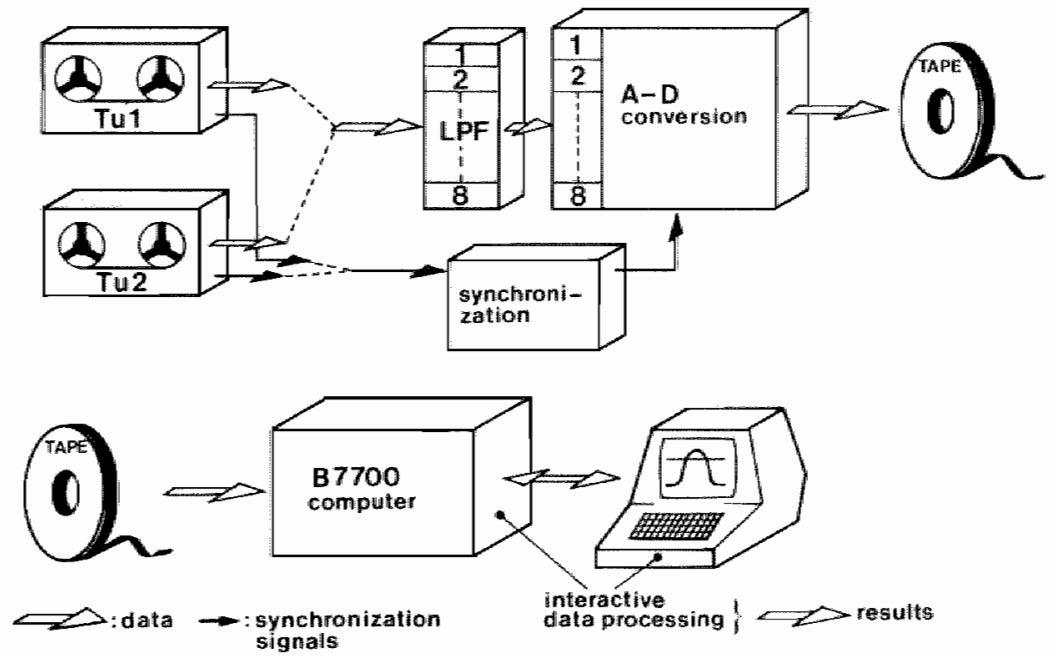
unit and 4 data signals by the other. Additionally a pulse signal and a square wave signal $(400 \mathrm{~Hz})$ were recorded by both tape units (figure 4.1) for the purpose of synchronization.

The 14 data signals were digitized using an analog-digital converter which could process a maximum of 8 data signals at the same time (figure 4.5). Consequently, to digitize 14 data signals 3 successive conversions were performed. In each of the 3 consecutive conversion cycles the same moment within a period of 30 seconds recording had to be found. For this purpose the pulse signal was used as follows. One of the 4-second pulses ifigure 4.1) was chosen to start the digitizing process. During replay of a tape unit the pulse signal was connected to the analog-digital converter, just before the appearance of this pulse. At its appearance the digitizing process was triggered to start automatically. In order to switch on the pulse signal just before the appearance of the pulse, this signal was visualized on an oscilloscope and the number of preceding pulses in the period of 30 seconds recording were counted from the display.

Synchronization of the 14 data signals may be affected by changes in tape speed of the two different tape units. This effect was compensated for by using the recorded $400 \mathrm{~Hz}$ square wave signal to control the digitizing process during the period of 10 seconds conversion. At each rising slope of the $400 \mathrm{~Hz}$ signal the analog-digital converter sampled all data signals, digitized the samples obtained and, next, stored the data on its own disc memory.

To check the analog-digital conversion an external, triangular shaped $40 \mathrm{~Hz}$ signal was also digitized during each conversion cycle. Occasional irregularities in the digital representation of the triangular signal indicated improper conversion.

Before a data signal entered the analog-digital converter, it passed a low pass filter in order to prevent aliasing due to undersampling of occasionally high frequency components ( $>200$ $\mathrm{Hz}$ ) of the analog signal (Bracewel1, 1978; figure 4.5). The low pass filter characteristics were chosen after evaluating the power spectra of the data signals (Hewlett Packard 5240A signal analyzer). A second-order low pass filter with a transition frequency of $150 \mathrm{~Hz} f-3 \mathrm{~dB}$ proved to be sufficient. 
The analog-aigital conversion has been performed with a $12-b i t$ resolution (Microconsultants and Digital PDP 11/60). During conversion data were stored on disc memory (Digital, RK 05) of the analog-aigital converter. As a routine, the data on the disc memory of the converter were copied on magnetic tape. The data on this magnetic tape were fed into the computer which was used for data analysis.

4.3.3. Data processing using interactive computer techniques

Out of each measuring period of 30 seconds an interval of 10 seconds was digitized. These intervals, denoted as data files, were stored on a magnetic computer tape (section 4.3.2; figure 4.5). The data files were processed by means of a video terminal and using a specially developed interactive computer program (Fortran IV).

The program has been designed to be able to deal with one data file at a time. At the beginning of the program the data file was read from magnetic tape (figure 4.5). Additional information about the measurements, such as calibration values of the signals, were read from the memory. Data processing was performed in the following way (figure 4.6).

- The calibration intervals of 6 data signals (figure 4.11 were displayed on the video terminal. By means of a cursor two calibration levels of each signal were marked. Consequently, the amplitudes of the data signals wexe converted from voltage to physical quantities according to calibration values which earlier had been stored in the memory of the computer. This procedure was repeated for all 14 data signals.

- The strain signals were shifted with respect to the time axis to correct for time delay of the signals $(1.0 \mathrm{~ms})$. The delay originated from the electronics in the measuring system and was the same for all strains.

- The data signals representing left ventricular pressure, aortic pressure at the level of the commissures and strain within the aortic ring were visualized for the entire interval of 10 seconds. of this interval, 5 consecutive cardiac cycles were 


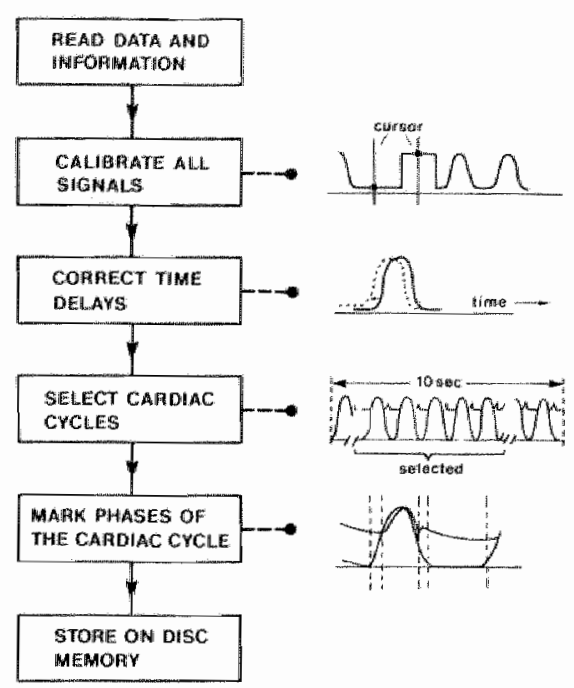

FIGURE 4.6

scheme of computer data processing.

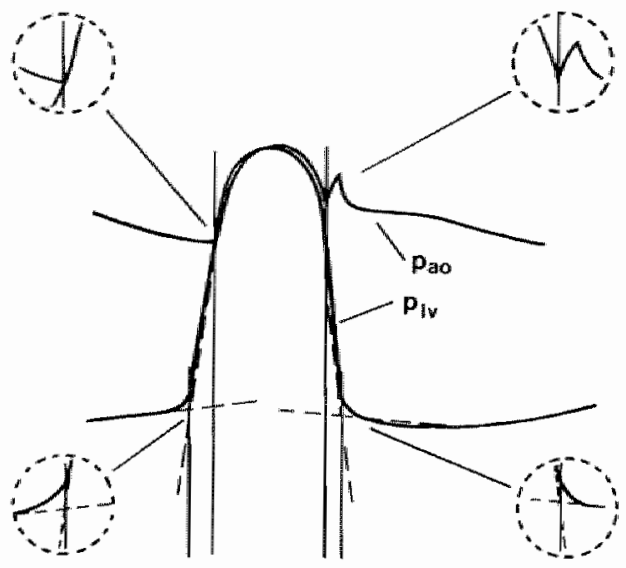

cursor locations

FIGURE 4.7

Cursor locations defining the phases of the cardiac cycle. $\mathrm{P}_{a 0}=$ aortic pressure; $P_{1 V}=$ left ventricular pressure.

selected and displayed on the terminal. Within each cardiac cycle displayed, the iscvolumilc contraction phase, the ventricular ejection phase, the isovolumic relaxation phase and the ventricular filling phase (figure 2.2) were marked by positioning a cursor on the screen at the sites as defined in Eigure 4.7. The inaccuracy in positioning the cursor was estimated to be maximum $5 \mathrm{~ms}$. The values of the visualized signals corcesponding to the 5 cardiac cycles were stored in a data file and labelled with the phase of the cardiac cycle to which they correspond. Finally, this data file was written on disc menory of the computer for later analysis.

\subsubsection{Evaluation of strains in the aortic ring}

For each 30 second period of measurement, a data file was written on the disc memory of the computer. This data file contained the 14 data signals during 5 consecutive cardiac cycles, whereas the phases of the cardiac cycle were marked (section 4.3.3). The data 
files on disc memory were used to evaluate the strains measured within the aortic ring according to the following procedure.

Each commissure strain measured was related to aortic pressure Pao and normalized transwalvular pressure $p_{n t}$. The latter pressure was defined as the ratio of aortic pressure minus left ventricular pressure and aortic pressure. It was assumed that the aortic pressure is the major cause of the changes in strain between commissure points due to the elastic behavior of the valve material. Normalized transvalvular pressure was assumed to determine the non-elastic component of the change in strain. The underlying mechanism is dealt with in chapter 5. The following equation was used to express the relationship between strain between commissure points and the pressures mentioned

$$
\text { strain }=a_{0}+a_{1} \cdot P_{a 0}+a_{2} \cdot p_{a o}^{2}+a_{3} \cdot p_{n t} \cdot S W
$$

where $\mathrm{SW}$ is a factor characterized by $\mathrm{SW}=0$ during the ventricular ejection phase and $S W=1$ during the three other phases of the cardiac cycle. This factor was introduced because during the ventricular ejection phase, when the valve is open, the influence of $P_{n t}$ on valve geometry is assumed to be small. The constant parameter $a_{0}$ was included in the equation in order to take into account the contribution of $c_{1}$, $d_{\text {ref }}$ and $f$ in equation (3.6) to the value of natural strain. A linear and a quadratic term in aortic pressure were included in the equation in order to describe the non-linear dependency of commissure strain on aortic pressure (figure 4.10 ).

In order to find the parameters a through $a_{3}$ in equation (4.1) multiple regression analysis was applied to each strain measured between comissure points. Therefore for each dog, the data filles on disc of the commissure strain signals which belonged to the same segment were combined to a large data file to cover a wide range of aortic pressures. The data files thus composed, were used to fit the parameters in equation (4.1) to each of the three comissure strains of each dog. The parameters fitted to all commissure strains measured, were tabulated and interpreted with respect to walue and sign. A parameter was 
denoted as nom-significant when its value was less than $\pm t_{v}$. (S.D.), where $t_{v}$ is the Student-T value at $p=0.001$. To check the reliability of the parameter estimation procedure, in a number of cases the commissure strains were plotted as a function of aortic pressure using data of the ventricular ejection and the ventricular filling phases (figure 4.10 ). In these plots also two plots of equation (4.1) were shown, one curve corresponding to a value of 0 of the normalized transvalvular pressure and the other one to a value of 1 of this quantity, whereas the parameters in equation 4.1 were obtained from table 4.1 of the related commissure strain. Furthermore, in several data files, an arbitrary cardiac cycle was taken out of the number of cardiac cycles used to 1 it comissure strain to equation (4.1). Next, the commissure strain during the chosen cardiac cycle was calculated by substituting into equation (4.1) both aortic pressure and normalized transvalvular pressure as measured during that particular cardiac cycle. This strain and the strain as measured directly during the same cardiac cycle were compared by plotting in the same figure.

From the data files which were stored on disc and containing 5 cardiac cycles with marked phases, the strains as measured in the base plane, and between base points and commissure points, were visualized on the display of the monitor together with left ventricular pressure and aortic pressure at the level of the commissure points. These data were not further processed, because of the limited number of experiments performed. Therefore, only typical direct recordings of strain are presented together with left ventricular and aortic pressure.

\section{4. RESULTS}

4.4.1. General results

In 11 dogs strains within the aortic ring were determined for various levels of mean aortic pressure. The number of strains that could be measured in each dog varied due to defects in the coils or their attachment, or the impossibility to mount the coils within each valve according to the protocol (section 
4.5.1). In 10 dogs one or more strains could be measured between the commissure points, in 4 dogs one or more strains in the base plane of the valve and in 5 dogs one or more strains between a base and a commissure point.

In 2 dogs, 3 strains between the commissure points and 3 strains in the base plane of the valve were measured simultaneously. In the latter 2 dogs the strains along the sides of the triangle formed by one base point and the two nearest commissure points were also recorded simultaneously.

An example of a simultaneous recording of aortic pressure, left ventricular pressure, 3 strains between the commissure points and 3 strains between the base points as an instantaneous function of time is presented in figure 4.8. In this figure strains are referred to in a commissure circle, through the commissure points 0,4 and $B$, and in a base circle through the base points 2,6 and 10. Part of the base circle adjoining the myocardial wall of the left ventricle and the septum is marked by a thick line. Generally strain variations are in the order of 0.1. For different dogs, the variations in strain between the commissure points and in the base plane are presented in sections 4.4 .2 and 4.4 .3 .

Aortic pressure, left ventricular pressure and strains along the sides of a triangle formed by one base point and two nearest commissure points as measured synchronously, are presented in figure 4.9. Unfortunately, the strain signals were quite noisy. In this experiment the variation in strain between base point and both commissure points during the cardiac cycle is in the order of 0.06 . Strain between base point and commissure point as measured in different dogs is presented in section 4.4 .4 .

\subsubsection{Strain between commissure points}

In 6 dags. 3 strains between the commissure points were measured simultaneously and in 4 dogs the strains were recorded in succession order. The courses of the strains between the commissure points as a function of time as presented in Eigure 4.8 , midpanel, are representative for all strains measured between com- 

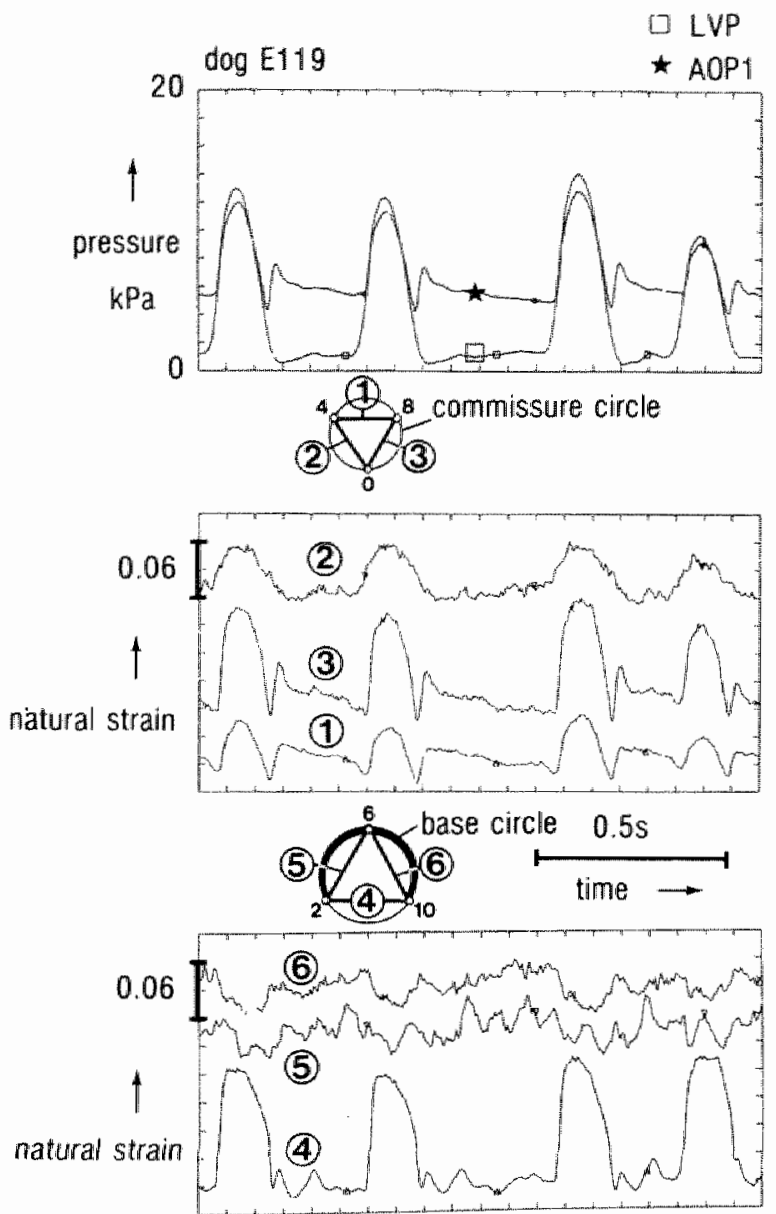

FIGURE 4.8

Simultaneous recordings of left ventricular pressure (IVP) and aortic pressure at the level of the comissure points (AOPl; top panel), strain between commissure points (mid panel) and strain between base points (bottom pane1), in one dog. The commissure strains are referred to in a commissure circle through the commissure points 0,4 and 8 . The base strains are referred to in a base circle through the base points 2,6 and 10 . The mutual positions of the commissure points and the base points are clockwise defined where 0 represents the commissure between the left and the posterior sinus of valsalva. The thick part of the base circle adjoins the septum and the wall of the left ventricle. The thin part adjoins the anterior mitral valve leaflet. Each interval along the time axis corresponds to $75 \mathrm{~ms}$. 


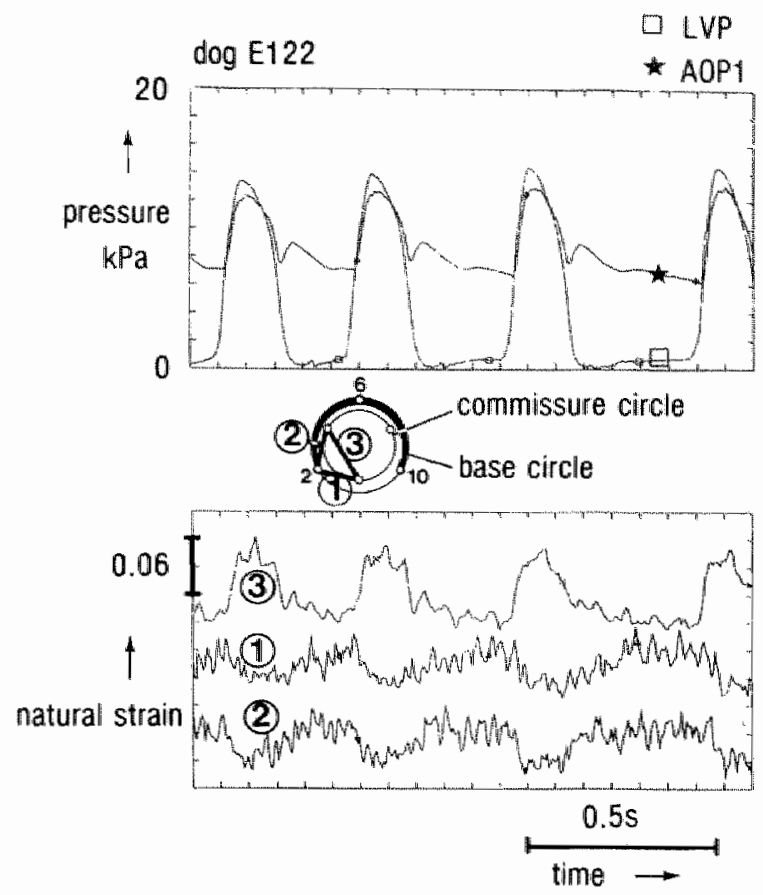

FIGURE 4.9

Simultaneous recordings of left ventricular pressure (LVP), aortic pressure at the level of the commissure points (AOP I; top panel), and strains along the three sides of a triangle defined by a base point on the base circle and two commissure points on the commissure circle. The commissure and base circles are defined in figure 4.8. Each interval along the time axis corresponds to 75 mis.

missure points. Every measurement of commissure strain showed different variation during the cardiac cycle. However, with respect to the entire group of dogs, no systematic pattern was observed in the differences between the three commissure strains. Generally, commissure strains started to increase in the early part of the isovolumic contraction phase.

The 26 commissure strains measured in 10 dogs were related to aortic pressure and normalized transvalvular pressure according to equation (4.1), using the procedure as described in section 4.3.4. The results are given in table 4.1. From these results the following was concluded. 
TABLE 4.1

parameters $a_{a}, a_{1}, a_{2}$ and $a_{3}$ of equation (4.1) as determined by multiple regression analysis on data files related to comissure strains. The presented wallues of the parameters are significant according to a student-T probability function $(p<0.001)$. CS = commissure strain; STR = strain defined according to the comissure circle in figure 4.8; SD = standard deviation; MC = multiple correlation coeficient; NDP = number of ata points; $N C C=$ number of cardiac cyclles; $\mathrm{SEE}=$ stemdard error of the estinate.

\begin{tabular}{|c|c|c|c|c|c|c|c|c|c|c|c|c|c|c|c|}
\hline $\mathrm{Cs}$ & Bot; & 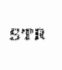 & value & 450 & 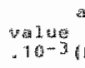 & $\begin{array}{l}3.909 \\
2-9\end{array}$ & $\begin{array}{c}x+100 \\
-10-6\end{array}$ & $\frac{2 \leq D}{(4-2)}$ & value & +50 & 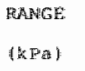 & $\begin{array}{l}\mathrm{AC} \\
=\end{array}$ & $\begin{array}{c}\text { MLP } \\
=\end{array}$ & $\begin{array}{c}\mathrm{M} 6 \mathrm{C} \\
-\end{array}$ & $\begin{array}{c}S E D \\
-\end{array}$ \\
\hline 1 & $\mathrm{E}: 22$ & $\operatorname{coc} A$ & -.163 & .001 & .0269 & . id 003 & -.0006 & $<\therefore .0001$ & -.0245 & .00004 & $8-\| A_{1} .5$ & .980 & 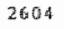 & 36 & .007 1 \\
\hline 2 & $" '$ & $\mathrm{C} \times \mathrm{CH}$ & -.206 & .0012 & . D 396 & 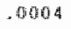 & -.007 72 & $\therefore 0001$ & -.0199 & .00006 & $4-14 d_{1} .5$ & .970 & 2604 & 16 & .0116 \\
\hline 3 & "' & cincis & -.3605 & .001 & .06007 & .0803 & -.0616 & 42.0001 & $-.05 \times 7$ & . Q000A & $4-1 / \|^{2} 5$ & .996 & 2604 & 96 & .0086 \\
\hline 4 & tis 124 & $\mathrm{Cacla}$ & -.153 & .006 & .010 & .002 & \multicolumn{2}{|c|}{ NS } & -.022 & ant & $4-12$ & .782 & 2790 & 20 & .0239 \\
\hline 5 & " & $\mathrm{C}[\mathrm{acdi}$ & -.372 & .006 & .055 & .001 & -.0017 & .0001 & -.050 & .60? & $4-12$ & .948 & 2798 & 20 & .0217 \\
\hline 6. & at & $\mathrm{CEC}$ d & -.134 & .003 & .026 & .001 & - „0039 & .0001 & -.0164 & .0007 & $4-12$ & 884 & 2798 & 20 & .0134 \\
\hline$y$ & E) 19 & CACH & $-2 \# 4$ & .005 & .018 & .001 & \multicolumn{2}{|c|}{$\mathrm{NS}$} & .017 & .001 & $A-12$ & .934 & 81043 & 7 & .0108 \\
\hline$\theta$ & $"$ & $60 \mathrm{C} 4$ & -.036 & .006 & -.006 & .001 & , 0606 & .0001 & -.0053 & .001 & $4-12$ & .949 & I的 43 & 7 & .0111 \\
\hline 9 & $\approx$ & $\mathrm{COCH}$ & $=.35$ & .000 & .069 & .002 & -.0027 & .0001 & -.036 & .0002 & $4=12$ & .977 & 1043 & 7 & .0161 \\
\hline 10 & Nitin & $\mathrm{coc}$ & -.158 & 10001 & $.002^{\circ}$ & .0003 & .0002 & $c * .0009$ & -.0470 & .0005 & $3-17$ & .950 & 2135 & 23 & .0121 \\
\hline$\$ 1$ & $"$ & $\mathrm{COC}^{\circ}$ & -.182 & "002 & .9128 & $.000 \%$ & -.0403 & $\approx .0001$ & -0259 & .0009 & $3+17$ & 85 & 2095 & 23 & .0176 \\
\hline 12 & $"$ & $64 C^{3}$ & -.179 & .002 & .0093 & .0004 & \multicolumn{2}{|c|}{ No } & -.0425 & .0006 & $3-17$ & .947 & 2655 & 23 & . 010 \\
\hline 3 & $1: 114$ & $\mathrm{C} 4 \mathrm{CH}$ & .017 & .002 & -01124 & .0003 & 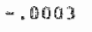 & .0001 & -.0178 & $.000 \mathrm{3}$ & $4-19.5$ & .940 & 2543 & $3 \overrightarrow{7}$ & $.00 ! 59$ \\
\hline 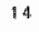 & " & $\mathrm{CaC}_{4}$ & $\approx 160$ & .003 & .0400 & .0005 & - & $\therefore 0001$ & -.0488 & .0006 & $5-19.5$ & .982 & 25.3 & 33 & .0105 \\
\hline $1:$ & - " & $\operatorname{coc} a$ & -.314 & .004 & .0562 & .0000 & $\approx .0016$ & 5.0001 & -.051 & .0006 & $4-19.5$ & .982 & 2504 & 37 & .10122 \\
\hline 86 & E 12 & Cuct & -.166 & .002 & .0289 & .0004 & $-.000 \%$ & 5.0001 & $m .0308$ & .0005 & $4-16$ & .981 & 3917 & 15 & .10097 \\
\hline 17 & " & $\operatorname{coc} \theta$ & -.181 & .002 & .0422 & .0004 & -.0013 & $=.0001$ & -.0789 & .0005 & $4,-76$ & .989 & 3,947 & 19 & .0102 \\
\hline 18 & $"$ & $\operatorname{cocs}$ &.$- \$ 16$ & .003 & .0659 & .0607 & -.0018 & .0001 & -.0155 & .0009 & $4-16$ & .980 & $39 \pi 7$ & 19 & .0181 \\
\hline 19 & E30\% & $\mathrm{coc}$ & -.230 & .003 & .0512 & .0009 & -.0017 & .0001 & -.0136 & .0005 & $4 .-11.5$ & .988 & 1279 & 7 & .0094 \\
\hline 20 & 2706 & $\operatorname{coc}$ & $-.3 B$ & .006 & .042 & .007 & -.0010 & .0001 & -.034 & .001 & $6-17$ & .979 & 1321 & 12 & $.0 \# 41$ \\
\hline $2 \%$ & " & $\mathrm{CAc} B$ & -.305 & .005 & .029 & -0001 & -.0005 & .0001 & -.111 & .001 & $5-15$ & .990 & 1287 & 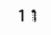 & .0129 \\
\hline 22 & "' & $\mathrm{Caco}$ & -.374 & -907 & .0423 & .06007 & -.0008 & 5.0001 & -.014 & .001 & $5-18$ & .952 & 1217 & 17 & .0124 \\
\hline 23 & 2615 & $\operatorname{coc} 4$ & -.172 & .005 & .021 & .002 & \multicolumn{2}{|c|}{ NSS } & -.093 & .001 & $4-8$ & .989 & 1018 & $4 i$ & .0106 \\
\hline 24 & 8610 & $\operatorname{coc} \theta$ & -.134 & .002 & .0172 & $=00007$ & .0049 & $\therefore 0001$ & -.80174 & .0004 & $5-9.5$ & .996 & 1773 & 9 & .0047 \\
\hline 25 & $"$ & $\operatorname{coc} 4$ & -.280 & .006 & $.06 \%$ & .002 & \multicolumn{2}{|c|}{$\mathrm{NS}$} & -.0157 & .001 & -8 & .997 & 831 & 6 & . D in \\
\hline $2 k$ & $"$ & 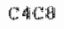 & \multicolumn{2}{|c|}{$\mathrm{MS}$} & $045 \%$ & .01 & -.0120 & .93006 & -.0171 & .006 & $6-12$ & .942 & 272 & 3 & .0356 \\
\hline
\end{tabular}

- For 10 dogs equation (4.1) could be fitted properly to the experimental data as indicated by the high value of the multiple correlation coefficient $M C$; in $23 \mathrm{fits} M C>0.934$ and in 3 fits $0.782 \leq \mathrm{MC}<0.934$. The value of the standard error of the fit, ranging in between 0.005 and 0.024 , was in the order of the expected inaccuracy of the measurement $(0.015$; section $3.4 .5)$.

- The value of the parameter $a_{0}$ determines the shift of the curve along the strain axis. Its value depends on the mutual coil orientation and the reference distance of natural strain (section 3.3 .1 ). Both quantities are different and unknown for each 
commissure strain, but obviously, the value of a is not important for comparison of the different commissure strains. However, its value is important in the calculation of strain by means of equation (4.1).

- The value of the linear parameter a was significantly different from zero for all 26 comissure strains. It ranged in between $-6 \times 10^{-6}$ and $69 \times 10^{-6} \mathrm{~Pa}^{-1}$, being positive for 25 commissure strains. The mean value of this parameter was $3.4 \times 10^{-5}$ $\pm 2.1 \times 10^{-5} \mathrm{~Pa}^{-1}$ (mean \pm standard deviation).

- For 21 commissure strains the quadratic term $a_{2}$ pao $^{2}$ was significantly different from zero. The value of $a_{2}$ ranged in between $-10 \times 10^{-10} \mathrm{~Pa}^{-2}$ and $20 \times 10^{-10} \mathrm{~Pa}^{-2}$. A negative value was found for 18 commissure strains and a positive one for 3 commissure strains. So, overall, $a_{2}$ was negative $(p<0.01)$, resulting in a concave shape of the curve.

- The derivative of commissure strain to aortic pressure at given normalized transvalvular pressure $\left(a_{1}+2 \cdot a_{2} \cdot p_{a o}\right)$ was calculated for each commissure strain in table 4.1 at an aortic pressure of $10 \mathrm{kPa}$. The mean value of this derivative was found to be $1.9 \times 10^{-5} \pm 1.2 \times 10^{-5} \mathrm{~Pa}^{-1}$ (mean \pm standard deviation; 26 comissure strains).

- Generally, strain between the commissure points decreased when normalized transvalvular pressure changed from 1 to 0 lexcept commissure strain 7). The mean value of the differences in strain (parameter $a_{3}$ ) over all 26 commissure strains as presented in table 4.1 , was determined to be $-0.041 \pm 0.028$ (mean \# standard deviation).

- The results presented in table 4.1 were derived from experiments under condition of a wide variation of heart rate 160 to 250 beats.min $^{-1}$ ).

For commissure strain 3 in table 4.1 , the measured values as a function of aortic pressure are shown in figure 4.10 for the ventricular ejection phase (upper group of measuring points) and the ventricular filling phase (lower group of measuring points) of the cardiac cycle. In figure 4.10 values of strain in the ventricular filling phase at aortic pressures less than about 7.5 $\mathrm{kPa}$, correspond to normalized transvalvular pressure of about 1. 


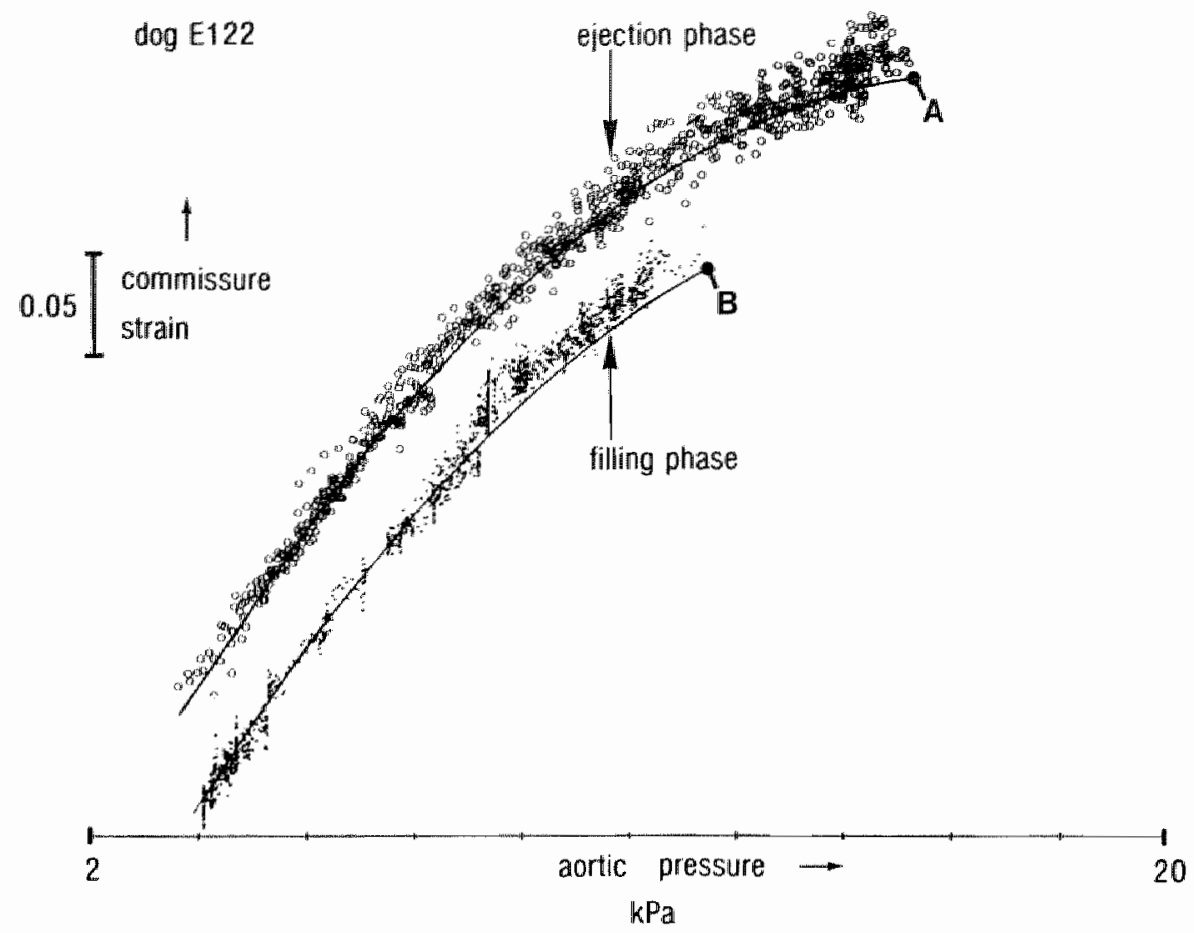

\section{FIGURE 4.10}

For commissure strain 3 in table 4.1 , strain is plotted as a function of aortic pressure for the ventricular ejection phase (upper points in the figure) as well as the ventricular filling phase (lower points in the figure). $A=$ strain calculated according to fitted equation (4.1) and $P_{n t}=0 ; B=$ strain calculated according to fitted equation (4.1) and $p_{n t}=1$.

Normalized transvalvular pressure ranged in between about 0.85 and 0.95 for values of strain in the ventricular filling phase at aortic pressures higher than about $7.5 \mathrm{kPa}$, because then diastolic left ventricular pressures were higher. The commissure strains for both cardiac phases as derived from equation (4.1), are show in the same figure (see section 4.3.4). As to the other measurements presented in table 4.1, similar results were found although the difference in strain between ventricular ejection phase and ventricular filling phase was often less pronounced.

As to commissure strains 3,5 and 11 in table 4.1 , the strain measured is shown in figure 4.11 as a function of time during one 


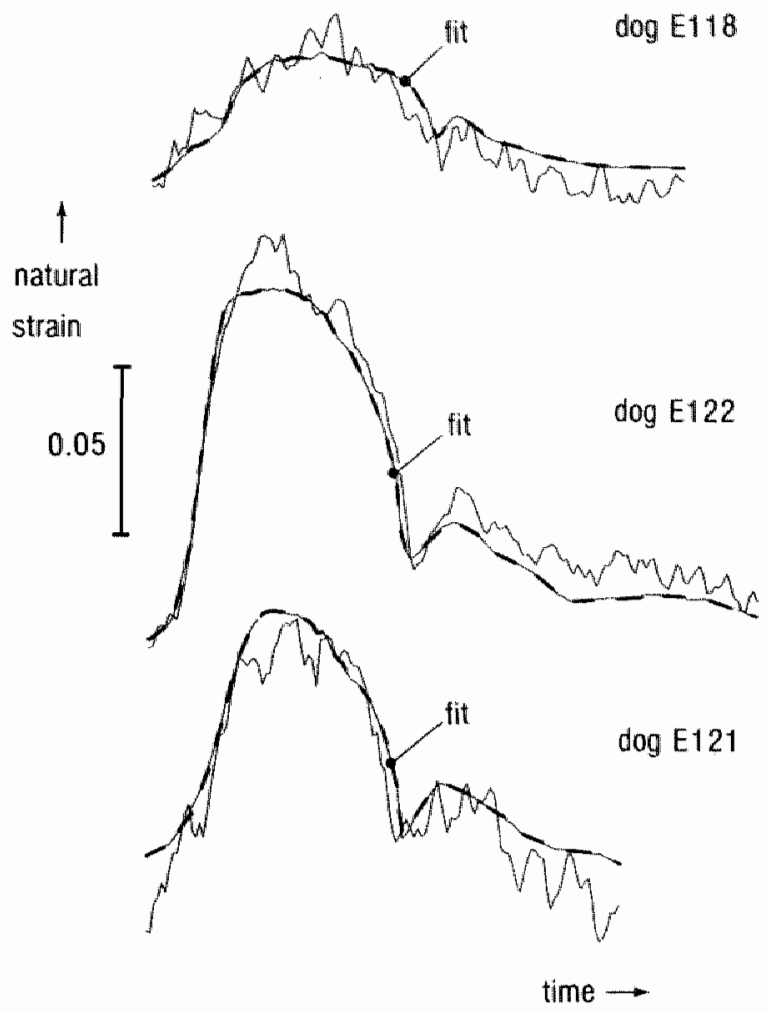

FIGURE 4.11

Calculated and directly measured strain as a function of time for commissure strains 3,5 and 11 in table 4.1. The strain was calculated by substitution of momentaneous values of aortic pressure and normalized transvallular pressure as measured during this particular cardiac cycle, into the related fitted

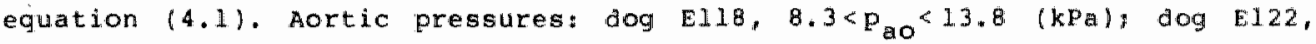
$7.6<\mathrm{p}_{\mathrm{aO}}<13.7(\mathrm{kPa}) ; \operatorname{dog} \mathrm{E} 1217.5<\mathrm{p}_{\mathrm{aO}}<11.6(\mathrm{kPa})$.

of the cardiac cycles to which regression analysis was applied. In the same figure, the commissure strain calculated by substitution of measured aortic and normalized transvalvular pressure in equation (4.1) is also shown. Calculated and measured strain agree fairly well. 
4.4.3. Strain in the base plane of the valve

Typical recoraings of the strains in the base plane as measured in 4 diferent dogs are presented in figure 4.12 . In 1 dog (panel E) strains were measured between the base points as indicated by the base circle in panel $\mathbb{E}$. In the other 3 dogs, strain was measured along various segments of the base circle. Precise positioning of the coils at the base was often difficult. With respect to the data presented in figure 4.12 the following could be concluded:

- No judgement can be given about the significance of the strains measured in the base plane since the number of measurements is too small and the sites between which strains were measured, were scattered over the base circle.

- All strains were found to vary during the cardiac cycle. The maximum variation ranged in between 0.03 (measurement in panel D) and 0.15 (measurement in panel C).

- With respect to the dog where strain was measured between the 3 base points (panel E) it was concluded:

- Along 2 segments adjoining the muscle wall (measurement 2 and 3 in panel E) the related strain decreased during the ejection phase of the cardiac cycle. However, along the segment adjoining the anterior mitral valve leaflet (measurement $\mathbb{I}$ in panel E), strain increased during this part of the cardiac cycle. In this particular experiment this phenomenon was observed in all heart beats.

- Along the segment between the base points 6 and 10 , adjoining the myocardial tissue of the septal wall (thick part of the base circlel, strain decreased about 0.05 during the ejection phase of the cardiac cycle. At approximately the onset of the ventricular ejection phase this strain decreased rapidy and later on more gradually until about $2 / 3$ of the ventricular ejection phase had elapsed. During the last third of this phase and during the ventricular relaxation phase, strain increased rapidly, followed by a gradual increase during the ventricular filling phase. The strain along the segment between the base points 2 and 6 , which adjoins the muscle wall of the ventricle, behaved analogously. 
- During the ventricular ejection phase of the cardiac cycle, strain along the segment between the base points 2 and 10 , adjoining the anterior mitral valve leaflet, increased up to about 0.14 with respect to the end-diastolic value of the strain. This maximum strain was usually reached early in the ventricular ejection phase. During the ventricular filling phase only small strain variations were observed.

- With respect to the 3 dogs in which strains were measured in the base plane along segments which were not in between 2 base points of the aortic ring it was observed that:

- Only 1 strain (measurement 3 in panel F) refers to a segment adjoining the myocardial wall. This strain increased rapidy late in the ventricular filling phase as well as during the isovolumic contraction phase, reaching its maximum at the onset of ejection, and gradually decreased during the ejection phase. The maximum variation in strain during the cardiac cycle was about 0.12 . The finding that strain decreased during ejection and increased during filling agrees with the results found for the 2 strains along the segments adjoining the muscle wall (panel E).

- The other strains along the segments adjoining both muscle wall and the anterior leaflet of the mitral valve (measurements in the panels $A, B, C, D$ and measurements 1 and 2 in panel $\mathrm{F}$ ). The course as a function of time of these strains behaved differently. In the measurement shown in panel $C$ and measurement 1 in panel $F$, strain decreased in the ejection phase. The decrease resembled the one observed in the strain between base points along the myocardial wall (measurements 1 and 2 in panel $\mathrm{E}$ ). In the measurements shown in panel $B$ and panel $D$, strain was larger during the ventricular ejection phase than the strain during the ventricular filling phase. In the measurement shown in panel $\mathrm{A}$ strain increased early in in the ejection phase and next, decreased in the remaining part of the ejection phase. In measurement 2 in panel $F$ strain behaved differently during the ejection phase.

- From the combined results from the 4 dogs it was concluded that strain along the muscle part of the base circle decreased 

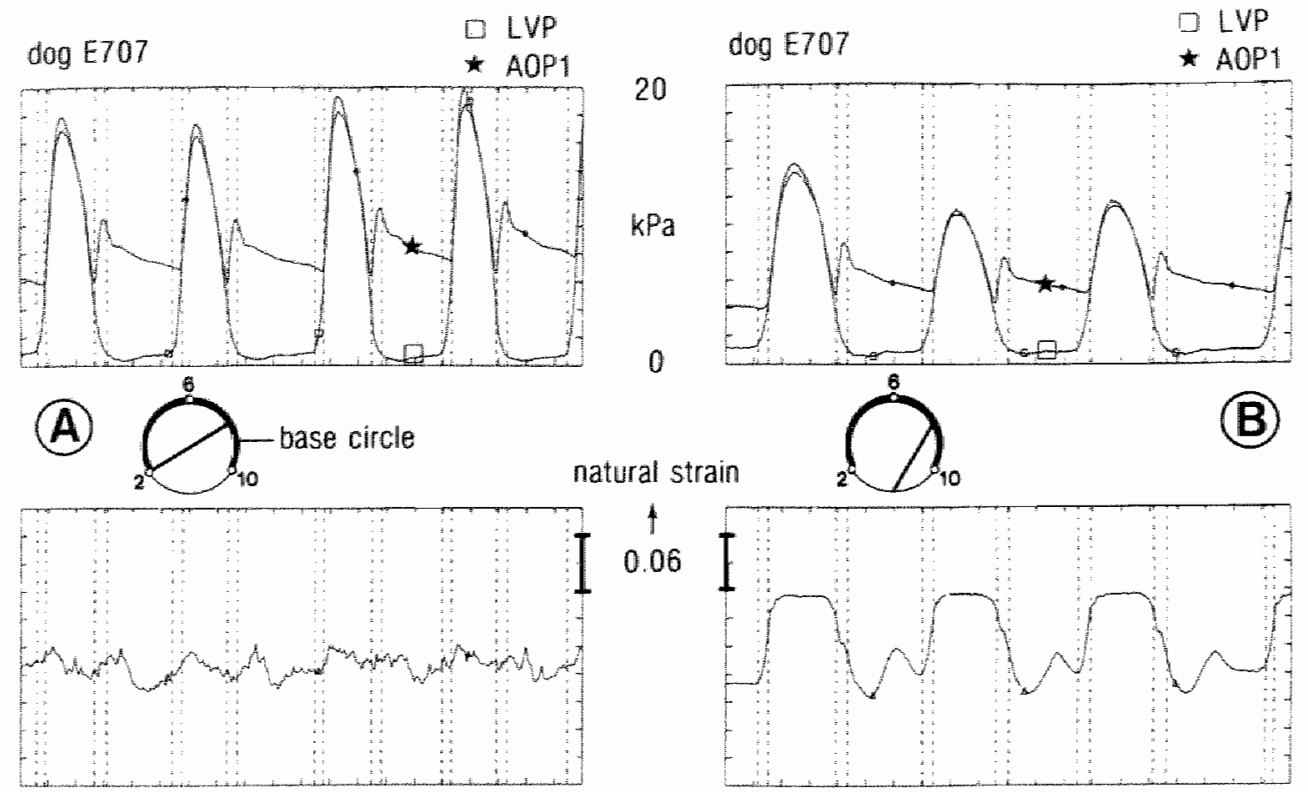

dog E707

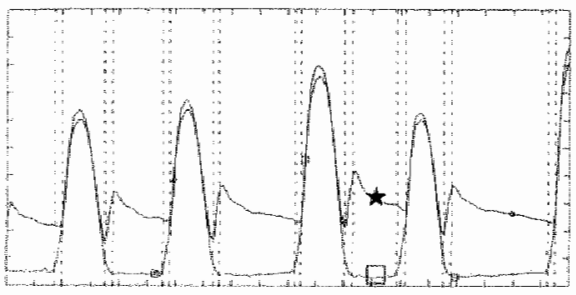

(C) $\bigcap_{10}^{6}$

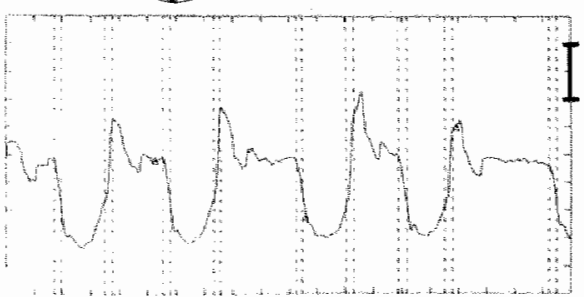

$\left[\begin{array}{c}\uparrow \\ 0.06\end{array}\right.$

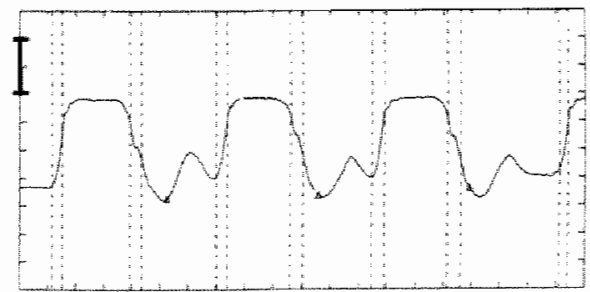

0

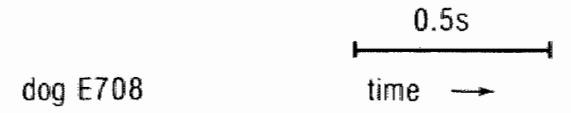

20

$\mathrm{kPa}$

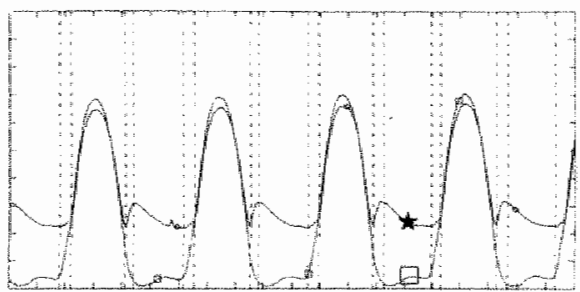

natural strain

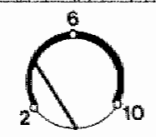

(D)

I $\begin{gathered}\uparrow \\ 0.06\end{gathered}$ 


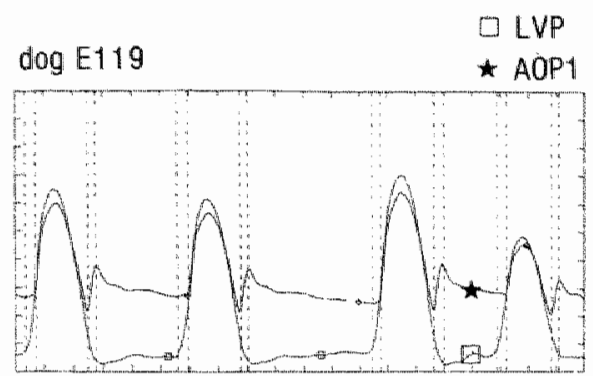

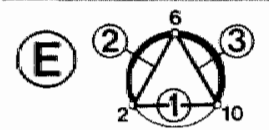
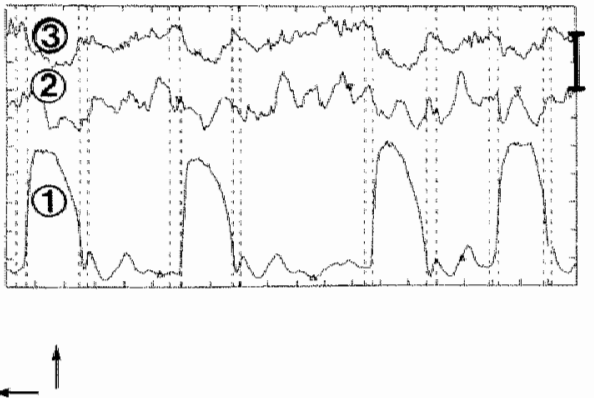
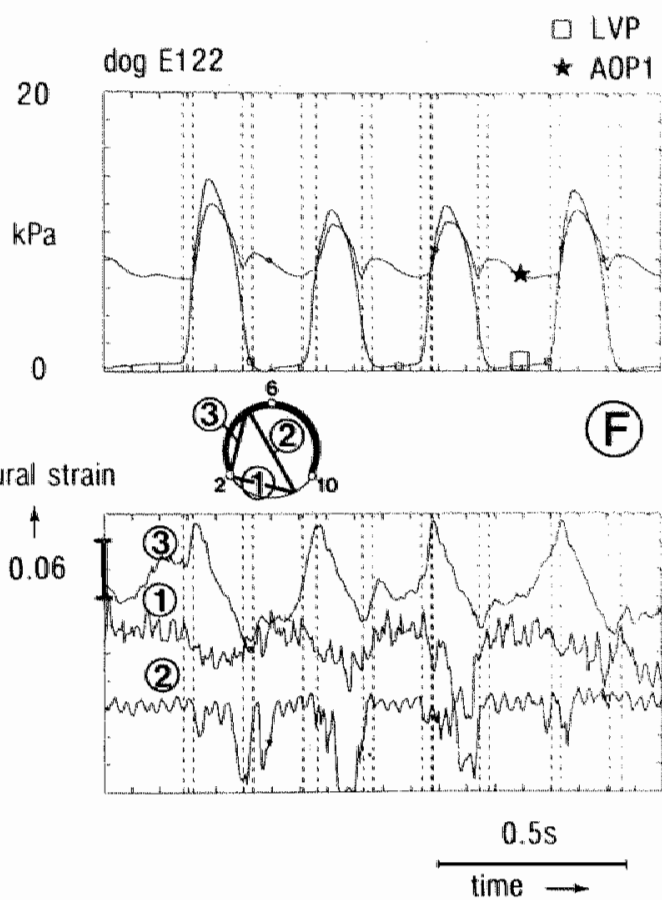

FIGURE 4.12

Typical recordings of strains in the base plane of the aortic valve, in four dogs. The strains are referred to in a base circle in each of the panels $A-F$. The base circle is defined in figure 4.8. Each interval along the time axis corresponds to $75 \mathrm{~ms}$.

during the ventricular ejection phase, whereas strain along the anterior mitral valve leaflet part of the base circle increased during this phase. If strain was measured along the muscle part as well as along the anterior mitral valve leaflet part of the base circle, the nett result depended on combination of decrease and increase of strain.

4.4.4. Strain between base and commissure points

In figure 4.13 typical recordings of the strains measured in 5 dogs along the segments between base and comissure points are presented. With respect to the data shown in this figure the following conclusions were drawn. 
78
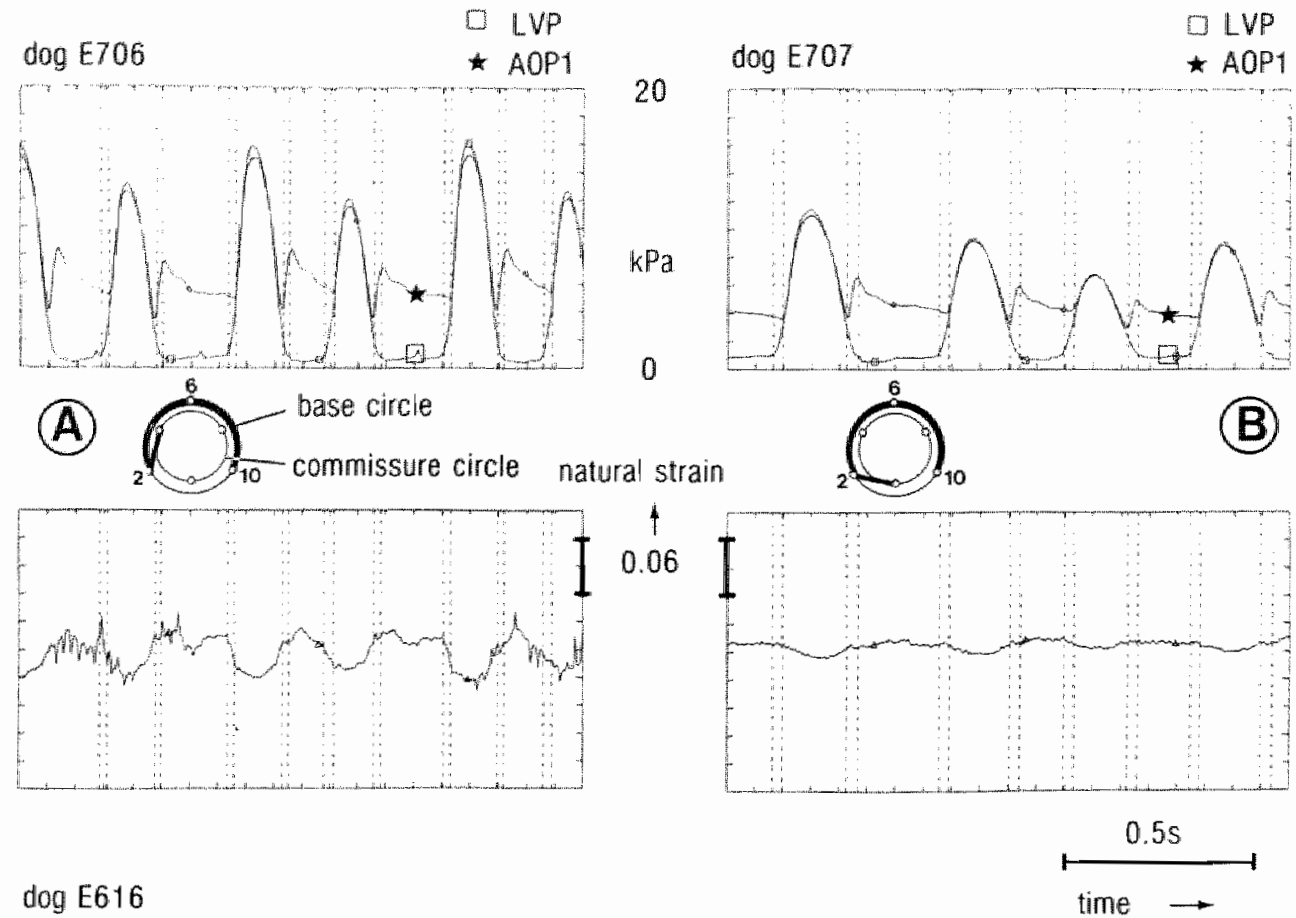

dog E616

20

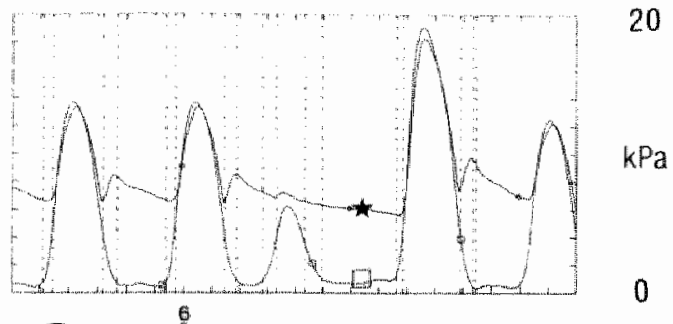

(C)

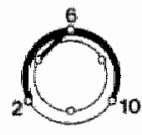

natural strain

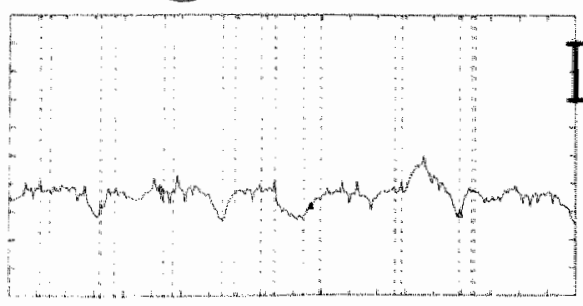

$\uparrow$
0.06 


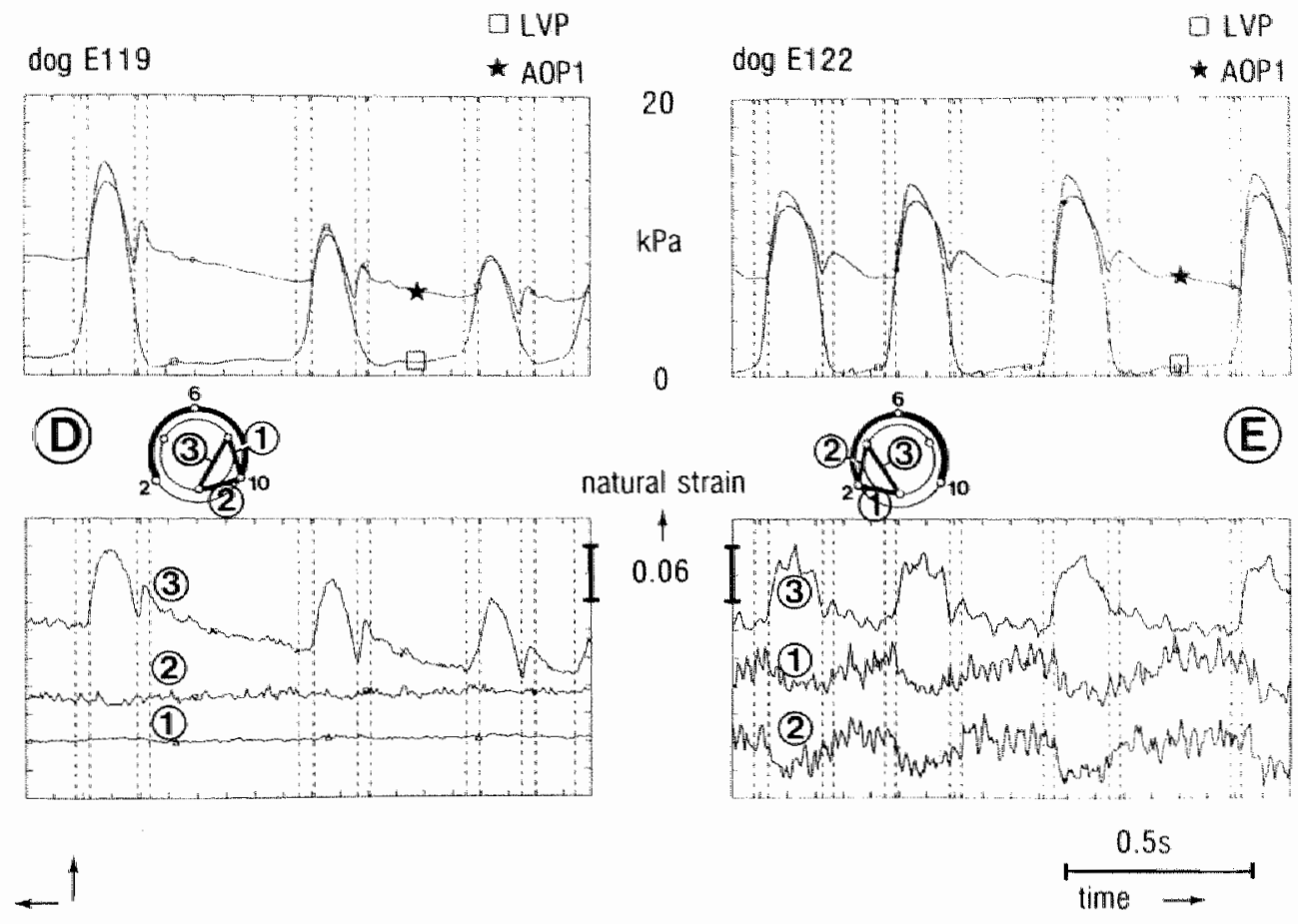

FIGURE 4.13

Typical recordings of strains between a commissure point and a base point, in five dogs. The strains are referred to in each of the panels A-E by a base point on the base circle and a comissure point on the conmissure circle. The commissure and base circles are defined in figure 4.8. Each interwal along the time axis corresponds to $75 \mathrm{~ms}$.

- No judgement can be given about the statistical significance of the strains measured, as the number of measurements is too smali (7).

- Variation in strain during the cardiac cycle was found to be less than 0.06 .

- In 4 out of 7 measurements strain was observed to decrease in the ejection phase (measurement 1 and 2 in panel $E$ and the measurements in the panels $A$ and $B$ ). In one measurement (panel C), strain decreased during the last part of the ejection phase in regular heart beats. In other measurements (panel $D$, measurements 1 and 2 ), no significant change in strain was observed during the cardiac cycle. 
- During the ventricular filling phase each of the 7 strains measured varied differently. Variations were found to be less than 0.03 .

\section{5. DISCUSSION}

4.5.1. General discussion

The study presented in this chapter shows that strains in the canine aortic ring can be measured during the cardiac cycle as an instantaneous function of time. The number of strains which could be measured in each dog varied because either we were not able to mount one or more coils to commissure and base points or coils broke down during the experiment. Coils could not be mounted for one of the following reasons.

- Coils were mounted through an incision in the aorta. This incision was made about $2 \mathrm{~cm}$ distal to the ostium of the right coronary artery to prevent disturbances in normal aortic valve behavior during the measurements. However, the location of the ostium of the right coronary artery in the right sinus of Valsalva varied widely. In some cases it was located close to the base plane and in another case beyond the commissure points. As a result the incision turned out to be sometimes too ciose and sometimes too far away from the commissure points. So in several cases commissure coils or base coils could not be mounted. We were not able to mount the base colls if the distance between the incision and the base plane was too large to manipulate the suturing tools.

- Too small a diameter of the aorta. In this case, manipulation space for the suturing tools was insufficient to mount the base coiss.

Colls broke down mainly during defibrillation of the heart. If one coil was not functioning, we could not measure 4 strains within the aortic ring as will be clear from figure 1.1.

The 3 coils at the base, were mounted at the ventricular side of the valve because only on this side the base points could clearly be distinguished. Moreover, on this side, the coils could 
be mounted so that their axes were approximately in the same plane. Coils were sutured because this proved to be the only way to keep the coils securily fastened to the wall during the experiment. Other techniques to fasten the coils were tried out such as glueing with histoacryl blau (Braun Melsungen), attachment by underpressure (Arts and Reneman 1980) pricking a barbed hook or turning a corkscrew-like fastener into the wall. None of these methods was as reliable as suturing.

It was tried to measure strains within the aortic ring at various levels of mean aortic pressure. Generally, mean aortic pressure was low ater terminating cardiopulmonary bypass $(\approx 8$ kPa), whereas the difference between maximum systolic and diastolic aortic pressure was increased significantly as compared with this difference before cardiopulmonary bypass. Aortic pressure could not be raised up to $30 \mathrm{kPa}$ according to the protocol described in section 4.2 .4 , because of rupturing of the sutured aortotomy or inadequate pump function of the heart. The highest pressure reached was $20 \mathrm{kPa}$. To raise the aortic pressure, noradrenaline was administered or blood was injected. To lower the aortic pressure, the animal was bleeded. These measures in order to change the mean aortic pressure may have affected the behavior of the aortic valve during the cardiac cycle. However, in our study no influence of these measures on artic valve behavior could be found.

In the experiments differences were observed between changes in the three comissure strains. The same is the case for changes in the base strains and changes in the base-comissure strains. The differences may result from:

- asymmetric distension of the aortic ring during the cardiac cycle due to asymmetry in geometry or biological variations in tissue properties of the wall.

- changes in mutual orientation of the coils due to tilting during deformation of the wall to which the coil is attached. An estimation of the inaccuracy in strain measurement caused by tilting of a coil was made in section 3.3.2. A change of $5^{\circ}$ in each of the three angles, which define the mutual orientation of coils (section 3.2 .2 ), was found to result in an inaccuracy in 
strain measurement of 0.01 for the commissure and base strains and of 0.04 for the commissure-base strain. Therefore, it is assumed that, although they reduce the accuracy of the measurement, changes in mutual coil orientation influence the commissure and base strain measurements to a limited extent. Since the changes of the commissure-base strain during the cardiac cycle were significantly smaller, the recorded variations of this strain may largely be caused by changes in mutual coll orientation.

4.5.2. Discussion of comissure strain

Comissure strain followed the changes in aortic pressure throughout the cardiac cycle. The average derivative of commissure strain to aortic pressure at a given normalized transvalvular pressure was calculated to be $1.9 \times 10^{-5} \pm 1.2 \times 10^{-5} \mathrm{~Pa}^{-1}$ (mean \pm standard deviation) at an aortic pressure of $10 \mathrm{kPa}$. strain at a given aortic pressure was systematically higher in the ventricular ejection phase than in the ventricular filling phase. The mean difference between these phases was 0.04 whereas it is likely to be independent of aortic pressure. Similar results were found by Thubrikar and co-investigators (1977a) who studied in the dog the variations of the perimeter of the triangle formed by the commissure points during the cardiac cycle. They used the following technique. The animals were placed on total cardiopulmonary bypass and radiopaque narkers were placed through an aortotomy on the commissures at the level of leaflet coaptation. The dogs were studied after 10 or more days. Marker movement in the beating heart was recorded by fluoroscopy on videotape. For 3 cardiac cycles, the perimeter of the triangle mentioned was determined off-line by analyzing frame by frame the video recordings (maximum frequency content $30 \mathrm{~Hz}$ ).

For one dog, the perimeter as a function of aortic pressure was presented in their figure 4. From this figure it was derived that strain of the perimeter showed a proportionality factor of $2 \times 10^{-5} \mathrm{~Pa}^{-1}$ with respect to aortic pressure. $18 \mathrm{kPa}<$ aortic pressure $<13 \mathrm{kPa}$. Moreover, at a given aortic pressure ranging 
in between $8 \mathrm{kPa}$ and $15 \mathrm{kPa}$, strain in the ventricular ejection phase was about 0.05 higher than in the ventricular filling phase. These results are in fair agreement with our's if it is assumed, that the variation in perimeter represented the average variation in the 3 strains between the commissure points.

In our experiments, we observed that commissure strain generally started to increase rapidly at the onset of the isovolumic contraction phase of the cardiac cycle. This is in agreement with the findings of Thubrikar and colleagues (1977a), who showed that the perimeter started to increase $20-40 \mathrm{~ms}$ before aortic valve opening. They were not able to measure the fast change more accurately because the number of video frames was 1 imited to 60 per second.

The commissure strain was related to normalized transvalvular pressure (non-elastic deformation) and aortic pressure (elastic deformation) according to equation (4.1). Only the linear and the quadratic term in aortic pressure were included in this equation. Higher order terms were not considered because they did not improve the resulting fit between commissure strain and aortic pressure. The left ventricular pressure was mot included directly in the equation as it appeared that the addition of this pressure to the equation did not diminish the residual variance of multiple regression analysis. For the same reason, higher orders of normalized transvalvular pressure were not added to equation (4.1).

The data on the parameters $a_{1}, a_{2}$ and $a_{3}$ in equation $(4.1)$ are interdependent because they were estimated from variables which are interdependent, e.g. aortic pressure, square of the aortic pressure and normalized transvalvular pressure. For commissure strain 3 in table 4.1 , the correlation coeficients between the parameters $a_{1}, a_{2}$ and $a_{3}$ were determined to be

$$
\rho_{a_{1}, a_{2}}=-0.998, \rho_{a_{2}, a_{3}}=0.687, \rho_{a_{1}, a_{3}}=-0.170
$$

The interdependency of $a_{1}, a_{2}$ and $a_{3}$ means that differences between the 26 parameters $a_{1}$ as presented in table 4.1 , cannot be discussed separately from the differences in the 26 parmeters $a_{2}$ 
and the 26 parameters $a_{3}$. Similarly differences between the 26 parameters $a_{2}$ and the 26 parameters $a_{3}$ cannot be discussed independently. Thus, it is not permissible to deal with the mean values of $a_{1}, a_{2}$ and $a_{3}$ as presented in section 4.4 .2 in one single equation. In fact these mean values have a restricted significance because they originate, from different numbers of data at different walues of aortic pressure. In this context it is remarked that these means and the average of the derivative of commissure strain to aortic pressure at given normalized transvalvular pressure, are meant to give an indication about the magnitude of these parameters, rather than to present precise walues.

The use of the multiple regression analysis to determine the values of the parameters $a_{1}, a_{2}$ and $a_{3}$ may be subject to criticism due to the following considerations.

- The measured values of strain and related aortic pressure were not uniformly distributed over the range of aortic pressure to which the regression was applied. Many data were obtained in mid-systole and in diastole where aortic pressure was relativeIy constant. Only a limited number of data was obtained in the isovolumic contraction phase, the early and late ejection phase and the relaxation phase, when major variations in aortic pressure occurred. Moreover, data obtained in systole systematically corresponded to higher aortic pressures than data obtained in diastole. However, the influence of non-uniformity of distribution was probably moderate, since generally a large overlap existed between aortic pressures as attained during systole and diastole, because mean aortic pressure was varied widely during the experiments.

- During the major part of the cardiac cycle, normalized transvalvular pressure was constant, either 0 during the ejection phase or about 1 during the ventricular filling phase. only during the relatively short periods of isovolumia, normalized transvalvular pressure varied significantly. Consequently, the parameter $a_{3}$ in equation (4.1) was estimated mainly on the basis of 2 levels of strain, one obtained during ventricular ejection and the other during ventricular filling. To get 
insight into the extent to which equation (4.1) describes strain at constant aortic pressure and during changing normalized transvalvular pressure, we evaluated strain during an extra-systole. Commissure strain both directly measured and calculated by substitution of measured aortic and normalized transvalvular pressure into equation (4.1), were compared in case of an extra-systole. The results shown in figure 4.14 suggest a fair agreement between measured strain and calculated strain, the more so since the extra-systole was not used to obtain the fit of commissure strain 5 in table 4.1. Thus, the term $a_{3} \cdot p_{n t}$ in relation (4.1) apparently describes the variation of commissure strain for $0<p_{n t}<1$ quite accurately.

\section{FIGURE 4.14}

Predicted and directly measured strain as a function of time during an extrasystole for comissure strain 5 in table 4.1. The strain was predicted by substitution of momentaneous values of aortic pressure ( $A O P I$ ) and normalized transvalvular pressure as measured during this extra-systole, into the fitted equation (4.1). LVF = left ventricular pressure.
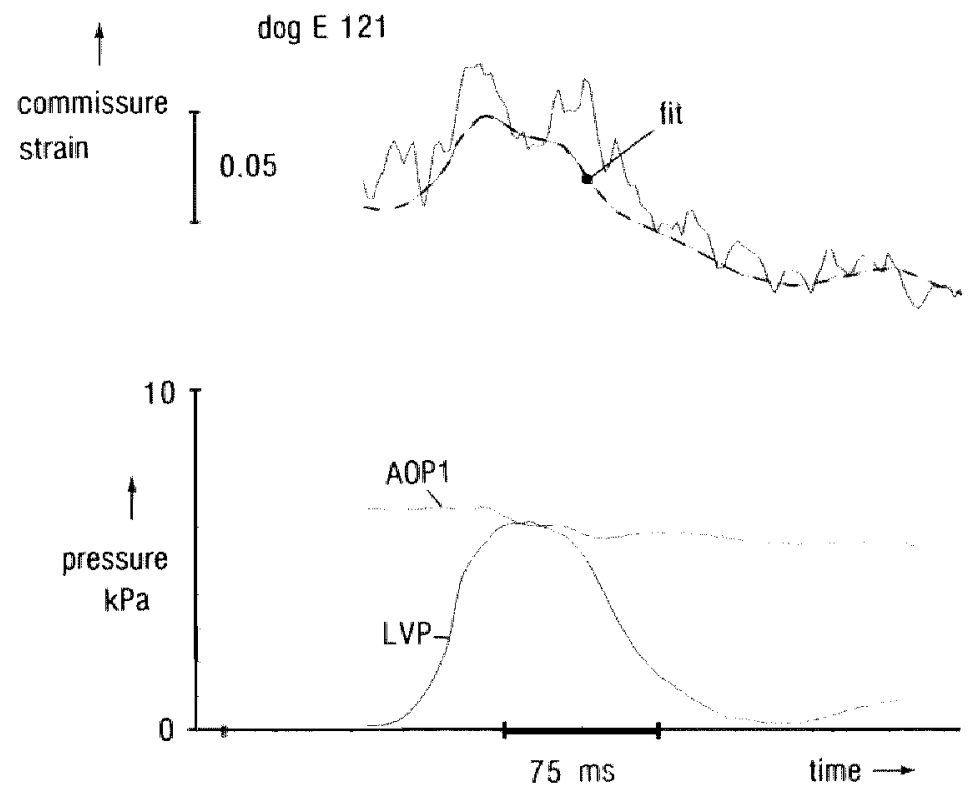
4.5.3. Discussion of strain in the base plane of the valve

Only in one dog strain between base points located at the aortic ring could be measured since coils were difficult to mount to these points (section 4.5.1). In this dog, strain along 2 segments adjoining the myocardium of the septum and the left ventricle (figure 4.12, panel $E$, measurements 2 and 3 ) decreased during the major part of the ventricular ejection phase and increased slowly during the ventricular filling phase. The decrease of these strains during the ejection phase is likely to be the result of the contraction of the myocardial wall (Ingels et a1. 1980). The increase of these strains during the filling period may be caused by the filling of the left ventricular cavity while the myocardium is relaxed.

The strain along a segment adjoining the anterior mitral valve leaflet, was found to be increased during the ejection phase as compared with a relatively constant value of this strain during the $\mathbb{f i l l}^{\mathrm{ing}}$ phase. The segment along which this strain was measured, in fact adjoins the collageneous tissue in the base plane of the left ventricle which separates the aortic valve and the anterior mitral valve leaflet (figure 2.5). Variations of this strain may result from a combination of the following factors.

- During the isovolumic contraction, ejection and isovolumic relaxation phases, the increased left ventricle pressure stretches the passive collageneous tissue.

- The collageneous tissue in the base plane of the left ventricle is attached to part of both the aortic valve and anterior mitral valve leaflet. At its endings the collageneous tissue is also attached to the myocardial wall which encloses the left ventricular cavity. Thus, mitral valve, aortic valve and myocardial wall may exert forces upon the collageneous tissue. The combination of these forces may stretch the tissue or change its shape in the 3-dimensional space.

Left ventricular pressure is probably not the only contributor to the variation of strain along the segment adjoining the anterior mitral valve leaflet, as can be seen in figure 4.12 , panel $E$, 
measurement 1. For the first three cardiac cycles, during the ejection phase maximum strain seemed to follow the variation of maximum left ventricular pressure. However for the last two cardiac cycles shown, maximum left ventricular pressure changed with about $4 \mathrm{kPa}$, while maximum strain hardy changed in the ejection phase.

Thubrikar and co-investigators (1980) studied the perimeter of the triangle formed by the base points located on the aortic ring. The technique they used, has been explained in section 4.5.2. In their measurements, during the cardiac cycle the variation of the perimeter ranged in between 5 and 28 percent of the end-diastolic value of the perimeter. In our measurements, the variation of the base strains during the cardiac cycle ranged in between about 3 and 15 percent. The course as a function of time of the perimeter as Thubrikar and colleagues (1980) Eound is qualitatively similar to the one shown in figure 4.12 , panel E, measurement 1 . The course as a function of $t i m e$ of the perimeter as described by them, can be approximated by averaging the recordings of the three base strains shown in figure 4.12 , panel E, which are typical for the experiment. Approximately at the onset of the ejection phase, strains 2 and 3 in panel E decreased whereas strain 1 rapidly increased. The increase was more pronounced than the combination of both decreases, so the average of the three strains increased. In the early part of the ejection phase, strains 2 and 3 decreased while strain 1 reached its maximum and next generally started to decrease, resulting in a decrease of the average strain. During the last part of the ejection phase, strains 2 and 3 increased while strain 1 decreased. The decrease was more pronounced than the combination of the increases so the average of the three strains continued to decrease. In the isovolumic relaxation and early filling phase no specific function of time of the average of the three strains could be distinguished. In the last two third of the filling phase, strain 1 was approximately constant and strains 2 and 3 gradually increased, so the average of the three strains increased. In the isovolumic contraction phase no specific function of time for the average of the three strains could be distinguished. 
Thus, our results are in agreement with the results of Thubrikar and his colleagues (1980).

The strain along the segment adjoining the anterior mitral valve leaflet was compared with the results on variation of the circumference of the mitral valve annulus as presented by Davis and Kinmonth (1963) and Tsakiris and co-investigators (1971) for dogs. In these studies, radiopaque markers were placed on different sites of the canine mitral valve annulus. The movement of the maxkers during the cardiac cycle was recorded using cineangiography (Davis and Kinmonth, 1963) or video-fluoroscopy (Tsakiris and associates, 1971). From the recordings changes of the circumference of the mitral annulus during the cardiac cycle were off-line determined. In both studies the circumference of the annulus of the mitral valve varied as a function of time simjlar to the plot shown in figure 4.12 , panel E, strain 3 . However, the tracing in their study was shifted in time such that maximum of strain in our case early in the ejection phase was located at the end of the filling phase. In both studies, the decrease in circumference during the cardiac cycle occurred along the part of the annulus which adjoins the myocardial wall. The investigators mentioned found that the circumference of the annulus, which is parallel to the segment in the base of the aortic valve which adjoins the anterior mitral valve leaflet, hardly varied during the cardiac cycle. This finding is in contradiction with our finding, saying that strain along the segment increased. This discrepancy may be caused by the technique they used to determine the circumference of the annulus as explained below. The positions of the radiopaque markers were projected on a plane approximately parallel to the plane in which the ostium of the mitral valve is located. Thus, information about movement of the markers in a direction perpendicular to the projection plane could not be obtained. Consequently, a distance between two markers may increase while the increase is not observed in the distance between the projected positions of the markers. Tsakiris and co-workers (1971) observed in another projection of the markers that the markers indeed moved in a direction perpendicular to the plane in which the ostium of the mitral valve was 
1ocated. During systole, the markers moved towards the ventricular apex over a distance of approximately 3 to 8 mm for the various markers.

4.5.4. Discussion of strain between commissure and base points

The aortic ring which forms the skeleton of the aortic valve is composed of collageneous and/or cartilagenous tissue (see section 2.2.4). It is assumed that strain along the skeleton is negligible, and that changes of strain between a commissure point and a base point are mainly caused by changes of the commissure and the base strains.

In our experiments, we found that the change of strain between a commissure and a base point varied from 0.00 to 0.06 during the cardiac cycle. This change may partly be seemingly due to changes in the mutual orientation of the coils (section 4.5.1). No specific course as a function of time of the strain was found to hold for all experiments. Thubrikar and co-investigators (1981) measured the variation of distance between a commissure point and a base point during the cardiac cycle by the technique as explained in section 4.5.2. These investigators also did not find a specific dependency of time for the change of distance during the cardiac cycle. In their study the maximum change of distance during the cardiac cycle was not given. From their figure 7 the maximum change during the cardiac cycle was estimated to be in the order of $5 \%$, which is in reasonable agreement with our findings.

4.5.5. Summary on strain in the aortic ring

The main results on strain measurement in the aortic ring as discussed in the previous sections are summarized. The study presented in this chapter shows that strains in the aortic ring of the dog can be measured during the cardiac cycle as an instantaneous function of time.

Commissure strains followed the changes in aortic pressure throughout the cardiac cycle. Commissure strain at a given aortic 
pressure was systematically higher in the ventricular ejection phase than in the ventricular filing phase. The relation between aortic pressure, normalized transvalvular pressure and commissure strain was described fairly well by equation (4.1).

Base strain along a segment adjoining the muscle part of the base circle decreased during the ventricular ejection phase. This decrease is likely to be the result of the contraction of the myocardial wall. Base strain along a segment adjoining the anterior mitral valve leaflet part of the base circle increased during the ventricular ejection phase. This strain was measured along passive collageneous tissue. The increase of this strain during the ejection phase may be the result from a combination of stretch of the collageneous tissue caused by the increased left ventricular pressure and deformation of the tissue caused by forces exerted upon the tissue by the myocardial wall and the mitral and aortic valve. If strain in the base plane is measured along the muscle part as well as along the anterior mitral valve leaflet part of the base circle the nett result depends on the combination of decrease and increase of strain.

Strain between a base and a commissure point of the aortic ring showed no specific relation with time. Changes of this strain during the cardiac cycle were small (0.00-0.06). It is assumed that the changes in this strain, provided that they were real, were mainly caused by changes in the commissure and the base strain as strain along the aortic ring is likely to be negligible because the aortic ring is composed of collageneous and/or cartilagenous tissue. 


\section{A MATHEMATICAL MODEL OF COMMISSURE DISPLACEMENT AS A FUNCTION OF NORMALIZED TRANSVALVULAR PRESSURE}

\subsection{INTRODUCTION}

A mathematical model of the mechanics of the closed aortic valve is presented which relates commissure radius $R_{c}$ to normalized transvalvular pressure $p_{\text {nt }}$ at constant aortic pressure. The commissure radius is defined as the radius of the circle through the three commissure points. Normalized transvalvular pressure is defined as transvalvular pressure $\left(\mathrm{P}_{\mathrm{ao}}{ }^{\left.-\mathrm{p}_{1 \mathrm{v}}\right)}\right.$ normalized to aortic pressure pao"

The mathematical model was formulated upon the principle of minimum energy. To that purpose, it was assumed that no energy could be stored or dissipated in the material of the valve. Furthermore, the geometry of the valve was simplified. The model assumptions are presented in section 5.2, whereas the mathematical model is described in section 5.3. Results of the model are given in section 5.4 . In section 5.5 the results of the model are discussed.

5.2. SIMPLIFICATIONS CONCERNING THE AORIIC VALVE AND ITS ADJACENT STRUCTURES

Changes of aortic valve geometry may result from elastic deformation of materials involved as well as from change in shape due to redistribution of forces at the attachments of the valve leatlets to the sinuses of Valsalva. In the present analysis the latter effect is simulated by a model which is free of elastic deformation or, more precisely, where all materials involved cannot store or dissipate energy due to strain. Thus, elasticity as well as viscoelasticity of materials are left out of account.

In developing this particular mathematical model of aortic valve mechanics, nevertheless some additional simplifying assumptions have to be made about the characteristics of the aortic valve: 
1. the aortic valve (figures 2.3 and 5.1 ) has three planes of symetry. Thus the geometry of a sector of 60 degrees defines the geometry of the value as a whole. Coronary ostia are not considered.

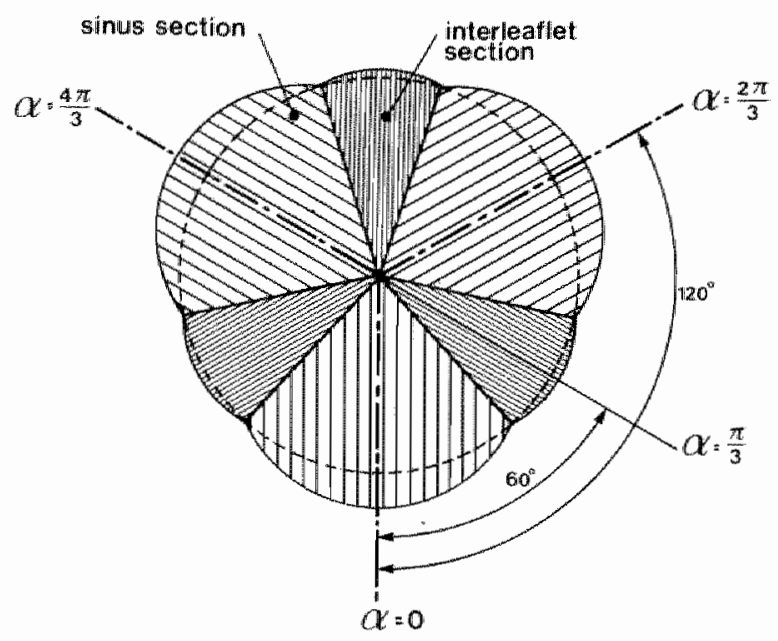

FIGURE 5.1

Schematic representation of a cross-section of the aortic valve in a plane perpendicular to the valve axis. Three planes of symmetry $(\alpha=0,2 \pi / 3,4 \pi / 3)$ and the sinus and interleaflet sections are denoted in the figure.

2. the aortic ring is the skeleton of the valve (figure 2.5). During deformation this ring stays on the surface of the truncated cone, defined by the commissure circle and the base circle (figure 5.2). The base circle is defined by the 3 base points in the base plane.

Whe shape of a segment of the aortic ring is defined in cylindrical coordinates $(r, \alpha, z)$ by a set of parametric equations where is the parameter

$$
\begin{aligned}
& z(\psi)=h_{C} \cdot\{1-\sin (\psi)\} \text { with } 0<\psi<\pi / 2 \\
& \alpha(\psi)=\frac{\pi}{3} \cdot \cos (\psi) \quad \text { with } 0<\alpha<\pi / 3 \\
& r(\psi)=R_{C} \cdot\{1-\sin (\psi)\}+R_{B} \cdot \sin (\psi)
\end{aligned}
$$


where

$$
\begin{aligned}
z & =\text { height above the base plane } \\
h_{c}= & \text { height af the commissure points above the base } \\
& \text { plane } \\
\alpha \quad & \text { coordinate angle in the cylindrical coordinate } \\
& \text { system (for a commissure point it holds that } \\
& \alpha=\pi / 3) \\
= & \text { radial coordinate } \\
r \quad & \text { radii of commissure and base circle. }
\end{aligned}
$$

Note that the coordinate angle $\alpha$ in equation (5.2) is defined within the range of 0 to $\pi / 3$. Applying properties of symmetry, the range of a can be extended to the entire circumference by

$$
a_{1-6}= \pm(\alpha+2 \pi \cdot k / 3) \text { where } k=1,2,3
$$

During deformation, the height $h_{c}$ is adjusted in that way to keep the length of the aortic ring constant.

\section{FIGURE 5.2}

Schematic representation of an artic ring segment on a truncated cone which is defined by commissure and base circle. $h_{C}=$ commissure height; $R_{C}, R_{B}=$ radii of commissure and base circle; $R_{T R C}=$ radius of the truncated cone.

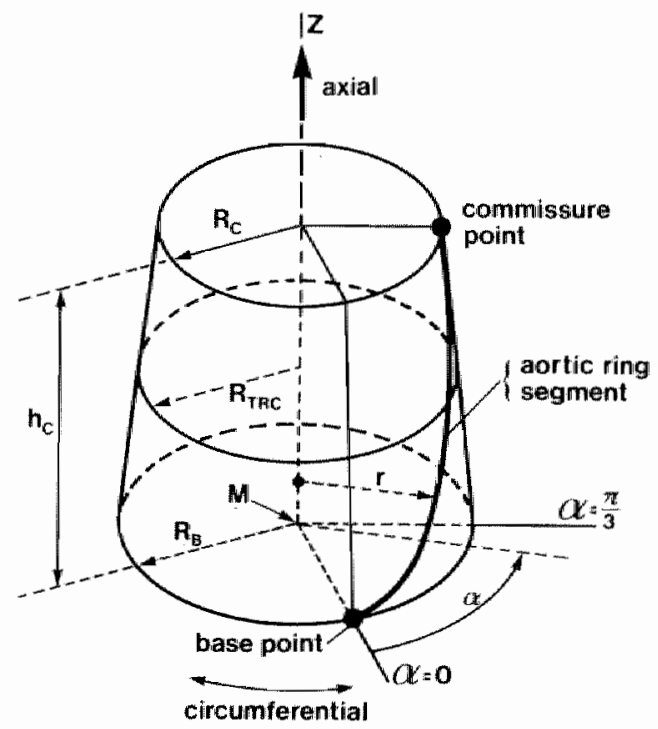


3. the circumference of any cross-section of the aortic valve by a plane perpendicular to its axis is subdivided in six parts (figure 5.1). Three of them correspond to section of a sinus of Valsalva, the other three originate from section of the interleaflet trigone. The total length of the sinus sections at the level $z$ is given by:

$$
\operatorname{CIRCS}\left(z_{n}\right)=\operatorname{CIRCM}\left(z_{n}\right) \cdot \frac{3 \alpha}{\pi}
$$

whereas the total length of the interleaflet sections is

$$
\operatorname{CIRCI}\left(z_{n}\right)=\operatorname{CIRCM}\left(z_{n}\right)-\operatorname{CIRCS}\left(z_{n}\right)
$$

where $\alpha$ is the coordinate angle calculated by using equation (5.2), $z_{n}$ the axial coordinate normalized to commissure height $h_{c} \cdot \operatorname{CIRCM}\left(z_{n}\right)$ stands for an assumed mean circumference of the valve wall in the cross-section. This mean circumference of the valve wall is assumed to remain constant during valve deformation.

4. the attachment of both the sinus sections and the interleaflet sections are situated on the truncated cone. During deformation these attachments can freely move in cirumferential direction.

5. In a cross-section perpendicular to the axis of the valve $(z=$ constant), the radii of curvature of the sinus sections $\left(R_{s}\right)$ and of the interleaflet sections $\left(R_{i}\right)$ are given by:

$$
\begin{aligned}
& \mathrm{R}_{\mathrm{s}}=\mathrm{T}_{\mathrm{s}} / \mathrm{P}_{\mathrm{aO}} \\
& \mathrm{R}_{i}=\mathrm{T}_{i} / \mathrm{P}_{1 \mathrm{v}}
\end{aligned}
$$

where $T_{s}$ and $T_{i}$ denote the local value of the circumferential component of wall tension $\left(\mathrm{N} . \mathrm{m}^{-1}\right)$ in the sinus of valsalva and interleaflet trigone, respectively. Thus the influence of the axial component of wall tension $\left(\mathrm{N} . \mathrm{m}^{-1}\right)$ on the radii of curvature is neglected. 
6. beyond the commissure circle $\left(z>h_{c}\right)$ the non-circular shape of the cross-section of the valve gradually changes in the circular cross-section of the aorta. The shape of the cross-section for $z>h_{c}$ is calculated under the assumption that the axial component of wall tension $\left(\mathrm{N} \cdot \mathrm{m}^{-1}\right)$ equals half the circumferential component of wall tension, which holds for a cylinder with an infinitely thin wall (e.g. Arts 1978). Moreover, as deviations from the circular cross-section are small, only the first order approximation is calculated (appendix A5.1).

7. the three aortic valve leaflets are considered to be infinite1y thin membranes which bear positive membrane tension $\left(\mathrm{N} \cdot \mathrm{m}^{-1}\right)$ directed from one conmissure point to the other. The membrane tension directed perpendicular to this direction is assumed to be zero.

8. in any cross-section of the valve perpendicular to its axis, the condition of equilibrium of hydrastatic and mechanical forces on the wall is satisfied.

9. during deformation the cross-section of the valve at the level of the base points $(z=0)$ remains a circle with constant circumference.

5.3. DESIGN OF THE MATHEMATICAL MODEL OF AORTIC VALVE MECHANICS

5.3.1. Introduction

The mathematical formulation of the model is derived in section 5.3.2. It contains several derivatives with respect to the commissure radius. The way in which these derivatives were determined, is explained in the sections 5.3 .3 through 5.3.5.

5.3.2. Mathematical formulation of the mode1

The mathematical analysis is based upon the principle of minimum energy applied to the deformation of the valve. The commissure radius $R_{c}$ is the only deformation parameter and its value is calculated to equal the derivative of total energy to comissure radius $\mathbb{R}_{c}$ to zero. 
In the analysis three components of energy were distinguished, each of them related to a change of the volume of a compartiment due to a change of the pressure within that compartment. One component of energy is related to the change of volume $\mathrm{V}_{1}$ of the compartment enclosed by the three valve leaflets and the plane through the three comissure points (figure 2.3). Within this compartment, prevails the aortic pressure. The second component of energy is related to the change in volume $v_{2}$ of the compartment enclosed by the three valve leaflets, the base plane of the valve and the three interleaflet trigones. The left ventricular pressure prevails within this compartment. The third component of energy is related to the change of volume $v_{3}$ of the compartment enclosed by the plane through the three commissure points, the circular cross-section of the aorta at the aortic border of the valve and the valve wall. The aortic pressure prevails within this compartment. Increments of these three energy components. depend on the instantaneous value of the forces which the leaflets exert upon the comissure points and the displacements of the latter.

As to the incremental energy $d E_{1}$, due to the pulling of the leaflets at the comissure points, it holds:

$$
\begin{aligned}
\mathrm{dE} & =\overrightarrow{\mathrm{F}}_{11} \circ \mathrm{d \vec {s } _ { 1 }}+\overrightarrow{\mathrm{F}}_{12} \circ \mathrm{d} \vec{s}_{2}+\vec{F}_{22} \circ \mathrm{d} \vec{s}_{2}+\vec{F}_{23} \circ \mathrm{d} \vec{s}_{3}+ \\
& +\vec{F}_{33} \circ \mathrm{d} \vec{s}_{3}+\vec{F}_{31} \circ \mathrm{d} \vec{s}_{1}
\end{aligned}
$$

In this equation $\vec{F}_{i j}$ represents the force which leaflet $i$ exerts upon commissure point $j$, and $d \vec{s}_{j}$ the incremental displacement of the commissure point $j$ in the plane intersecting this point and the axis of the valve. Let us consider the incremental energy $\mathrm{dE}_{11}$ which corresponds to leaflet $1(-\pi / 3<a<\pi / 3)$, being typical for all three leaflets.

It holas:

$$
d E_{11}=\vec{F}_{11} \circ d \vec{s}_{1}+\vec{F}_{12} \circ \overrightarrow{d s}_{2}
$$

The two forces $\vec{F}_{11}$ and $\vec{F}_{12}$ in this equation are equal in magni- 

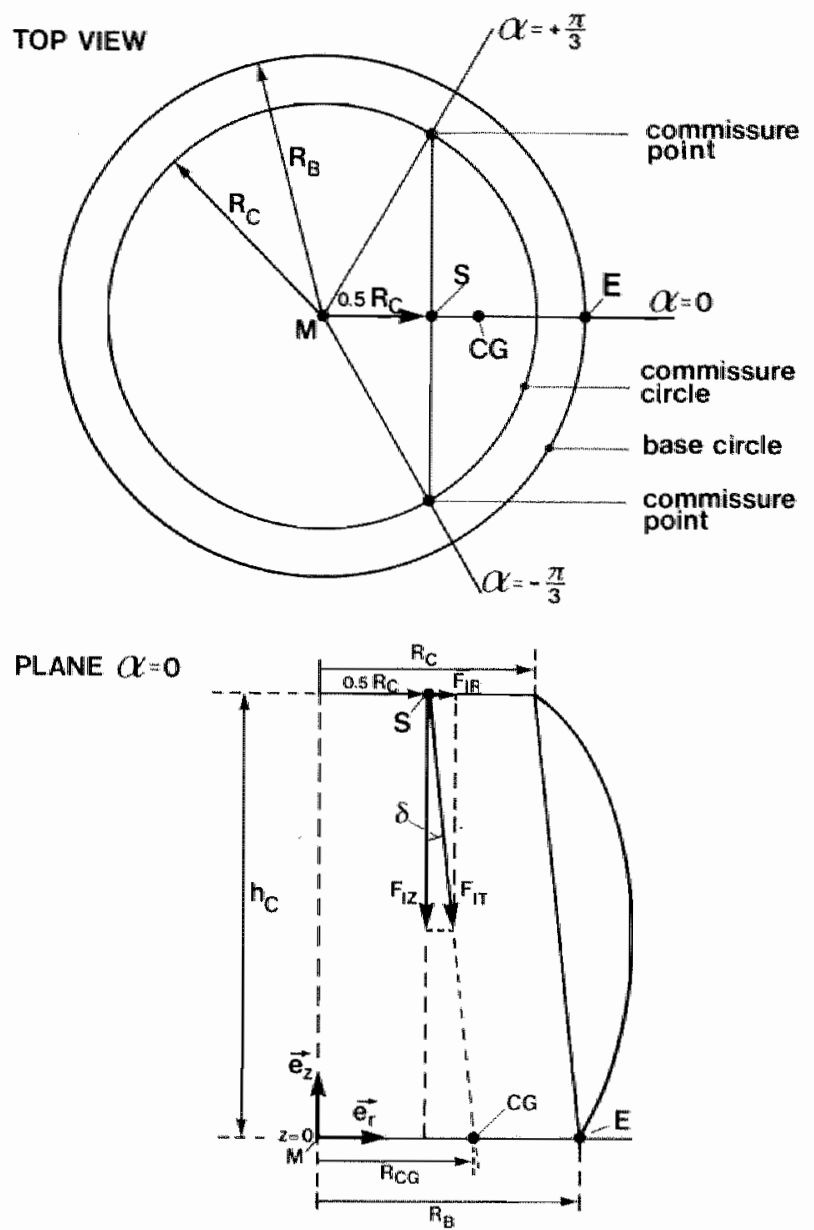

FIGURE 5.3

Schematic representation of the aortic valve and the force $F_{1 T}$ exerted by one leaflet upon its commissure points. $C G=$ center of gravity of projected leaflet area the base; $E=$ point on the base circle where $=0 ; F_{1 R^{\prime}} F_{1 . Z}=$ radial and axial components of the force $F_{1 T} ; h_{C}=$ comissure height; $M$ = center of the base circle; $R_{B^{\prime}} R_{C}=$ radii of base and commissure circle; $R_{C G}=$ distance between $M$ and $C G ; S=$ point on the line of connection of the two comissure points where $\mathrm{a}=0$. 
tude and are assumed to have the same direction perpendicular to the line of connection of the comissure points (appendix A5.2). They lie in a plane intersecting the commissure points and the center of gravity $C G$ of the projection of the leaflet on the base plane of the valve $(z=0)$ (figure 5.3 ). Combining the two forces $\overrightarrow{\mathrm{F}}_{11}$ and $\overrightarrow{\mathrm{F}}_{12}$ and the two incremental displacements $\mathrm{d} \vec{s}_{1}$ and $\mathrm{d} \vec{s}_{2}$ " at the point of intersection $s$ of the line of connection of the commissure points and the plane defined by $\alpha=0$, the incremental energy" can be written as

$$
\mathrm{dE}_{11}=\overrightarrow{\mathrm{F}}_{1 \mathrm{~T}} \circ \mathrm{d} \overrightarrow{\mathrm{s}}_{1 \mathrm{~T}}
$$

where $\overrightarrow{\mathrm{F}}_{1 \mathrm{~T}}=2 \cdot \overrightarrow{\mathrm{E}}_{11}, \overrightarrow{\mathrm{F}}_{1 \mathrm{~T}}$ being directed from the point of intersection $s$ towards the center of gravity $C G$ : $d \vec{s}_{1 T}$ is the incremental displacement of the point of intersection $S$, which equals to the sum of the incremental displacements $\mathrm{d} \vec{s}_{1}$ and $\mathrm{d} \vec{s}_{2}$. The force $\vec{F}{ }^{\prime} \mathbb{T}$ can be expressed as

$$
\overrightarrow{\mathrm{F}}_{1 \mathrm{~T}}=\mathrm{F}_{1 \mathrm{R}} \cdot \overrightarrow{\mathrm{e}}_{\mathrm{r}}+\mathrm{F}_{1 z} \cdot \overrightarrow{\mathrm{e}}_{z}
$$

where

$$
\begin{aligned}
& F_{1 R}=\tan (s) \cdot F_{1 z} \\
& F_{1 z}=-\pi / 3 \cdot R_{B}^{2} \cdot\left(P_{a O}-p_{1 v}\right)
\end{aligned}
$$

and $\quad \mathrm{P}_{\text {ao }}-\mathrm{P}_{1 \mathrm{v}}=$ pressure difference across the leaflet.

For the angle $s$ it holds:

$$
\begin{aligned}
& \tan (\mathbb{B})=\left(\mathbb{R}_{\mathrm{CG}}-\frac{\mathrm{L}}{\mathrm{U}} \cdot \mathrm{R}_{\mathrm{C}}\right) / \mathrm{h}_{\mathrm{C}} \\
& { }_{\mathrm{CG}} \quad=\text { radial coordinate of the center of gravity } \mathrm{CG} \\
& \mathrm{R}_{\mathrm{C}} \quad=\text { radius of the commissure circle } \\
& h_{\mathrm{c}} \quad=\text { commissure height. }
\end{aligned}
$$

Obviously it holds $R_{C G}=(\sqrt{3} / \pi) \cdot R_{B}$, CG being the center of gravity of the circle sector $-\pi / 3<\alpha<\pi / 3$. The incremental displace- 
ment of the point of intersection $s$ at the middle of the line of the connection of the commissure points 1 and 2 is expressed as

$$
d \vec{s}_{1 T}=\frac{11}{2} \cdot d R_{C} \cdot \vec{e}_{r}+d h_{C} \cdot \vec{e}_{z}
$$

where $d R_{c}$ is the incremental radial displacement and dh the increment in commissure height.

By combining the equations (5.11) through (5.13), the incremental energy $d E_{1 T}$ can be written as

$$
d E_{1}=3 d E_{11}=\pi \cdot\left(P_{a o}-P_{1 v}\right) \cdot R_{B}^{2} \cdot\left\{-d h_{c}+d R_{c} \cdot \frac{\frac{\sqrt{3}}{\pi} \cdot R_{B}-\frac{1}{2} R_{C}}{2 \cdot h_{c}}\right)
$$

Due to the displacement of the commissure points the volume of the valve enclosed by the valve wall changes. Conseguently, the volumes $v_{1}, v_{2}$ and $v_{3}$ as have been defined previously in the present section, change. The incremental energy $\mathrm{dE}_{2}$ which corresponds to the increments $d V_{1}, d V_{2}$ and $d V_{3}$ of these three volumes can be expressed as

$$
d E_{2}=p_{a 0} \cdot d V_{1}+p_{1 v} \cdot d V_{2}+p_{a o} \cdot d V_{3}
$$

The total increment of energy is found by adding equations (5.14) and $(5.15)$ :

$$
d E=d E_{1}+d E_{2}
$$

According to the principle of minimum energy in the state of equilibrium it holds

$$
\frac{d E}{d R_{C}}=0
$$

Using the equations $(5.16),(5.14)$ and $(5.15)$ with

$$
p_{n t}=\left(p_{a O}-p_{1 v}\right) / p_{a o}
$$

it follows from equation $(5.17)$ that 


$$
\begin{aligned}
& \pi \cdot P_{n t} \cdot R_{B}^{2} \cdot\left\{-\frac{d h_{C}}{d R_{C}}+\frac{\frac{\sqrt{3}}{\pi} \cdot R_{B}-\frac{1}{2} R_{C}}{2 \cdot h_{C}}\right\}+ \\
& +\left\{\frac{d V_{1}}{d R_{c}}+\frac{d V_{3}}{d R_{c}}+\left\{1-P_{n t}\right\} \cdot \frac{d V_{2}}{d R_{c}}=0\right.
\end{aligned}
$$

In the present model equation (5.19) is solved numerically in terms of $R_{c}$. After all, all derivatives with respect to $R_{c}$ can be expressed as a function of $R_{C}$ and the normalized transvalvular pressure $p_{n t}$. Thus the radius $R_{c}$ of the commissure circle is determined as a unique function of $p_{n t}$.

5.3.3. Calculation of $h_{c}$ and $d h_{c} / d R_{c}$ from the commissure radius $\mathbb{R}_{\mathrm{C}}$

In a calculation procedure the height $h_{c}$ of the comissure points over the base plane is obtained by solving the equation

$$
L_{A R}=L\left(h_{c}, R_{C}\right)
$$

where $L\left(h_{c}, \mathbb{R}_{c}\right)$ represents the length of $1 / 6$ of the aortic ring as a function of $h_{c}$ and $R_{c}$, whereas $L_{A R}$ represents the length of the aortic ring segment as calculated through $L\left(h_{c}, R_{c}\right.$ ) by introducing the values of $h_{c}$ and $R_{c}$ at normalized transvalvular pressure 1. Using the equations (5.1), (5.2) and (5.3), for the function $L_{c}\left(h_{c} R_{c}\right)$ it holds

$$
\begin{aligned}
L\left(h_{c}, R_{C}\right)= & \int_{\psi=0}^{\pi / 2}\left(\left(\frac{d z}{d \psi}\right)^{2}+\left(r \cdot \frac{d \alpha}{d \psi}\right)^{2}+\left(\frac{d r}{d \psi}\right)^{2}\right)^{\frac{1}{2}} \cdot d \psi(5 \cdot 21) \\
= & \int_{\psi=0}^{\pi / 2}\left[h_{c}^{2} \cdot \cos ^{2}(\psi)+\frac{\pi^{2}}{9}(1-\sin (\psi)) \cdot R_{c}+\right. \\
& \left.\left.+\sin (\psi) \cdot R_{B}\right)^{2} \cdot \sin ^{2}(\psi)+\left(R_{C}-R_{B}\right)^{2} \cdot \cos ^{2}(\psi)\right)^{\frac{1}{2}} d \psi
\end{aligned}
$$

This integral can be calculated numerically. It is a function of only the two variables $R_{C}$ and $h_{C}$, since the base radius $R_{B}$ is assumed to be constant. Using a numerical procedure to solve equation (5.20), both the commissure height $h_{c}$ and the derivative $\mathrm{dh}_{\mathrm{c}} / \mathrm{dR}$ are calculated numerically as a function of $\mathrm{R}_{\mathrm{c}}$. 
5.3.4. Calculation of $\mathrm{dV}_{1} / \mathrm{dR}_{\mathrm{c}}$ and $\mathrm{dV}_{2} / \mathrm{dR}_{\mathrm{c}}$

The volume $v_{1}$ of the compartment enclosed by the three leaflets and the plane intersecting the three commissure points can be found as the integral of the cross-sectional surface area $A_{1}$ of the three sinus sections (figure 5.1) over the normalized axial coordinate $z_{n}\left(z_{n}=z / h_{c}\right)$. Thus, it holds

$$
\left.\frac{d V_{1}}{d R_{c}}=\frac{d}{d R_{c}} I \int_{0}^{1} A_{1} d z_{n}\right]
$$

The volume $v_{2}$ of the compartment enclosed by the three leaflets, the base plane of the valve and the three interleaflet trigones can analogously be determined by integrating the cross-sectional surface area $A_{2}$ of the three interleaflet sections over the normalized axial coordinate $z_{n}$. Thus

$$
\frac{\mathrm{dv}_{2}}{\mathrm{dR}_{\mathrm{C}}}=\frac{\mathrm{d}}{\mathrm{dR}_{\mathrm{C}}}\left[\int^{1} \mathrm{~A}_{2} \mathrm{dz_{n }}\right]
$$

The surface areas $A_{1}$ and $A_{2}$ can be expressed as a function of $R_{C}$ ' $z_{n}$ and $p_{n t}$ (appendix 5.3 ; figure 5.4). Thus, it holds

$$
\begin{aligned}
A_{1}= & 6 A_{11}=\frac{1}{2} \cdot R_{\operatorname{TRC}}\left(z_{n}\right) \cdot \operatorname{CIRCS}\left(z_{n}\right) \cdot \frac{\sin (\beta / 2)}{\beta / 2} \cdot \cos (\lambda-\beta / 2)+ \\
& +\frac{\pi}{12} \cdot\left\{\operatorname{CIRCS}\left(z_{n}\right)\right\}^{2} \cdot\{\beta-\sin (\beta)\} / \beta^{2} \\
A_{2}= & 6 A_{12}=\frac{1}{2} \cdot \operatorname{R}_{\operatorname{TRC}}\left(z_{n}\right) \cdot \operatorname{CIRCI}\left(z_{n}\right) \cdot \frac{\sin (\gamma / 2)}{\gamma / 2} . \\
& \cdot \cos (\pi / 3-\lambda-\gamma / 2)+\frac{1}{12} \cdot\left\{\operatorname{CIRCI}\left(z_{n}\right)\right\}^{2} \cdot\{\gamma-\sin (\gamma)\} / \gamma^{2}
\end{aligned}
$$

with the following expression for the radius of the truncated cone

$$
R_{T R C}\left(z_{n}\right)=\left(1-z_{n}\right) \cdot R_{B}+z_{n} \cdot R_{C}
$$

Furthermore, $z_{n}=$ axial coordinate $z$ normalized to $h_{c}$

$\lambda=$ value of $\alpha$ where sinus of Valsalva adjoins interleaflet trigone 
$\beta=$ angle of the circle segment corresponding to half the sinus section

$r=$ angle of the circle segment corresponding to half the interleaflet section.
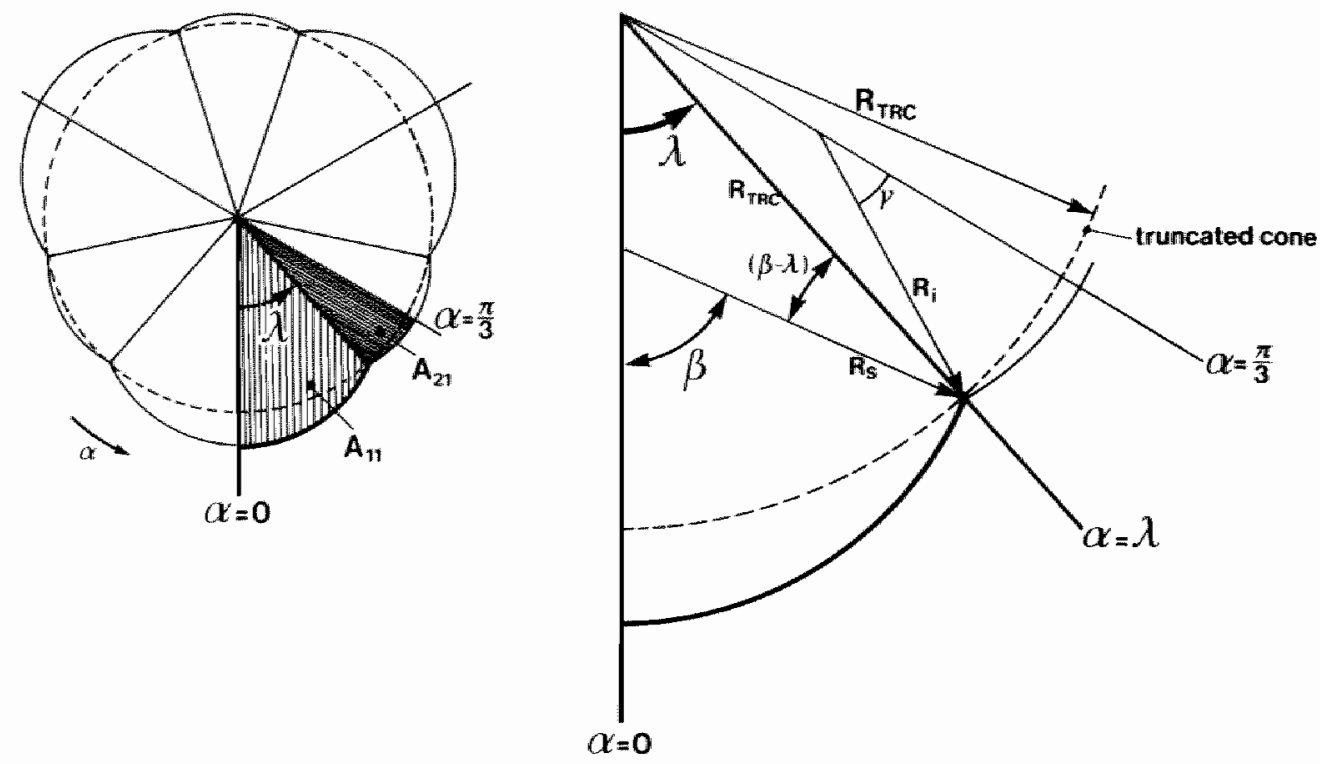

\section{FIGURE 5.4}

Schematic representation of a cross-section of the aortic valve in a plane perpendicular to the valve axis. Half the surface areas of a sinus $\left(A_{11}\right.$ ) and an interleaflet $\left(A_{21}\right)$ section are denoted. $A=$ value of $\alpha$ where sinus of valsalwa adjoins interleaflet trigone, $B=$ angle of the circle segment corresponding to half the sinus section; $Y=$ angle of the circle segment corresponding to half the interleaflet section; $R_{i}$, $R_{s}=$ radil of curvature of interleaflet and sinus section; $R_{T R C}=$ radius of the truncated cone.

The angle $\lambda$ is calculated (appendix A5.3) by solving the equation

$$
\begin{aligned}
& {\left[\cos (\beta-\lambda) \cdot \operatorname{cIRCS}\left(z_{n}\right) / \beta-\left(1-p_{n t}\right) \cdot \operatorname{CIRCI}\left(z_{n}\right) \cdot\right.} \\
& \cdot \cos (\gamma-\pi / 3+\lambda) / \gamma]=0
\end{aligned}
$$

where 


$$
\begin{aligned}
& \beta=\operatorname{arcsinc}\left\{\frac{6 \cdot \sin (\lambda) \cdot R_{\operatorname{TRC}}\left(z_{n}\right)}{\operatorname{CIRCS}\left(z_{n}\right)}\right\} \\
& \gamma=\operatorname{arcsinc}\left\{\frac{6 \cdot \sin (\pi / 3-\lambda) \cdot R_{\operatorname{TRC}}\left(z_{n}\right)}{\operatorname{CIRCI}\left(z_{n}\right)}\right\}
\end{aligned}
$$

The function $y=\operatorname{arcsinc}(x)$ is defined by its inverse

$$
x=\sin (y) / y
$$

When equation (5.27) is solved, the angle $\lambda$ is known. Moreover, the angles $\beta$ and $\gamma$ follow from equations (5.28) and (5.29).

\subsubsection{Calculation of $\mathrm{dV}_{3} / \mathrm{dR}_{\mathrm{C}}$}

In the compartment enclosed by the plane intersecting the commissure points, the circular cross-section of the aorta at the aortic border of the valve and the valve wall, the circumference of a cross-section perpendicular to the valve axis is assumed to be constant and equal to CIRCM(1) at the level of the commissure points. Unlike the cross-section of the aorta the cross-section at the level of the commissure points is not a circle. Hence the latter surface area is less than the former and consequently the volume $\mathrm{V}_{3}$ of the compartment depends on the shape of the circumference at the level of the commissure points. As to the difference in volume $v_{\cdot 3}$ corresponding to an overall cylindrical shape it is found to hold (appendix A5.1):

$$
\begin{aligned}
-\Delta V_{3}= & {\left[\{\operatorname{CIRCM}(1))^{2} / 4 \pi-A_{1}\left(h_{C}\right)\right] . } \\
& \cdot\{\operatorname{CIRCM}(1) / 2 \pi\} \cdot(0.1812)
\end{aligned}
$$

Since $A_{1}\left(h_{c}\right)$ depends on $h_{c}, \mathbb{R}_{c}$ and $p_{n t}$ (equation $(5.24)$ ) and $h_{c}$ itself can be expressed as a function of $R_{c}$ (equation $(5.20)$ ), it follows that $\Delta V_{3}$ is a function of $R_{c}$ and $p_{n t}$. Thus, the derivative $d V_{3} / d R_{c}$ can be calculated numerically from equation $(5.31)$. 
5.4. RELATION BETWEEN MORMALIZED TRANSVALVULAR PRESSURE AND COMMISSURE RADIUS AS FREDICTED EY THE MOLEL

The mathematical model described in the previous section has been implemented to a computer system (VAX 11-780) through a FORTRANIV computer program. In this way, normalized transvalvular pressure $p_{n t}$ ranging in between 0 and 1 was related to commissure radius $R_{c}$. To this purpose the geometry of the valve at normalized transvalvular pressure 1 was defined by the values of the commissure radius, the base radius, the commissure height and the mean circumference of the valve wall between base level and commissure level (section 5.3.1). The latter quantity $\operatorname{CIRCM}\left(\mathrm{z}_{\mathrm{n}}\right)$ as a function of normalized axial coordinate $z_{n}$ (figure 5.5) is given by

$$
\begin{aligned}
\operatorname{CIRCM}\left(z_{n}\right)= & 2 \pi \cdot R_{\operatorname{TRC}}\left(z_{n}\right) \cdot\left[1+M P 3 \cdot\left[1-z_{n} / \operatorname{MP1}\right\}^{2-M P 2}\right. \\
& \left.\cdot\left\{z_{n} / M P 1\right\}^{M P 2}\right]
\end{aligned}
$$

where $z_{n}=$ normalized axial coordinate, being defined as $z_{n}=$ $z / h_{c}$, where $h_{c}$ is the height of the commissure points over the base plane of the valve

$R_{T R C}=$ radius of the truncated cone as a function of the normalized axial coordinate $z_{n}$ (equation $(5.26)$ )

MP3 = parameter which determines the amount of bulging with respect to the radius $\mathrm{R}_{\mathrm{TRC}}(0.5)$

MP2 = aspect parameter of the bulge

MPI = parameter which determines the axial length of the bulge in terms of commissure height $h_{c}$.

In simulations with the mode1, parameters MP1, MP2 and MP3, and commissure radius, base radius and commissure height were derived from data after Swanson and Clark (1974) and Thubrikar and co-investigators (1981).

Swanson and clark (1974) determined the dimensions of the closed human aortic valve from a series of silicone rubber casts, which had been made at aortic pressures ranging in between 0 and 


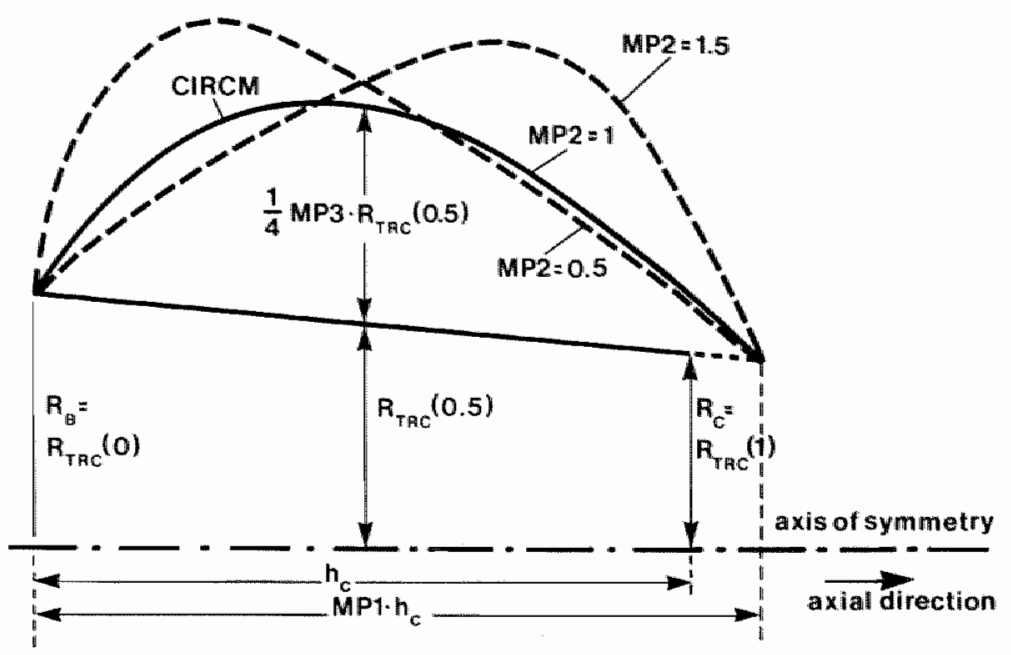

FIGURE 5.5

Schematic representation of the shape of the mean circumference CIRCM compared to the truncated cone in a cross-section of the valve for a given value of (figure 5.2). $h_{c}=$ commissure height; MP1, MP2, MP3 = parameters in the expression for the mean circumference (equation $(5.32)$ ); $R_{C}, R_{B}=$ radil of commissure and base circle: $R_{T R C}=$ radius of the truncated cone.

$16 \mathrm{kPa}$. To this purpose, fresh human hearts as obtained at autopsy were stored at $4^{\circ} \mathrm{C}$ and used within $1-3$ days after death. In their study, the ratio of commissure radius to base radius $\left(\mathbb{R}_{C} / R_{B}\right)$, the ratio of commissure height to base radius $\left(h_{c} / R_{B}\right)$ and the ratio of axial length of the sinuses of valsalva to base radius $\left(1_{s} / R_{B}\right)$ were determined. These investigators also determined a mean radius of the sinus of Valsalva ( $\left.R_{S M}\right)$ which was defined as the radius of a circle with a surface area equal to the maximum cross-sectional surface area of the valve in a plane perpendicular to the valve axis. The data after Swanson and Clark (1974) were used to define the geometry of the present model as follows. The base radius $\mathbb{R}_{B}$ was taken to be $10 \mathrm{~mm}$, enabling the calculation of commissure radius $R_{C}$ and commissure helght $b_{c}$. The value of parameter MP1 in equation (5.3.2) was determined as the ratio of the axial length of the sinuses of valsalva to the commissure height $\left(1_{s} / h_{c}\right)$. The parameter MP2 was set to $1_{i}$ the maximum of bulging being located halfway the axial length of the 
sinus of Valsalva. The chosen value of MP3 was to equalize the maximum difference of radii of bulge and truncated cone to the difference between the mean radius of the sinus of Valsalva $\left(R_{S M}\right)$ and the radius of the truncated cone $\left(R_{T R C}\right)$. In this way the geometry of the valve has been determined in order to perform a number of four simulations (see table 5.1).

In the dog, Thubrikar and co-investigators (1981) measured the ratio of the base radius to commissure radius $\left(R_{B} / R_{C}\right)$ and the ratio of commissure height to commissure radius $\left(h_{c} / R_{c}\right)$, in mid-diastole. They reported that $R_{B} / R_{C}=1.2 \pm 0.1(6 \mathrm{dogs})$ and $\mathrm{h}_{\mathrm{C}} / \mathrm{R}_{\mathrm{C}}=1.4 \pm 0.1$ ( 3 dogs) for aortic pressures ranging in between $100 / 85$ and $180 / 146 \mathrm{mmHg}(14 / 12-26 / 21 \mathrm{kPa}$; systolic/diastolic pressure). The technique they used, has been explained in section 4.5.2. The data by Thubrikar and associates (1981) were used for one single model simulation (table 5.1, case 5). To that purpose, the base radius was set to $10 \mathrm{~mm}$. The values of the parameters MP1, MP2 and MP3 were derived from the data by Swanson and Clark (1974).

\section{TABLE 5.1}

Input data used for model simulation and results obtained. $R_{c}=$ commissure radius; $R_{B}=$ base radius; $h_{c}=$ commissure height; MP1, MP2, MP3 parameters in equation $(5.3 .2) ; \Delta s t r a i n=$ change of strain of comissure radius due to change of normalized transvalvular pressure from 1 to 0 . Geometry in cases 1 through 4 was derived from data as presented by swanson and Clark (1971). Cases 1 and 2 apply to casts of their valve made at aortic pressures of 13.3 and $5.3 \mathrm{kPa}$ respectively. Cases 3 and 4 apply to casts of their valve 7 made at the artic pressures 26.0 and $5.3 \mathrm{kP}$ respectively. Case 5 originates from data fer Thubrikar and associates (1981).

\begin{tabular}{|c|c|c|c|c|c|c|c|}
\hline Case & $\begin{array}{c}R_{c} \\
10^{-2} . m\end{array}$ & $10^{-2} \cdot m$ & $\begin{array}{c}\mathrm{h}_{\mathrm{c}} \\
10^{-2} \cdot \mathrm{m}\end{array}$ & MP1 & MP2 & MP3 & Mstrain \\
\hline 1 & 1.23 & 1 & 1.42 & 1.34 & 1 & 1.72 & 0.007 \\
\hline 2 & 1.06 & 1 & 1.38 & 1.35 & 1 & 1.24 & -0.001 \\
\hline 3 & 1.00 & 1 & 1. 34 & 1.24 & 1 & 0.48 & -0.006 \\
\hline 4 & 0.85 & $\mathbb{1}$ & 1.40 & 1.16 & 1 & 0.28 & -0.014 \\
\hline 5 & 0.83 & 1 & 1.17 & 1.25 & 1 & 0.50 & -0.026 \\
\hline
\end{tabular}


Natural strain of commissure radius appeared to depend approximately linearly on normalized transvalvular pressure. This justifies the assumption made to this point in the analysis of the animal experiments (equation (4.1); section 4.5 .2 ) the results for strain of commissure radius also apply to strain between 2 commissure points because of the symmetric geometry of the valve in the model. In table 5.1, last column, changes of natural strain of commissure radius are presented when normalized transvalvular pressure falls from 1 to 0 . In the animal experiments, change in commissure strain due to a change in normalized transvalvular pressure from 1 to 0 , proved to be positive in 25 cases (0.0133-0.110, table 4.1) and negative in only one measurement $(-0.017$, commissure strain 7 in table 4.1$)$. The fact that this change of strain in the animal experiments in a general sense was positive disagrees with the prediction by the model this to be negative. Moreover after a change of normalized transvalvular pressure from 1 to 0 , the magnitude of the change of strain was in general higher in the animal experiments than in the model simulations.

\subsection{DISCUSSION}

In a general sense the model predicts a decrease of commissure strain when normalized transvalvular pressure decreases. This fact disagrees with the results of our animal experiments. On the other hand, changes of commissure strain were found to be minor in the model as well as in the animal experiment.

To obtain insight into the influence of the shape of the sinuses of Valsalva on the change in commissure strain as predicted by the model, the function determining this shape (equation (5.32)) was adapted to case 5 in table 5.1. For a number of different values of the parameters MP1, MP2 and MP3, the change of strain due to a change of normalized transvalvular pressure from 1 to 0 , was determined. The results are presented in table 5.2 . 
TABLE 5.2

Change of conmissure strain due to a change of normalized transvalvular pressure from 1 to 0 , for different shapes of the mean circumference. The data shown, refer to case 5 , table 5.1. $R_{C}=$ commissure radius; $R_{B}$ = base radius; $h_{c}=$ commisgure height; MPI, MP2, MP3 = parameters in equation (5.32): $\Delta$ strain = change of commisure strain as described above. Underlined values are changed with respect to case 5 , table 4.1 .

\begin{tabular}{ccccccc}
\hline $\begin{array}{c}\mathrm{R}_{\mathrm{C}} \\
10^{-2} . \mathrm{m}\end{array}$ & $\begin{array}{c}\mathrm{R}_{\mathrm{B}} \\
10^{-2} \cdot \mathrm{m}\end{array}$ & $\begin{array}{c}\mathrm{h}_{\mathrm{C}} \\
10^{-2} \cdot \mathrm{m}\end{array}$ & MP1 & MP2 & MP3 & sstrain \\
\hline 0.83 & 1 & 1.17 & 1.25 & 1 & 0.50 & -0.023 \\
0.83 & 1 & 1.17 & 1.25 & 1 & $\underline{0.10}$ & -0.026 \\
0.83 & 1 & 1.17 & 1.25 & 1 & $\underline{0.90}$ & -0.017 \\
0.83 & 1 & 1.17 & 1.25 & $\frac{0.5}{1.5}$ & 0.50 & -0.018 \\
0.83 & 1 & 1.17 & 1.25 & $\frac{1.50}{1}$ & 0.50 & -0.030 \\
0.83 & 1 & 1.17 & $\underline{1.00}$ & 1 & 0.017 \\
0.83 & 1 & 1.17 & $\underline{1.50}$ & 1 & 0.50 & -0.024 \\
\hline
\end{tabular}

From the results in table 5.2 it was concluded that the influence of the shape of the sinuses of Valsalva on the change of strain as predicted by the madel is moderate.

However, some more assumptions in the model must be considered in the context of disagreement.

- The forces which a leaflet exerts upon its commissure points were assumed to be in a plane through these commissure points and the center of gravity of the projection of the leaflet on the base plane (section 5.3.2, figure 5.3). This assumption may be incorrect. Because of this assumption, the radial component of the force (equation (5.12b)), is directed in positive radial direction (outwards the valve) in the cases 2 through 5 , table 5.1, and in negative radial direction (inwards the valve) for case 1, table 5.1. Solely in the latter case commissure strain increases when normalized transvalvular pressure decreases.

- The description of the geometry of the leaflets perhaps is not sufficiently accurate. If in figure 5.3 , the distance between point $S$ and point $E$ is larger than assumed (1.20; appendix 
A5.2), the forces which a leaflet exerts upon its commissure points (equation (5.9)) also have components directed from the one commissure to the other. As a consequence these components of force induce an inwards directed radial force at each commissure.

- The leaflet is considered to be part of the surface of a rotational symmetric body, where the axis of symmetry is the line of connection of the commissure points (appendix A5.2). Consequently, in figure 5.3 the margin of the leaflet in a plane $a=0$ is approximately parallel to the base plane. As a matter of fact, the actual margin of the leaflet in a plane $a=0$ intersects the base plane at an angle of about 20 degrees in positive axial direction (Thubrikar et al. 1981). This slope of the leaflets also results in an inwards directed radial component of force at each commissure point. This component may be even more pronounced by the presence of a coaptive area in each leaflet (figure 2.4), as this area is positioned in axial. direction.

- In the leaflet collageneous bundles are found which run from the one commissure to the other parallel to the free edge of the leaflet (see section 2.3.2). The two or three bundles clearly visible in the coaptive area of the leaflet (Sauren 1981) mainly exert inwards directed radial forces upon the commissure points.

The merits of the present model, even in its far from perfect quality, can be stated to be as follows.

- The deformation of the aortic valve at a given aortic pressure could be described by one single parameter, namely the commissure radius. This parameter in turn depends on one gingle parameter, being the normalized transvalvular pressure.

- The use of the principle of minimum energy and the assumption that energy cannot be dissipated or stored in the valve material, greatly facilitates the analysis of deformation of the aortic ring.

- The commissure strain was related to normalized transvalvular pressure. The relation appeared to be approximately linear. 
Changes of commissure strain by changes in normalized transvalvular pressure from 1 to 0 were found to be minor.

- In the model changes of the shape of the sinuses of valsalva have little effect on the relation between commissure strain and nomalized transvalvular pressure.

It is belleved that the model needs to be improved by describing more accurately both the forces acting in the leaflets and the geometry of leaflets. Dealing in more detail with the bundle structure of the leaflets 111 be necessary. To this purpose, more detailed data on the mechanics of the aortic valve leaflet as presented by sauren (1981) may be useful. 


\section{SUMMARY AND CONCLUSIONS}

The investigations dealt with in the present thesis were performed within the framework of the Eindhoven-Maastricht heart-valve research project (appendix Al.1). The aim of the project is to obtain specifications for the design and the implantation of artificial triple-leaflet-valve prostheses which have a longer 1 ife than the ones in use nowadays. For this purpose the behavior of the natural as well as the artificial valves presently available is investigated with respect to their hydrodynamical and mechanical performance. One of the topics of the project concerns the determinants of the instantaneous value of the stresses in the leaflets of the natural aortic valve during the cardiac cycle. These stresses are mainly determined by the forces exerted by the blood upon the leaflets, by the instantaneous three-dimensional geometry of the skeleton of the aortic valve (aortic ring) and the material properties of the leaflets. The present study was directed to get insight into the changes of the three-dimensional geometry of the aortic ring during the cardiac cycle and the mechanism which controls this geometry.

From literature no detailed information could be obtained about the relation between instantaneous changes in the geometry of the aortic ring and changes in hemodynamic variables, such as aortic and left ventricular pressure during the entire cardiac cycle. In the present investigations, the changes in three-dimensional geometry of the dog aortic ring during the cardiac cycle were studied in vivo. For this purpose changes in the mutual positions of the commissure points and the base points were determined by measuring natural strains between the commissure points, the base points and the commissure and base points (figure 1.1) during the cardiac cycle. Natural strain was defined as the natural logarithm of the ratio of the instantaneous distance between two points and an original distance between these points. The change of natural strain between two points corresponds to the change of distance between these points. Natural strain was 
chosen to be measured because, also for large strain, changes of strain are found as the logarithm of the ratio of instantaneous distances between two points, whereas the original distance is insignificant. Consequently comparison of strain behavior of valves of aifferent size becomes feasible.

Natural strains in the aortic ring of the dog were determined by a specially designed and developed measuring system, which is based on an electromagnetic induction technique (chapter 3 ). The measuring technique basically uses two coils." One coil transmits an alternating magnetic field, which induces a voltage in the other coil. Because of the decrease of the strength of the magnetic field with increasing distance from the transmitter coil, the induced voltage is a measure for the distance between the coils. Strain is derived from the induced voltage, using electronic circuitry and assuming that the mutual orientation of the coils remains the same. To each of the commissure and base points of the aortic ring a coil was attached. So, strain between the commissure points, the base points and the commissure and base points could be measured. Inaccuracy in strain determination due to changes in mutual coil orientation was expected to be less than 0.01 for the strain between commissure points or between base points and less than 0.04 for the strain between commissure and base points. For appropriate description of aortic ring motion as many strains in the aortic ring as feasible have to be measured simultaneously. Therefore, an electronic multiplexing system was designed to measure six strains at the same time: three strains between the commissure points and three strains between the base points. By this device, but not at the same time as the former measurements, one strain between two commissure points and two strains between these commissure points and the nearest base point could also be measured simultaneously. The in vitro specifications of the measuring device were found to be:

- Erequency response $0-150 \mathrm{~Hz}$ (f $-3 \mathrm{~dB}$ ).

- within the distance range of 5 to $25 \mathrm{~mm}$, the maximum error of the strain measurement due to non-linearity was 0.008 when natural strain was in the range of \pm 0.20 , and 0.011 when natural strain was in the range of \pm 0.30 . 
- the zero drift was determined over a period of four hours and proved to be less than 0.006 in terms of natural strain.

Chapter 4 describes the measurement of strains in the canine aortic ring during the cardiac cycle. Strains were measured by the inductive technique. To that purpose a coil was sutured to each of the commissure and base points of the aortic ring using a cardiopulmonary bypass technique. After termination of the bypass and stabilization of the hemodynamic variables, strains in the aortic ring were measured during the cardiac cycle at aortic pressures ranging in between 4 and $20 \mathrm{kPa}$. Simultaneously, aortic pressure at the level of the commissure points and left ventricular pressure were measured. The strain and pressure signals were recorded on magnetic tape for off-line data processing. The data processing was performed using interactive computer technigues. The variations of strains in the aortic ring during the cardiac cycle were measured with respect to the changes of three variables:

- aortic pressure at the level of the commissure points.

- left ventricular pressure.

- normalized transvalvular pressure, defined as the ratio of the difference between aortic and left ventricular pressure to aortic pressure.

These variables were chosen because they describe the pressure load of the valve completely, assuming that the pressure in the thoracic cavity can be neglected. Hence, these variables might be the major determinants of the geometry of the aortic valve. The main results with respect to the evaluation of strains in the aortic ring during the cardiac cycle are as follows.

- Comissure strain appeared to follow the changes in aortic pressure throughout the cardiac cycle. At a given aortic pressure commissure strain was found to be systematically higher during the ventricular ejection phase than during the ventricular filling phase of the cardiac cycle. The mean value of the difference in strain between these phases was found to be 0.041 +0.028 (mean \pm standard deviation; 26 commissure strains). In the analysis this difference was assumed to be linear with 
nomalized transvalvular pressure. The derivative of commissure strain to aortic pressure at a given normalized transvalvular pressure was calculated to be $1.9 \times 10^{-5} \pm 1.2 \times 10^{-5} \mathrm{~Pa}^{-1}$ (mean \pm stanard deviation; 26 comissure strains) for an aortic pressure of $10 \mathrm{kPa}$.

- During the cardiac cycle all strains in the base plane of the valve were found to vary. The base plane was defined as the plane intersecting the three base points, whereas the base circle is the circle through these points. The maximum variation during the cardiac cycle ranged in between 0.03 and 0.15 . Base strain along a segment adjoining the myocardium at the base circle of the valve, decreased during the ventricular ejection phase. This decrease is likely to be due to contraction of the myocardial wall of the ventricle and the septum. Base strain along a segment adjoining the non-contracting anterior mitral valve leaflet, increased during the ventricular ejection phase. This strain was measured along passive collageneous tissue in between the mitral and aortic valve orifice (figure 2.5). The increase of this strain during the ejection phase may result from a combination of stretch of the collageneous tissue caused by the increased left ventricular pressure, and forces exerted upon the tissue by the myocardial wall and the mitral and aortic valve. If strain in the base plane is measured allong a segment containing both a myocardial segment and a, segment adjoining the anterior mitral valve leaflet, the nett change of strain is determined by the combination of a decrease and an increase of strain.

- Strain between a base and a commissure point of the aortic ring showed no specific course as a function af time. Changes of this strain during the cardiac cycle were small (0.00-0.06) and may partly be seemingly due to changes in the mutual orientation of the coils. Strain along the aortic ring is likely to be negligible because the aortic ring is composed of collageneous and/or cartilagenous tissue. Thus, it is assumed that the changes of the strains between commissure and base points, providing that they are real, mainly originate from changes of the commissure and base strains. 
In chapter 5 commissure strain was related to normalized transvalvular presssure using a mathematical model. This model was formulated according to the principle of minimum energy. Deformation of the valve due to elastic deformation of the wall was excluded by assuming that energy neither could be stored nor dissipated in the material of the valve. Model simulations have been performed resulting in relations between normalized transvalvular pressure and commissure strain. In the simulations descriptions of the geometry of the closed aortic valve as have been presented in literature were used. The merits of the present model can be stated to be as follows.

- The use of the principle of minimum energy and the assumption that energy neither can be dissipated nor stored in the valve material, largely facilitated the analysis of deformation of the aortic ring.

- The non-elastic deformation of the aortic valve has been described by one parameter, namely the commissure radius. The parameter is a function of normalized transvalvular pressure only.

- The commissure strain was related to normalized transvalvular pressure. The relation appeared to be approximately linear which justifies the assumption made regarding this point in the evaluation of strain in the aortic ring in the animal experiments. Change of commissure strain due to change of normalized transvalvular pressure from 1 (ventricular filling phase) to 0 (ventricular ejection phase) was found to be minor ( 33 ). This agrees with the findings in the animal experiments. However, the sign of the change of commissure strain was found to be negative in the model simulations and positive in the animal experiments.

- In the model, changes of the shape of the sinuses of Valsalva had little effect on the relation between commissure strain and normalized transvalvular pressure.

It is believed that the model needs to be improved by describing more accurately the forces acting in the leaflets and the geometry of leaflets. Dealing with the bundle structure of the leaflets in more detail will be necessary. 



\section{SAMENVATTING}

Het onderzoek is uitgevoerd in het kader van het Eindhoven-Maastricht hartkleppen project (appendix Al.1). Het doel van dit project is specificaties op te stellen voor het ontwerp en de implantatie van betere vliesklepprothesen. Laartoe wordt onder andere het gedrag van de natuurlijke aortaklep bestudeerd. De aortaklep is een van de vier kleppen in het hart. zij bevindt zich tussen de linker hartkamer (linker ventrikel) en de grote lichaamsslagader (aorta). Een van de onderzoeksgebieden binnen het hartkleppen project houdt zich bezig met de beschrijving van de mechanische spanningstoestand in de vliezen van de natuurlijke aortaklep. Deze spanningstoestand hangt voornamelijk af van de krachten die het bloed op de vliezen uitoefent, de ruimtelijke vorm van de vliesophanging (aortaring) en de materiaaleigenschappen van de vliezen. In dit proefschrift zijn de resultaten neergelegd van een onderzoek naar de veranderingen in de ruimtelijke vorm van de aortaring gedurende de hartcyclus.

Eerst is bekeken welke veranderingen in de vorm van de aortaring het belangrijkste zouden zijn voor de spanningstoestand in de vliezen. Op basis van literatuur over de ophanging van de vliezen aan de aortaring (Sauren 1981) werd aangenomen, dat de onderlinge posities van de commissuur- en basispunten van de aortaring de vorm van de aortaring voldoende zouden vastleggen (figuur 1.1). De veranderingen in de onderlinge posities van deze punten gedurende de hartcyclus werden bepala door de natuurlijke rek te meten tussen de drie commissurpunten, tussen de drie basispunten, en tussen de commissuur- en basispunten (figuur 1.1). Natuurlijke rek werd daarbij gedefiniëerd als de naturlijke logaritme van de verhouding tussen de momentane afstand tussen twee punten en een oorspronkelijke afstand tussen deze punten. Een verandering in de onderlinge positie tussen twee punten correspondeert met een verandering in de natuurlijke rek. Er werd voor natuurlijke rek gekozen omdat, zelfs voor grote natuurlijke rek, veranderingen in de natuurlijke rek bepaald 
worden door de logaritme van de verhouding tussen momentane afstanden tussen de twee punten, warbij de oorspronkelijke lengte tussen de punten er niet toe doet. Daardoor kan het strain gedrag van kleppen van verschillende grootte gemakkelijk vergeleken worden.

De natwurlijke rekken in de aortaring van de hond werden bepald met een speciaal daarvoor ontwikkeld meetapparaat (hoofdstuk 3) dat op de inductieve meetmethode is gebaseera. Bij de bepaling van een natuurlijke rek met de inductieve meetmethode worden twee spoelen gebruikt. De ene spoel zendt een wisselend magnetisch veld uit wardoor in de andere spoel een kleine elektrische wisselspanning wordt opgewekt. Omdat deze spanning kleiner is naarmate de spoelen verder uit elkaar liggen, is de opgewekte spanning een mat voor de afstand tussen de twee spoelen. De natuurlijke rek tussen de twee spoelen kan electronisch afgeleid worden van de opgewekte spanning. Een voorwaarde daarbij is dat de onderlinge orientatie van de twee spoelen gelijk blijft. Op elk commissuurpunt en elk basispunt van de aortaring werd een spoel aangebracht. Daardoor konden met de inductieve meetmethode natuurlijke rekken tussen de commissuurpunten, tussen de basispunten en tussen de commissuur- en basispunten gemeten worden. De onnauwkeurigheid in de bepaling van natuurlijke rek in de aortaring gedurende de hartcyclus met de inductieve meetmethode is geschat op minder dan 0.01 voor de rek tussen commissuurpunten en tussen basispunten; en op minder dan 0.04 voor de rek tussen een commissuur- en een basispunt. Voor een nauwkeurige beschrijving van de vervormingen van de aortaring is het wenselijk dat zoveel mogelijk natuurlijke rekken tegelijkertijd gemeten worden. Daarom werd een multiplexend electronisch systeem ontwikkeld voor de gelijktijdige meting van zes natuurlijke rekken, te weten drie rekken tussen de commissurpunten en drie rekken tussen de basispunten. Met hetzelfde systeem kunnen overigens ook een natuurlijke rek tussen twee commissuurpunten en twee natuurlijke rekken tussen deze commissuurpunten en het dichtstbijzijnde basispunt simultaan gemeten worden. De specificaties van de meetapparatuur werden in vitro bepaald. Deze zijn:

- Erequentie responsie van $0-150 \mathrm{~Hz}$ (f $-3 \mathrm{~dB}$ ). 
- voor afstanden tussen 5 en 25 mill is de maximale fout in de rekmeting ten gevolge van niet-lineariteit $0.008 \mathrm{bij}$ een natuurlijke rek van $\# 0.20$ en 0.011 bij een natuurlijke rek van \pm 0.30 .

- de drift van het inductieve meetapparat werd bepaald gedurende een periode van vier uur." Deze was minder dan 0.006, uitgedrukt in natuurlijke rek.

In hoofdstuk 4 van dit proefschrift is de meting van natuurlijke rekken in de aortaring van de hond beschreven. Om natuurlijke rek met de inductieve meetmethode te kunnen meten, werd een spoel gemonteerd op elk commissuurpunt en elk basispunt van de aortaring. Daartoe werd gebruik gemakt van open-hartchirurgie. Na stopzetting van de hartlongmachine en nadat de hemodynamische variabelen van het nog steeds onder narcose zijnde dier gestabilisserd waren, werden de natuurlijke rekken in de aortaring gemeten gedurende de hartcyclus. Dit werd gedaan bij bloeddrukken tussen 4 en $20 \mathrm{kPa}$. Tegelijkertijd werden de aortadruk ter hoogte van de commissurpunten en de linkerventrikeldruk gemeten. De natuurlijke rek en de druksignalen werden op magneetband opgenomen voor latere verwerking. De verwerking van de signalen vond plaats met behulp van interactieve computertechnieken. De veranderingen van de natuurlijke rekken in de aortaring gedurende de hartcyclus werden geanalyseerd met betrekking tot de veranderingen in arie variabelen:

- de aortadruk ter hoogte van de commissururpunten.

- de 1 inkerventrikeldruk.

- de genormaliseerde transvalvulaire druk die gedefinieerd is als de verhouding tussen het verschil van aortadruk en linkerventrikeldruk en aortadruk.

Deze variabelen werden gekozen omdat ze de drukbelasting van de aortaklep geheel beschrijven, annemende dat de druk in de borstholte zo laag is dat die verwaarloosd kan worden. De vorm van de aortaklep wordt voornamelijk bepaald door de drukbelasting. De belangrijkste resultaten met betrekking tot de analyse van natuurlijke rek in de aortaring zijn hieronder opgesomd. 
- De natuurlijke rek tussen de commissuurpunten bleek de veranderingen in de aortadruk in de gehele hartcyclus te volgen. Voor een gegeven aortadruk was deze natuurlijke rek tijdens de ejectiefase systematisch hoger dan tijdens de vullingsfase van de hartcyclus. De gemiddelde warde van dit verschil tussen de twee fasen bleek $0.041 \pm 0.028$ te zijn (gemiddelde \pm standaard afwijking; 26 natuurlijke rekken tussen commissuurpunten). In de analyse is aangenomen dat dit verschil tussen de fasen in lineair verband stond met de genormaliseerde transvalvulaire druk. De afgeleide van de natuurlijke rek tussen de commissurpunten met betrekking tot de aortadruk, voor een gegeven warde van de genormaliseerde transvalvulaire druk, was bij een aortadruk van $10 \mathrm{kPa}: 1.9 \times 10^{-5} \pm 1.2 \times 10^{-5} \mathrm{~Pa}^{-1}$ (gemiddelde \pm standaard afwijking, 26 natuurlijke rekken tussen commissuurpunten).

- Alle natuurlijke rekken gemeten in het basisvlak van de klep variëerden gedurende de hartcyclus. Het basisvlak is gedefinieerd door het vlak door de arie basispunten van de aortaring. Natuurlijke rek in het basisvlak langs het gedeelte van de klep dat grenst aan de spierwand van de linkerventrikel of het septum nam af gedurende de ejectiefase van de hartcyclus. Deze afname wordt waarschijnlijk veroorzaakt door de samentrekking van het spierweefse1. De natuurlijke rek in het basisvlak langs het gedeelte van de klep dat grenst aan de mitraalklep nam toe gedurende de hartcyclus. Deze natuurlijke rek werd gemeten langs collageen weefsel. De toename van de natuurlijke rek gedurende de ejectiefase zow veroorzaakt kunnen zijn door de combinatie van rek van het collageen weefsel tengevolge van een toegenomen linker ventrikeldruk, en krachten die op het weefsel uitgeoefend worden door de mitralklep, de aortaklep en de spierwand. Als natuurlijke rek gemeten wordt langs een segment dat gedeeltelijk grenst aan de spierwand en gedeeltelijk aan de mitraalklep, dan hangt de netto verandering in de natuurlijke rek af van de combinatie van toe- en afname van natuurlijke rek.

- De natuurlijke rekken tussen een basispunt en een commissuurpunt waren klein $(0.00-0.06)$ en hadden nogal wat verschillende 
tijdsverlopen. De veranderingen in deze natuurlijke rek gedurende de hartcyclus kunnen veroorzaakt zijn door variatie in de onderlinge orientatie van de spoelen. Aangenomen wordt dat de veranderingen in deze natuurlijke rek, indien ze reëel zijn, hoofdzakelijk verband houden met de veranderingen in de natuurlijke rekken tussen commissuurpunten en tussen basispunten, omdat natuurlijke rek langs de aortaring vermoedelijk verwaarloosbaar is gezien de collageen-kraakbeenachtige opbouw van de aortaring.

In hoofastuk 5 van dit proefschrift werd de natuurlijke rek tussen de commissuurpunten in verband gebracht met de genormaliseerde transvalvulaire druk door gebruik te maken van een wiskundig model. Het model werd geformuleerd op basis van het minimum energie principe. De vervorming van de aortaklep ten gevolge van elastische vervorming van het klepweefsel werd in het model buiten beschowing gelaten door aan te nemen dat energie niet opgeslagen of gedissipeerd kan worden in het klepweefsel. Met het model zijn simulaties uitgevoerd die resulteerden in verbanden tussem natuurlijke rek tussen de commissuurpunten en de genormaliseerde transvalvulaire druk. Voor deze simulaties werden geometrie beschrijvingen van de gesloten aortaklep uit de literatuur gebruikt. De verdiensten van het wiskundig model kunnen als volgt samengevat worden.

- Door gebruik te maken van het minimum energie principe en de aanname dat geen energie gedissipeerd of opgeslagen kan worden in het klepweefsel, is de analyse van de vervorming van de aortaring sterk vereenvoudigd.

- De vervorming van de aortaklep bij een gegeven aortadruk is beschreven met een parameter, namelijk de straal van de cirkel door de commissuurpunten. Deze parameter hangt van slechts ển drukparameter af, de genormaliseerde transvalvulaire druk

- De natuurlijke rek tussen de commissuurpunten werd in verband gebracht met de genormaliseerde transvalvulaire druk. De relatie tussen deze twee variabelen was bij benadering 1 ineair hetgeen een ondersteuning is voor de aanname hierover bij de dierproeven. De verandering in de natuurlijke rek tussen de 
commissuurpunten ten gevolge van een verandering in de genormaliseerde transvalvulaire druk van 1 (vullingsfase van de hartcyclus) naar 0 (ejectiefase) bleek gering te zijn $(<3 q)$. Dit kwam overeen met de resultaten van de dierproeven. Echter bij de modelsimulaties bleek de verandering in natuurlijke rek negatief te zijn en bij de dierproeven positief.

- In het model hadden veranderingen in de geometrie van de sinussen wan Valsalva weinig invloed op de relatie tussen matuurlijke rek tussen commissurpunten en genormaliseerde transvalvulaire druk.

Vermoedelijk kan het model verbeterd worden door de krachten in de vliezen en de vliesgeometrie beter te beschrijven. Bovendien zou de bundelstructuur in de vliezen beter in rekening gebracht moeten worden. 
APPENDICES 

A1. 1. THE PURPOSE AND THE SCOPE OF THE EINDHOVEN-MAASTRICHT HEART VALVE RESEARCH PROJECT

In the present appendix a concise outline of the EindhovenMaastricht heart-valve research project is given. Therefore a description of the project as has been given by Sauren (1981) and van Steenhoven $(1979 \mathrm{~b})$ was updated.

The Eindhoven-Mastricht heart-valve research project was initiated because of the limited life of biological, tripleleaflet valve prostheses. Apart from eventual tissue degeneration, abnormal hydrodynamical and mechanical conditions were recognized as the possible major contributing factors to valve failure. It is assumed that such fallure is due to higher local stresses in the leaflets of the prosthesis compared to the natural valve. The ultimate goal of the project is twofold:

- to determine by means of theoretical and experimental mode1ling, the parameters which govern the stress in valve leaflets, and

- to formulate technical specifications for the design and implantation of artificial triple-leaflet valve prostheses of which function and $l$ ife are much nearer the optimum.

The research philosophy is based on the view that observation of natural aortic valve behavior gives insight into the relevancy of various parameters. This behavior can be investigated in experiments with an analogue model as well as in vivo experiments. From the resulting knowledge, specifications may be derived for artificial valves. The project has four main aspects:

- hydrodynamic behavior of the aortic valve. The aim of this aspect is to describe the interaction between flow pattern and cusp motion. The main subject of investigation has been the closing mechanism of the aortic valve. For this purpose experiments were performed with an analogue model to find a physical basis mechanism (Van Steenhoven and Van Dongen 1979a). Furthermore the valve closure was studied in animal experiments in vivo (Van steenhoven et al. 1981). 
- dynamic behavior of the aortic valve.

As to this aspect the relationship between changes in the geometry of the aortic valve and pressure differences across the valve components is studied. On the one hand changes in the geometry of the aortic ring in relation to the pressure differences is investigated experimentally during the cardiac cycle in the dog (Van Renterghem et al. 1981, present thesis). On the other hand the pressure differences across the valve components are related to the changes in geometry of the valve in terms of valve compliance (Van Renterghem et al. 1979, Van Renterghem et a1. 1982).

- mechanical behavior of the aortic valve.

As to this aspect the pressure difference across the valve is correlated to the local stresses within the valve components. For this purpose valve histology (Sauren et al. 1980) and the mechanical properties of the valve tissue (Sauren et al. 1983; Sauren and Rousseau 1983) have been studied with the ultimate goal of developing a theoretical model of valve mechanics.

- application of basic information to valve protheses. In order to apply such basic information to a better design of heart-valve prostheses, the natural stress-reducing mechanisms must be translated into design specifications (Van Steenhoven et al. 1982). Material behavior (Rousseau et al. 1982) and valve geometry are some important specifications. They are incorporated in a numerical model of a triple-leaflet valve prosthesis in order to evaluate their influence on the state of stress in a leaflet. Design specifications will be tested in prototypes. 
A3.1. DERIVATION OF THE INDUCED VOLTAGE IN A RECEIVER COIL

Combination of the equations $(3,3)$ and $(3.4)$ results in

$$
v_{R C}\left(\rho_{R}, k_{R}, \theta_{R}\right)=k_{R} \cdot \frac{\partial}{\partial t}\left(A_{R} \cdot\left(\vec{B}\left(\rho_{R}, K_{R}, \theta_{R}\right) \circ \vec{n}_{R}\right)\right\}
$$

Substitution of the scalar product of $\vec{B}$ and $\vec{n}_{R}$ into equation $\left(\mathrm{A} 3.1 .11\right.$ renders $\mathrm{V}_{\mathrm{RC}}$ as:

$$
\begin{aligned}
v_{R C}\left(\rho_{R}, k_{R}, \theta_{R}\right)=k_{R} \cdot \frac{\partial}{\partial t}\left\{A _ { R } \cdot \left(B_{1} \cdot \cos \left(n_{R}\right) \cdot \cos \left(\nu_{R}\right)+\right.\right. \\
\left.\left.+B_{3} \cdot \cos \left(n_{R}\right) \cdot \sin \left(v_{R}\right)\right)\right\}
\end{aligned}
$$

Substituting $B_{1}$ and $B_{3}$ into $(A 3.1 .2)$ gives

$$
\begin{aligned}
v_{R C}\left(\rho_{R}, k_{R}, \theta_{R}\right)=k_{R} * \frac{\partial}{\partial t}\left[\rho _ { R } ^ { - 3 } \cdot A _ { R } \cdot \operatorname { c o s } ( \eta _ { R } ) \cdot \left(2 \cdot \cos \left(\theta_{R}\right) \cdot \cos \left(v_{R}\right)+\right.\right. & + \\
& \left.\left.+\sin \left(\theta_{R}\right) \cdot \sin \left(\nu_{R}\right)\right) \cdot \exp \left(i \omega_{T} t\right)\right]
\end{aligned}
$$

Let us write equation $(A 3.1 .3)$ as

$$
v_{R C}\left(\rho_{R}, k_{R}, \theta_{R}\right)=k_{R} * \frac{\partial}{\partial t}\left\{A_{R} \cdot \rho_{R}^{-3} \cdot g\left(\theta_{R}, n_{R}, v_{R}\right) \cdot \exp \left(i \omega_{T} t\right)\right\}
$$

After performing the partial derivation in expression (A3.1.4), $\mathrm{V}_{\mathrm{RC}}$ is expressed as:

$$
\begin{aligned}
v_{R C}\left(\rho_{R}, k_{R}, \theta_{R}\right)= & k_{R} \cdot A_{R} \cdot \rho_{R}^{-3} \cdot g\left(\theta_{R}, n_{R}, v_{R}\right) \cdot \exp \left(i \omega_{T} t\right) . \\
& \cdot\left\{-\frac{3}{\rho_{R}} \cdot \frac{d \rho_{R}}{d t}+\frac{\frac{\partial g}{\partial t}}{g\left(\theta_{R}, \eta_{R} \cdot v_{R}\right)}+i \cdot \omega_{T}\right)
\end{aligned}
$$

Assuming $\left|\frac{-3}{\rho_{R}} \cdot \frac{d \rho_{R}}{d t}\right| \cdot\left|\frac{\partial g}{\partial t} \cdot\left(g\left(\theta_{R}, n_{R}, \nu_{R}\right)\right)^{-1}\right| \ll \omega_{T^{\prime}}$

equation (A3.1.5) is approximated by

$$
v_{R C}\left(\rho_{R}, k_{R}, \theta_{R}\right)=k_{R} \cdot A_{R} \cdot i \cdot w_{T} \cdot g\left(\theta_{R}, n_{R}, v_{R}\right) \cdot \exp \left(i \omega_{T} t\right) \cdot \rho_{R}^{-3}(A 3 \cdot 1.6 A)
$$


where,

$$
g\left(\theta_{R}, \eta_{\mathbb{R}^{\prime}}, v_{R}\right)=\cos \left(\eta_{R}\right) \cdot\left\{2 \cdot \cos \left(\theta_{R}\right) \cdot \cos \left(v_{R}\right)+\sin \left(\theta_{R}\right) \cdot \sin \left(v_{R}\right)\right\}
$$

The equations $(A 3.1 .6)$ can be written as

$$
v_{R C}\left(\rho_{R}, k_{R}, \theta_{R}\right)=i \cdot \hat{v}_{R C}\left(\rho_{R}, k_{R}, \theta_{R}\right) \cdot \exp \left(i_{\omega_{T}} t\right)
$$

where,

$$
\hat{v}_{R C}\left(\rho_{R}, k_{R}, \theta_{R}\right)=C_{1} \cdot \rho_{R}^{-3} \cdot g\left(\theta_{R}, \eta_{R}, \nu_{R}\right)
$$

Let us evaluate whether the approximation holds for the inductive technique as applied in the present work:

$$
\frac{\partial g}{\partial t} \cdot g\left(\theta_{R}, \eta_{R}, v_{R}\right)^{-1}=g_{1}\left(\theta_{R}, v_{R}\right)+g_{2}\left(\theta_{R}, v_{R}\right)+g_{3}\left(\eta_{R}\right)
$$

where,

$$
\begin{aligned}
& g_{I}\left(\theta_{R}, v_{R}\right)=\frac{-2 \cdot \tan \left(\theta_{R}\right)+\tan \left(v_{R}\right)}{2+\tan \left(\theta_{R}\right) \cdot \tan \left(v_{R}\right) \cdot \frac{d \theta_{R}}{d t}} \\
& g_{2}\left(\theta_{R} \cdot v_{R}\right)=\frac{-2 \cdot \tan \left(v_{R}\right)+\tan \left(\theta_{R}\right)}{2+\tan \left(\theta_{R}\right) \cdot \tan \left(v_{R}\right) \cdot \frac{d v_{R}}{d t}} \\
& g_{3}\left(n_{R}\right)=-\tan \left(\eta_{R}\right) \cdot \frac{d \eta_{R}}{d t}
\end{aligned}
$$

Let us assume that the following estimations

$$
\begin{gathered}
\rho_{R}=1.3 \times 10^{-2} \mathrm{~m}, \frac{d \rho_{R}}{d t}<1 \mathrm{~m} \cdot \mathrm{s}^{-1},\left|\theta_{R}\right|=\frac{\pi}{6},\left|v_{R}\right|=\frac{\pi}{12}, \\
\left|\eta_{R}\right|=0, \frac{d \theta_{R}}{d t} \frac{d v_{R}}{d t} \frac{d \eta_{R}}{d t}<30 \pi s^{-1}
\end{gathered}
$$

are representative for the state of strain in the aortic ring, 
than

$$
\begin{aligned}
& \left|-3 \cdot p_{R}^{-1} \cdot \frac{d \rho_{R}}{d t}\right|<400 \\
& \left|\frac{\partial g}{\partial t} \cdot g\left(\theta_{R} \cdot n_{R} \cdot v_{R}\right)^{-1}\right| \cong 12 \pi
\end{aligned}
$$

For the inductive technique $\omega_{T^{n}}>4.4 \times 10^{5}$, which justifies the approximation. 

A3.2. ANALYSIS OF THE ACCURACY OF THE STRAIN MEASUREMENT APPLYING THE INDUCTIVE TECHNIQUE

A mathematical procedure is presented through which the function f (section 3.1 ) can be evaluated when knowing position and orientation of the coils in the aortic ring. In the first place position and orientation of both a transmitter coil and a receiver coil are defined in the three-dimensional space with respect to a fixed coordinate system. Next, the terms in which $f$ is expressed (equation (3.6b)) are determined. Finally, the contribution of stochastic and non-stochastic small variations of position and orientation of both colls to the change of $f$ are mathematically expressed.

Let us make the following assumptions in order to define the positions and the orientations of the coils in the aortic ring:

- in a point $F$ in three-dimensional space a fixed cartesian coordinate system $\left(X_{F^{\prime}}, Y_{F}, Z_{F}\right)$ is defined with an orthonormal. vector base

$$
\vec{e}_{F}=\left[\begin{array}{lll}
\vec{e}_{F_{X}} & \vec{e}_{F_{Y}} & \vec{e}_{F_{Z}}
\end{array}\right]
$$

as shown in figure A3.2.1.

- cylindrical coordinates $(r, \alpha, z)$ are defined as

$$
\begin{aligned}
& X_{F}=r \cdot \cos (\alpha) \\
& { }_{F}=r \cdot \sin (\alpha) \\
& { }_{F}=z
\end{aligned}
$$

The positions of the transmitter coil and the receiver coil now can be defined. The transmitter coil is located in point $\mathrm{P}_{T}$ given by:

where

$$
\overrightarrow{\mathrm{P}}_{\mathrm{T}}=\underline{\mathrm{P}}_{\mathrm{T}}^{\mathrm{T}}, \mathrm{F} \cdot \overrightarrow{\vec{e}}_{\mathrm{F}}
$$

$$
\underline{P}_{T, F}^{T}=\left[P_{T, F} P_{T}, F_{Y} P_{T, F_{z}}\right]
$$




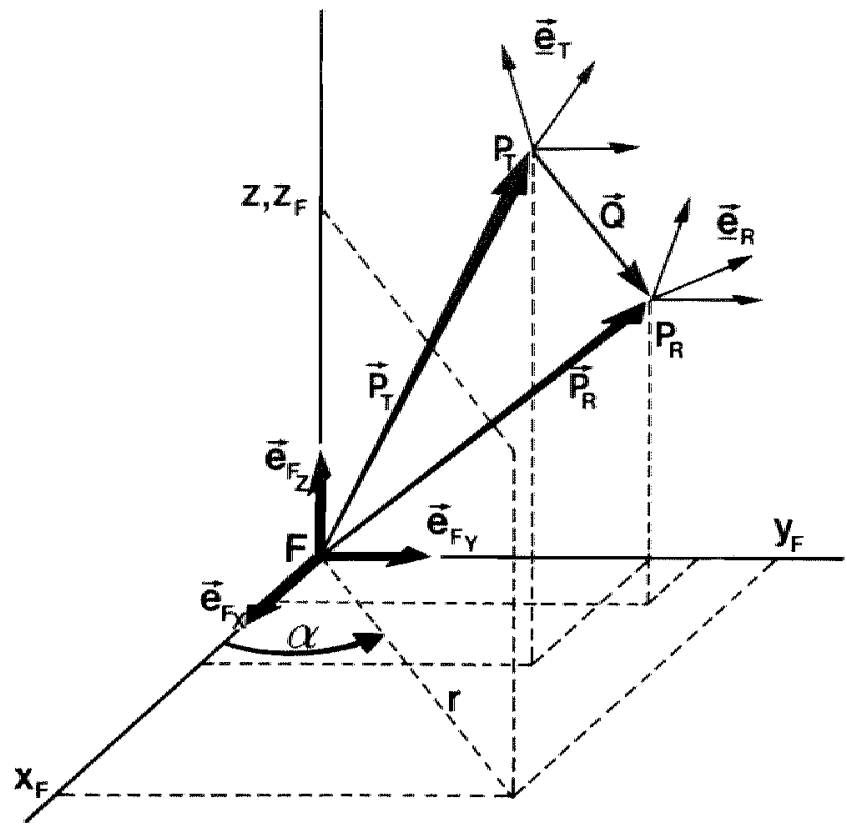

FIGURE A.3.2.1

schematic representation of position and orientation of a transmitter and a recelver coil in a fixed cartesian coordinate system $\vec{e}_{F_{X}}$, $\vec{e}_{F_{Y}}$ " $\vec{e}_{F_{Z}}$ with coordinates $X_{F}, Y_{F}$ and $z_{F}, r, a, z$ denote cylindrical coordinates; $F_{R}{ }^{\prime} \mathbb{P}_{T}$ is the location of the receiver and the transmitter coil respectively. $\vec{e}_{R}$ and $\vec{e}_{T}$ define the orlentation of the receiver and the transmitter coil respectively with respect to $\overrightarrow{\underline{e}}_{\vec{F}}$.

and

$$
\begin{aligned}
& \mathrm{P}_{\mathrm{T}, \mathrm{F}_{\mathrm{X}}}=\mathrm{r}_{\mathrm{T}} \cdot \cos \left(\alpha_{\mathrm{T}}\right) \\
& \mathrm{P}_{\mathrm{T}, \mathrm{F}_{Y}}=r_{\mathrm{T}} \cdot \sin \left(\alpha_{\mathrm{T}}\right) \\
& \mathrm{P}_{\mathrm{T}, \mathrm{F}_{\mathrm{Z}}}=\mathrm{Z}_{\mathrm{T}}
\end{aligned}
$$

The receiver coil is located in the point $P_{\mathbb{R}^{\prime}}$ given by:

where

$$
\overrightarrow{\mathrm{P}}_{\mathrm{R}}=\underline{\mathrm{P}}_{\mathrm{R}, \mathrm{F}}^{\mathrm{T}} \cdot \overrightarrow{\vec{e}}_{\mathrm{F}}
$$

$$
\text { and } \quad \underline{\mathrm{P}}_{\mathrm{R}, \mathrm{F}}^{\mathrm{T}}=\left[\mathrm{P}_{\mathrm{R}, \mathrm{F}} \mathrm{P}_{\mathrm{R}, \mathrm{F}} \mathrm{P}_{\mathrm{R}, \mathrm{F}}\right]
$$

$$
\begin{aligned}
& \mathrm{P}_{R_{1} F_{X}}=r_{R} \cdot \cos \left(\alpha_{R}\right) \\
& P_{R}=r_{R} \cdot \sin \left(\alpha_{R}\right) \\
& { }_{R_{Z}, F_{Z}}=z_{R}
\end{aligned}
$$


- in the point $P_{T}$ a local cartesian coordinate system $\left(X_{T}, Y_{T}\right.$ " $\mathrm{Z}_{T}$ ) is defined with an orthonormal vector base (figure $A 3.2 .2$ )

$$
\overrightarrow{\mathrm{e}}_{\mathrm{T}}^{\mathrm{T}}=\left[\begin{array}{lll}
\overrightarrow{\mathrm{e}}_{\mathrm{T}_{\mathrm{X}}} & \overrightarrow{\mathrm{e}}_{\mathrm{T}_{\mathrm{Y}}} & \overrightarrow{\mathrm{e}}_{\mathrm{T}_{\mathrm{z}}}
\end{array}\right]
$$

The unit vector of the coil is chosen in the $\vec{e}_{T_{Z}}$-direction (figure A3.2.2) as expressed by

$$
\overrightarrow{\mathrm{n}}_{\mathrm{T}}=\underline{\mathrm{n}}_{\mathrm{T}}^{\mathrm{T}}, \mathrm{T} \cdot \overrightarrow{\underline{e}}_{\mathrm{T}}
$$

where

$$
\underline{n}_{T}^{T}, T=\left[\begin{array}{lll}
0 & 0 & 1
\end{array}\right]
$$

FIGURE A3.2.2

Schematic representation of the mutual position and the mutual orientation of a transmitter coil $\mathrm{TC}$ and a receiver coll $\mathrm{RC} . \vec{e}_{\mathrm{T}_{\mathrm{T}}}, \vec{e}_{\mathrm{T}_{\mathrm{Y}}}, \vec{e}_{\mathrm{T}_{\mathrm{Z}}}$ define carteslan

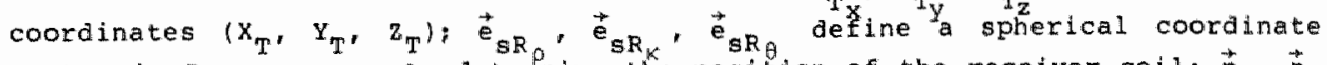
system in $P_{R}$, $\rho_{R^{\prime}},{ }^{k} R^{\prime}{ }_{R}$ determine the position of the receiver coil, $\vec{n}_{T}$ " $\vec{n}_{R}$ denote unit direction vector of transmitter and receiver coil respectively: $n_{R}$. $v_{R}$ are angles which define the orientation of the receiver coil; $\vec{n}_{R P}$ is the projection of $\vec{n}_{R}$ on the plane determined by $\vec{e}_{T_{z}}$ and the 1 ine $P_{T_{R}} P_{R} \vec{R}_{R}$ is the vector which defines the location of $P_{R}$ (unit vector $\vec{n}_{Q}$ ), $\vec{n}_{Q p}$ is the projection of $\overrightarrow{\mathrm{n}}_{\mathrm{Q}}$ on the plane determined by $\overrightarrow{\mathrm{e}}_{\mathrm{I}_{\mathrm{X}}}$ and $\overrightarrow{\mathrm{e}}_{\mathrm{T}_{\mathrm{Y}}}$.

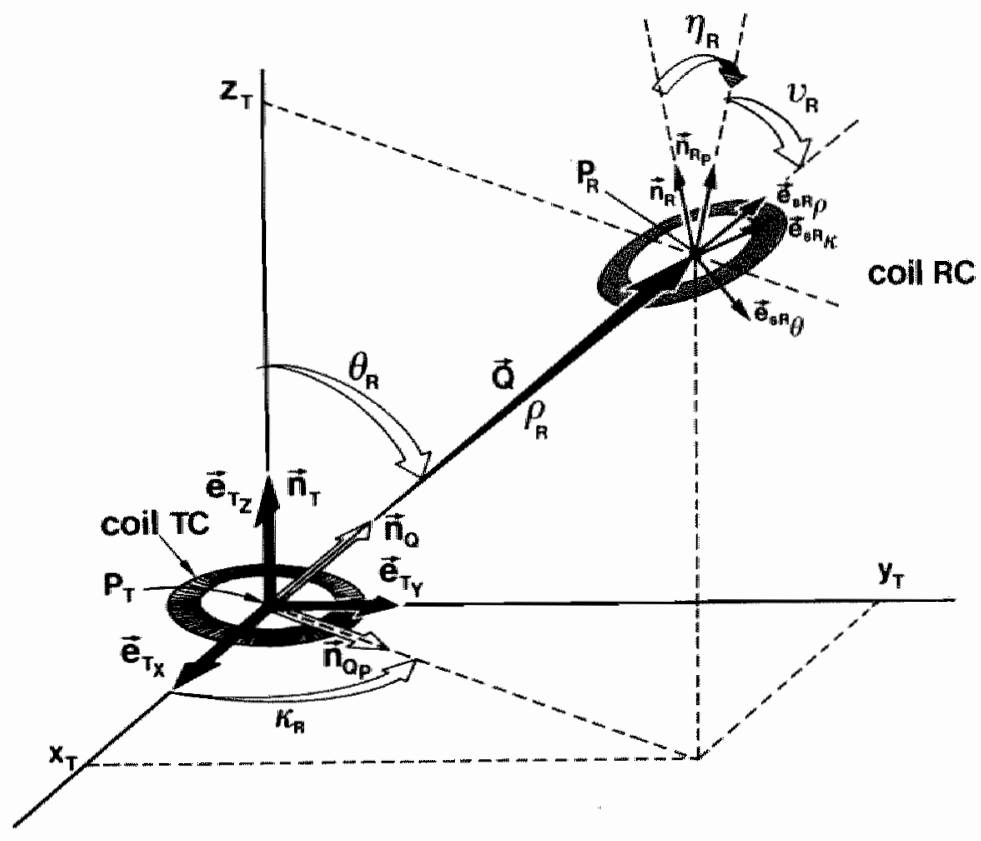


As it is assumed that the coll is rotational symmetric, the orientation of the coil relative to the $\vec{e}_{E}$-system is defined by two angles $\gamma_{T}$ and ${ }_{T}$. Hence two rotations are necessary in order to get the $\vec{e}_{F}-$ system orientated in space like the $\vec{e}_{\mathrm{T}}$ system. Starting from $\vec{e}_{F}$ the vector base $\vec{e}_{\mathrm{T}}$ is obtained by first rotating the vector base $\vec{e}_{F}$ over an angle $\gamma_{T}$ around $\vec{e}_{F}$ resulting in the vector base $\underline{E}_{A}$, as shown in figure A3.2.3. $\mathrm{a}$. The vector base $\vec{e}_{A}$ is expressed as

$$
\vec{e}_{A}=M_{A}, F \cdot \vec{e}_{F}
$$

where

$$
\underline{M}_{A, F}=\left(\begin{array}{ccc}
\cos \left(\phi_{T}\right) & \sin \left(\phi_{T}\right) & 0 \\
-\sin \left(\phi_{T}\right) & \cos \left(\phi_{T}\right) & 0 \\
0 & 0 & 1
\end{array}\right)
$$

FIGURE $\mathrm{A} 3.2 .3$

Schematic representation of the orientation of the $\vec{e}_{\mathbb{T}}$-system with respect to the $\vec{e}_{\mathrm{F}}$-system. The angles $\phi_{\mathrm{T}}$ and $\gamma_{\mathrm{T}}$ define the subsequent rotations of the $\vec{e}_{\mathrm{F}}$-system to obtain the $\overrightarrow{\underline{e}}_{\mathrm{T}}$-system.
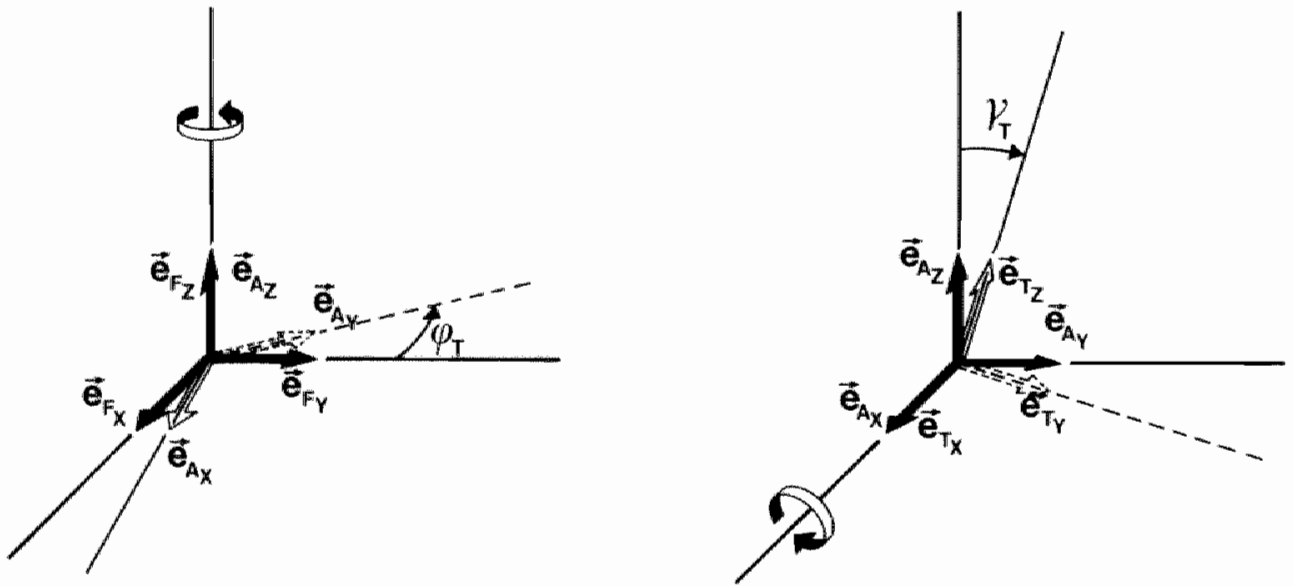

This rotation is followed by a rotation of the vector base $\vec{e}_{A}$ over an angle $\gamma_{T}$ around $\vec{e}_{A_{X}}$ resulting in the vector base $\vec{e}_{T}$ (figure $A 3.2 .3 \mathrm{~b}$ ). The vector base $\vec{e}_{T}$ is given by

$$
\vec{e}_{T}=\underline{M}_{T}, A \cdot \vec{e}_{A}
$$


where

$$
\underline{M}_{T, A}=\left(\begin{array}{ccc}
1 & 0 & 0 \\
0 & \cos \left(\gamma_{T}\right) & -\sin \left(\gamma_{T}\right) \\
0 & \sin \left(\gamma_{T}\right) & \cos \left(\gamma_{T}\right)
\end{array}\right)
$$

The vector base $\vec{e}_{T}$ is found by combining the equations (A3.2.7) and $($ A.3.2.9):

$$
\overrightarrow{\underline{e}}_{T}=\underline{M}_{T, A} \cdot \underline{M}_{A, F} \cdot \underline{\vec{e}}_{F}=\underline{M}_{T}, F \cdot \underline{\vec{e}}_{F}
$$

where

$$
\underline{M}_{T, F}=\left(\begin{array}{llc}
\cos \left(\phi_{T}\right) & \sin \left(\phi_{T}\right) & 0 \\
-\sin \left(\phi_{T}\right) \cdot \cos \left(\gamma_{T}\right) & \cos \left(\phi_{T}\right) \cdot \cos \left(\gamma_{T}\right) & -\sin \left(\gamma_{T}\right) \\
-\sin \left(\phi_{T}\right) \cdot \sin \left(\gamma_{T}\right) & \cos \left(\phi_{T}\right) \cdot \sin \left(\gamma_{T}\right) & \cos \left(\gamma_{T}\right)
\end{array}\right)
$$

In the same way a local orthonormal vector base $\overrightarrow{\vec{e}}_{R}$ is defined in point $P_{R}$ (figure $A 3.2 .1$ ) to describe the orientation of the receiver coil:

$$
\overrightarrow{\underline{e}}_{\mathrm{R}}=\underline{\mathrm{M}}_{\mathrm{R}}, \mathrm{F} \cdot \overrightarrow{\underline{\mathrm{e}}}_{\mathrm{F}}
$$

where

$$
\underline{M}_{R, F}=\left(\begin{array}{llc}
\cos \left(\phi_{R}\right) & \sin \left(\phi_{R}\right) & 0 \\
-\sin \left(\phi_{R}\right) \cdot \cos \left(\gamma_{R}\right) & \cos \left(\phi_{R}\right) \cdot \cos \left(\gamma_{R}\right) & -\sin \left(\gamma_{R}\right) \\
-\sin \left(\phi_{R}\right) \cdot \sin \left(\gamma_{R}\right) & \cos \left(\phi_{R}\right) \cdot \sin \left(\gamma_{R}\right) & \cos \left(\gamma_{R}\right)
\end{array}\right)
$$

and $\quad \vec{n}_{R}=\underline{n}_{R}^{T}, R \cdot \vec{e}_{R}$

with $\quad \underline{n}_{\mathrm{R}, \mathrm{R}}^{\mathrm{T}}=\left[\begin{array}{lll}0 & 0 & 1\end{array}\right]$

- spherical coordinates $(\rho, \kappa, \theta)$ are defined with respect to the point $P_{T}$ according to (figure $\mathrm{A} 3.2 .2$ )

$$
\begin{aligned}
& x_{T}=p \cdot \sin (\theta) \cdot \cos (k) \\
& Y_{T}=p \cdot \sin (\theta) \cdot \sin (k) \\
& z_{T}=p \cdot \cos (\theta)
\end{aligned}
$$


In a point with coordinates $\left(\mathrm{X}_{\mathrm{T}}, \mathrm{Y}_{\mathrm{T}}, \mathrm{Z}_{\mathrm{T}}\right)$ an orthonormal vector base is defined

$$
\underline{\vec{e}}_{S}^{T}=\left[\vec{e}_{S_{p}} \vec{e}_{S_{K}} \vec{e}_{S_{\theta}}\right]
$$

where $\overrightarrow{\underline{e}}_{\mathbf{S}}{ }^{\mathrm{T}}=\underline{M}_{\mathrm{S}}, \mathrm{T} \cdot \overrightarrow{\underline{e}}_{\mathrm{T}}$

and $\quad M_{S, T}=\left(\begin{array}{llc}\sin (\theta) \cdot \cos (k) & \sin (\theta) \cdot \sin (k) & \cos (\theta) \\ -\sin (k) & \cos (k) & 0 \\ \cos (\theta) \cdot \cos (k) & \cos (\theta) \cdot \sin (k) & -\sin (\theta)\end{array}\right)(A 3 \cdot 2 \cdot 19)$

The position of $P_{R}$ in spherical coordinates (figures A3.2.1, A3.2.2) now can be given by

$$
\vec{Q}_{R}=\underline{Q}_{R}^{T}, s \cdot \vec{e}_{T}
$$

where $\underline{Q}_{R, s}^{T}=\left[Q_{R, s_{X}} Q_{R, s_{Y}} Q_{R, s_{z}}\right]$

and

$$
\begin{aligned}
& Q_{R, s_{X}}=\rho_{R} \cdot \sin \left(\theta_{R}\right) \cdot \cos \left(k_{R}\right) \\
& Q_{R, s_{Y}}=\rho_{R} \cdot \sin \left(\theta_{R}\right) \cdot \sin \left(k_{R}\right) \\
& Q_{R, s_{z}}=\rho_{R} \cdot \cos \left(\theta_{R}\right)
\end{aligned}
$$

The spherical coordinate system in $P_{R}$ has an orientation which depends on the value of ${ }_{R}$ and ${ }^{K} R$. This coordinate system is denoted as

$$
\overrightarrow{\underline{e}}_{\mathrm{SR}}^{\mathrm{T}}=\left[\overrightarrow{\mathrm{e}}_{S R_{\rho}} \overrightarrow{\mathrm{e}}_{\mathrm{SR}_{K}} \overrightarrow{\mathrm{e}}_{\mathrm{SR}}\right]
$$

where $\overrightarrow{\underline{e}}_{S R}=\underline{M}_{S}, T_{R} \cdot \overrightarrow{\vec{e}}_{T}$

and $M_{S}, T_{R}$ is given by $(A 3.2 .19)$ with $\theta=\theta_{R}$ and $k=\kappa_{R}$.

With these assumptions the position and the orientation of both the transmitter and the receiver coil relative to the $\vec{e}_{F}$-system are defined. 
As described in section 3.1 , the function $f$ is

$$
\begin{aligned}
f=-\frac{1}{3} \cdot \ln \left[\cos \left(n_{R}\right) \cdot(\right. & 2 \cdot \cos \left(\theta_{R}\right) \cdot \cos \left(v_{R}\right)+ \\
& \left.\left.+\sin \left(\theta_{R}\right) \cdot \sin \left(v_{R}\right)\right]\right]
\end{aligned}
$$

which is a function of three variables. The angle ${ }_{R}$ has been defined earlier. The angle $\eta_{R}$ is the angle between the unit vector of the coil $\vec{n}_{R}$ and its projection on the plane defined by $\vec{e}_{s R_{0}}$ and $\vec{e}_{s R_{\theta}}$. The unit vector of this projection (figure A3.2.2) is expressed as

$$
\vec{n}_{R P}=\frac{\vec{n}_{R}-\left(\vec{n}_{R} \circ \vec{e}_{S R_{K}}\right) \cdot \vec{e}_{S R_{K}}}{\left\|\vec{n}_{R}-\left(\vec{n}_{R} \circ \vec{e}_{S R_{K}}\right) \cdot \vec{e}_{S R_{K}}\right\|}
$$

The angle $v_{R}$ is the angle between the projection vector $\vec{n}_{R p}$ and the vector $\vec{e}_{S R_{p}}$. This angle is taken positive if it is measured from $\vec{e}_{S R_{\rho}}$ towards $\vec{n}_{R p}$ in direction of $\vec{e}_{S R_{\theta}}$. In order to express the terms in the right part of equation $(3.6 \mathrm{~b})$ we define a unit vector $\overrightarrow{\mathrm{n}}_{Q}$ (figure $\mathrm{A} 3.2 .2$ ) as

$$
\overrightarrow{\mathrm{n}}_{\mathrm{Q}}=\frac{\overrightarrow{\mathrm{Q}}_{\mathrm{R}}}{\left\|\overrightarrow{\mathrm{Q}}_{\mathrm{R}}\right\|}=\frac{\overrightarrow{\mathrm{P}}_{\mathrm{R}}-\overrightarrow{\mathrm{P}}_{\mathrm{T}}}{\left\|\overrightarrow{\mathrm{P}}_{\mathrm{R}}-\overrightarrow{\mathrm{P}}_{\mathrm{T}}\right\|}
$$

By combining equations (A3.2.24a), (A3.2.4a), (A.3.2.3a) and (A3.2.11) this vector is found to be:

$$
\overrightarrow{\mathrm{n}}_{Q}=\frac{\left(\underline{\mathrm{P}}_{\mathrm{R}, \mathrm{F}}^{\mathrm{T}}-\underline{\mathrm{P}}_{\mathrm{T}, \mathrm{F}}^{\mathrm{T}}\right)}{\left\|\overrightarrow{\mathrm{P}}_{\mathrm{R}}-\overrightarrow{\mathrm{P}}_{\mathrm{T}}\right\|} \cdot \underline{M}_{\mathrm{T}}^{\mathrm{T}}, \mathrm{F} \cdot \overrightarrow{\mathrm{e}}_{\mathrm{T}}
$$

Next, the vector $\vec{n}_{R}$ is expressed relative to the vector base $\overrightarrow{\mathbf{e}}_{\mathbf{S R}}$ as 


$$
\vec{n}_{R}=\underline{n}_{R, s R}^{T} \cdot \overrightarrow{\underline{e}}_{S R}
$$

where $\quad \underline{n}_{R, s R}^{T}=\left[n_{R, s R} n_{R, s R} n_{R, s R_{\theta}}{ }^{\top}\right.$

The latter equation is obtained by combining equations $(A 3.2 .15 a),(A 3.2 .13),(A 3.2 .11)$ and $(A 3.2 .22)$

$$
\underline{\mathrm{n}}_{\mathrm{R}, \mathrm{sR}}^{\mathrm{T}}=\underline{\mathrm{n}}_{\mathrm{R}, \mathrm{R}}^{\mathrm{T}} \cdot \underline{\mathrm{M}}_{\mathrm{T}, \mathrm{F}}^{\mathrm{T}} \cdot \underline{\mathrm{M}}_{\mathrm{S}}, \mathrm{T}_{\mathrm{R}}
$$

The terms in equation (3.6b) now can be determined to be:

$$
\begin{aligned}
& \cos \left(\theta_{R}\right)=\vec{n}_{Q} \circ \vec{e}_{T_{Z}} \\
& \sin \left(\theta_{R}\right)=\left\|\vec{n}_{Q} * \vec{e}_{T_{z}}\right\| \\
& \cos \left(n_{R}\right)=\vec{n}_{R} \circ \vec{n}_{R p} \\
& \cos \left(\nu_{R}\right)=\vec{e}_{S_{R}} \circ \vec{n}_{R p} \\
& \sin \left(\nu_{R}\right)=\left\|\vec{e}_{s R_{\rho}} * \vec{n}_{R p}\right\| \cdot s_{\nu_{R}}
\end{aligned}
$$

where $\quad s_{v_{R}}=1$ if $n_{R_{r}, R_{\theta}} \geqq 0$

and

$$
s_{v_{R}}=-1 \text { if } n_{R_{r} s R_{\theta}}<0
$$

In order to determine the matrix $\underline{M}_{S,} T_{R}$ are furthermore needed:

$$
\begin{aligned}
& \cos \left(k_{R}\right)=\vec{e}_{T_{X}} \circ \vec{n}_{Q p} \\
& \sin \left(\kappa_{R}\right)=\left\|\vec{e}_{T_{X}} * \vec{n}_{Q P}\right\| \cdot s_{K_{R}}
\end{aligned}
$$

where $s_{K_{R}}=1$ if $\left(\vec{e}_{T_{Y}} \circ \vec{n}_{Q p}\right) \geq 0$

and

$$
s_{\kappa_{R}}=-1 \text { if }\left(\vec{e}_{T_{y}} \circ \vec{n}_{Q p}\right)<0
$$

and 


$$
\vec{n}_{Q}=\frac{\vec{n}_{Q}-\left(\vec{n}_{Q} \circ \vec{e}_{T_{Z}}\right) \cdot \vec{e}_{T_{Z}}}{\left\|\vec{n}_{Q}-\left(\vec{n}_{Q} \circ \vec{e}_{T_{Z}}\right) \cdot \vec{e}_{T_{Z}}\right\|}
$$

which is the unit vector of the projection of $\vec{n}_{Q p}$ on the plane determined by $\vec{e}_{T_{X}}$ and $\vec{e}_{T_{Y}}$ (figure $A 3.2 .2$ ).

Change_of both__coiㅣㅁㅗ

The function $f$ can be calculated for each position and orientation of both coils by combining of the equations (3.6b) and $(A 3.2 .2 B)$ up to $(A 3.2 .30)$ included. The dependency of $f$ on position and orientation of both the transmitter coil and the receiver coil is expressed as

$$
I=H\left(\theta_{R}, n_{R} \cdot v_{R}\right)
$$

where

$$
\begin{aligned}
& \theta_{R}=h_{1}\left(r_{T}, \alpha_{T}, r_{R}, \alpha_{R}, z_{R}-z_{T}, \gamma_{T}, \phi_{T}\right) \\
& { }_{R}=h_{2}\left(r_{T}, \alpha_{T}, r_{R}, \alpha_{R}, z_{R}-z_{T}, \gamma_{T}, \phi_{T}, \gamma_{R}, \phi_{R}\right) \\
& \nu_{R}=h_{3}\left(r_{T}, \alpha_{T}, r_{R}, \alpha_{R}, z_{R}-z_{T}, \gamma_{T}, \phi_{T}, \gamma_{R}, \phi_{R}\right)
\end{aligned}
$$

Let us investigate the influence of small variations of position and orientation of each coil. Two kinds of variations are being considered; i.e. non-stochastic and stochastic variations.

Non-stochastic variations:

It is assumed that small variations in position and orientation of each coil result in small changes $\Delta \theta_{R^{\prime}} \Delta \eta_{R}$ and $\Delta v_{R^{*}}$ In this case the change of $f$ can be written to be:

$$
\mathrm{f}+\Delta \mathrm{f}=\mathrm{H}\left(\theta_{\mathrm{R}}+\Delta \theta_{\mathrm{R}}, \eta_{\mathrm{R}}+\Delta \eta_{\mathrm{R}^{\prime}} \nu_{\mathrm{R}}+\Delta v_{\mathrm{R}}\right)
$$

By developing equation (A3.2.35) in a Taylor-series (Spiegel, 1968) and neglecting higher order derivatives the equation (A3.2.35) is rewritten as 


$$
E+\Delta f=H\left(\theta_{R} \cdot \eta_{R} \cdot v_{R}\right)+\Delta \theta_{R} \cdot\left(\frac{\partial H}{\partial \theta}\right)+\Delta v_{R} \cdot\left(\frac{\partial H}{\partial n_{R}}\right)+\Delta v_{R} \cdot\left(\frac{\partial H}{\partial v_{R}}\right)
$$

The partial derivatives in (A3.2.36) refer to the situation before change occurs. By combining equations $(\mathrm{A} 3.2 .36)$ and $(\mathrm{A} 3.2 .34 \mathrm{a}), \mathrm{I}$ is expressed as

$$
\Delta \mathrm{E}=\Delta \theta_{\mathbb{R}} \cdot\left(\frac{\partial H}{\partial \theta_{R}}\right)+\Delta n_{R} \cdot\left(\frac{\partial H}{\partial \eta_{R}}\right)+\Delta \nu_{R} \cdot\left(\frac{\partial H}{\partial \nu_{R}}\right)
$$

In an analogous way $\Delta \theta_{\mathbb{R}^{\prime}} \Delta \eta_{R^{\prime}} \quad \Delta v_{R}$ are expressed in terms of variation of position and orientation of each coil

$$
\begin{aligned}
& \Delta a_{R}=\Delta r_{T} \cdot\left(\frac{\partial h_{1}}{\partial r_{T}}\right)+\Delta \alpha_{T} \cdot\left(\frac{\partial h_{1}}{\partial \alpha_{T}}\right)+\cdots+\Delta \phi_{T} \cdot\left(\frac{\partial h_{1}}{\partial \phi_{T}}\right)(A 3.2 .37 b) \\
& \Delta n_{R}=\Delta r_{T^{*}} \cdot\left(\frac{\partial h_{2}}{\partial r_{T}}\right)+\ldots \ldots \ldots+\Delta \phi_{R} \cdot\left(\frac{\partial h_{2}}{\partial \phi_{R}}\right)(A 3.2 .37 \mathrm{C}) \\
& \Delta \nu_{R}=\Delta r_{T} \cdot\left(\frac{\partial h_{3}}{\partial r_{T}}\right)+\ldots \ldots \ldots \ldots+\Delta \phi_{R} \cdot\left(\frac{\partial h_{3}}{\partial \phi_{R}}\right) \text { (A3.2.37d) }
\end{aligned}
$$

By a numerical evaluation of the 28 partial derivatives in (A3.2.37) for a particular situation, the influence of changes in position and orientation of the two coils on the accuracy of the strain measurement can be investigated.

Stochastic variations:

It is assumed that position and orientation of each coil change due to independent stochastic variations of each variable in the equations (A3.2.34 B) up to (A3.2.34C) included. Each stochastic variation is supposed to obey a gaussian distribution. The mean of a stochastic variable $\stackrel{*}{v}$ is denoted as $\vec{v}$. The variance of $v^{*}$ is denominated $\operatorname{var}(\stackrel{*}{v})$. In a way similar to the one followed in analyzing non-stochastic variations, the stochastic variation in $\mathbb{f}$ is found to be:

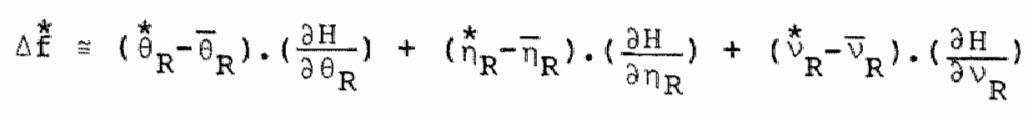


where $\quad \quad_{\mathrm{\theta}}^{*}-\bar{\theta}_{\mathrm{R}}=\left(\vec{r}_{\mathrm{T}}-\overline{\mathrm{r}}_{\mathrm{T}}\right) \cdot\left(\frac{\partial h_{1}}{\partial r_{\mathrm{T}}}\right)+\ldots+\left({ }_{\mathrm{T}}-\bar{\phi}_{\mathrm{T}}\right) \cdot\left(\frac{\partial h_{1}}{\partial \phi_{\mathrm{T}}}\right)$

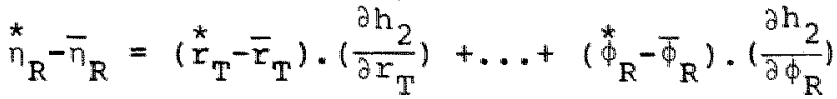

$$
{\stackrel{*}{v_{R}}}-\bar{v}_{\mathrm{R}}=\left(\stackrel{*}{r}_{\mathrm{T}}-\bar{r}_{\mathrm{T}}\right) \cdot\left(\frac{\partial h_{3}}{\partial r_{\mathrm{T}}}\right)+\ldots+\left(\stackrel{*}{\phi}_{\mathrm{R}}-\bar{\phi}_{\mathrm{R}}\right) \cdot\left(\frac{\partial h_{3}}{\partial \phi_{\mathrm{R}}}\right)
$$

The stochastic variation in $f$ follows a gaussian distribution, because of the linear nature of (A.3.37) and independency of variables. The variance of $\Delta t$ is expressed as

$$
\begin{aligned}
& \operatorname{var}(\Delta \stackrel{*}{\mathrm{f}})=\operatorname{var}\left(\stackrel{\theta}{\theta}_{R}\right) \cdot\left(\frac{\partial H}{\partial \theta_{R}}\right)^{2}+\operatorname{var}\left(\left(_{R}^{*}\right) \cdot\left(\frac{\partial H}{\partial \eta_{R}}\right)^{2}+\right.
\end{aligned}
$$

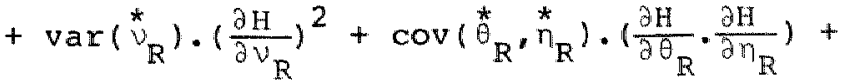

$$
\begin{aligned}
& +\operatorname{cov}\left(\stackrel{*}{\theta}_{R}, \stackrel{*}{v}_{R}\right) \cdot\left(\frac{\partial H}{\partial \theta_{R}} \cdot \frac{\partial H}{\partial v_{R}}\right)+\operatorname{cov}\left(\stackrel{*}{\eta}_{R} \cdot \stackrel{*}{v}_{R}^{*}\right) . \\
& \cdot\left(\frac{\partial H}{\partial \eta_{R}} \cdot \frac{\partial H}{\partial v_{R}}\right)
\end{aligned}
$$

where

$$
\begin{aligned}
& \operatorname{var}\left(\stackrel{\theta}{\theta}_{\mathrm{R}}\right)=\operatorname{var}\left({\stackrel{r_{T}}{\mathrm{~T}}}^{*} \cdot\left(\frac{\partial h_{1}}{\partial r_{T}}\right)^{2}+\ldots+\operatorname{var}\left(\stackrel{*}{\phi}_{\mathrm{T}}^{*}\right) \cdot\left(\frac{\partial h_{1}}{\partial \phi_{\mathrm{T}}}\right)^{2}(\mathrm{~A} 3.2 .39 \mathrm{~b})\right. \\
& \operatorname{var}\left({ }_{\mathrm{n}}^{*}\right)=\operatorname{var}\left({\stackrel{1}{r_{\mathrm{T}}}}^{*}\right) \cdot\left(\frac{\partial \mathrm{h}_{2}}{\partial \mathrm{r}_{\mathrm{T}}}\right)^{2}+\ldots \cdot
\end{aligned}
$$

$$
\operatorname{var}\left(\stackrel{*}{v}_{R}^{*}\right)=\operatorname{var}\left(\stackrel{*}{r}_{T}\right) \cdot\left(\frac{\partial h_{3}}{\partial r_{p}}\right)^{2}+\ldots \cdots
$$

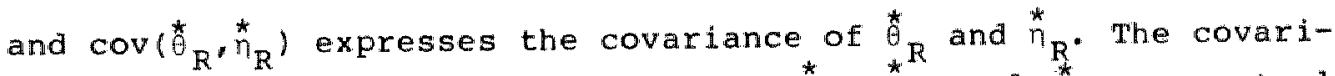
ances appear in the equation because ${ }_{\hat{\theta}_{R}}^{*}{ }^{*}{ }_{R}$ and ${ }^{*}{ }_{R}$ are mutual dependent due to equations $(3.2 .34)$ and the assumed independency between position and orientation of the coils. The inaccuracy of strain measurement due to stochastic behaviour of $f$ can be approximated, assuming a 958 reliability interval, by

$$
-2 \cdot \sqrt{\operatorname{var}(\Delta \stackrel{\star}{f})} \leq \operatorname{strain} \operatorname{error} \leqq 2 \cdot \sqrt{\operatorname{var}(\Delta \stackrel{\hbar}{f})}
$$

where $\operatorname{var}(\Delta \stackrel{ \pm}{ \pm})$ is determined by $(\mathrm{A} 3.2 .39)$. For numerical evaluation of the quantity $\operatorname{var}(\Delta \stackrel{*}{\mathrm{f}}), \operatorname{var}\left({\stackrel{*}{r_{T}}}^{*}\right)$ as well as all other vari- 
ables in the equations (A3.2.39b) - (A3.2.39d) are approximated by

$$
\operatorname{var}\left(\ddot{r}_{\mathrm{T}}\right)=1 / 4 . \max \text { imum deviation of } \Delta \mathrm{r}_{\mathrm{T}^{*}} \quad(\mathrm{~A} 3.2 .41)
$$


A5. 1. CALCULATION OF VOLUME V TAKING INTO ACCOUNT THE NON-CIRCULAR SHAPE OF THE VALVE CROSS-SECTION AT THE LEVEL OF THE COMMISSURES

Distant from the aortic valve, the aorta is assumed to be cylindrical. In a thin-walled cylindrical tube it holds

$$
\mathrm{T}_{\mathrm{c}}=2 \cdot \mathrm{T}_{\mathrm{a}}
$$

where $T_{C}$ and $T_{a}$ are the circumferential and the axial component of wall tension $\left(\mathrm{N} \cdot \mathrm{m}^{-1}\right)$, respectively. Equation $(\mathrm{A} 5.1 .1)$ is assumed to hold beyond the commissures $\left(z>h_{c}\right)$. As to the circumferential and axial radii of curvature, $\rho_{c}$ and $\rho_{a}$ " the following relation holds

$$
\frac{T_{c}}{\rho_{c}}+\frac{T_{a}}{2 \cdot \rho_{a}}-p_{a 0}=0
$$

The surface of the infinitely thin aortic wall is defined in cylindrical coordinates $(r, \alpha, z)$ by the function $R_{A}(\alpha, z)$. Its deviation from a cylinder with radius $R_{0}$ is controlled by a function $u(\alpha, z)$ and hence it holds:

$$
R_{A}(\alpha, z)=R_{O}\{1+u(\alpha, z)\}
$$

since only a first order approximation is calculated it is assumed that $|u| \ll 1$. In general, radius of curvature $\rho_{\alpha}$ of a surface described in polar coordinates $r(\alpha)$ is determined by

$$
\frac{1}{p_{\alpha}}=\frac{1}{r} \cdot\left(1-\frac{1}{r} \cdot \frac{d^{2} r}{d \alpha^{2}}\right) \cdot\left[1+\left(\frac{1}{r} \cdot \frac{d r}{d \alpha}\right)^{2}\right\}^{-3 / 2}
$$

Applying (A5.1.4) to equation (A5.1.3) it is found

$$
\frac{1}{\rho_{C}}=\frac{1}{R_{0}} \cdot \frac{\left(1+u+\frac{\partial^{2} u}{\partial \alpha^{2}}\right) \cdot(1+u)}{\left(1+2 u+u^{2}+\left(\frac{\partial u}{\partial \alpha}\right)^{2}\right)^{3 / 2}} \cong \frac{1}{R_{0}}\left(1-u-\frac{\partial^{2} u}{\partial \alpha^{2}}\right)
$$

In rectangular coordinates the radius of curvature $\rho_{z}$ of the sur- 
face $r(z)$ is determined by

$$
\frac{1}{P_{z}}=-\frac{d^{2} r}{d z^{2}}\left\{1+\left(\frac{d r}{d z}\right)^{2}\right\}^{-3 / 2}
$$

Applying equation (A5.1.6) to equation (A5.1.3) and neglecting terms of second order and higher it follows

$$
\frac{1}{\rho_{a}} \cong-R_{0} \cdot \frac{\partial^{2} u}{\partial z^{2}}
$$

Substituting equations $(A 5.1 .7)$ and $(A 5.1 .5)$ into equation (A5.1.2) renders:

$$
1-u-\frac{\partial^{2} u}{\partial \alpha^{2}}-\frac{\partial^{2} u}{\partial w^{2}}-\frac{P_{a o} \cdot R_{o}}{T_{C}} \approx 0
$$

where $\quad w=\left\{\left(z-h_{c}\right) / R_{o}\right\} \cdot \sqrt{2}$ where $z \geq h_{c}$

For large values of $w$, the function $u$ vanishes, hence

$$
\frac{P_{a o} \cdot R_{0}}{T_{C}} \cong 1
$$

Assuming that $\mathrm{T}_{\mathrm{C}}$ is approximately independent of place since $u$ is assumed to be small, equation (A.5.1.8) transforms into

$$
u+\frac{\partial^{2} u}{\partial \alpha^{2}}+\frac{\partial^{2} u}{\partial w^{2}} \cong 0
$$

The general solution of equation (A5.1.10) is

$$
u=\sum_{i=1}^{n} A_{1} \cdot \exp \left(a_{1} \cdot \alpha+b_{1} \cdot w\right)
$$

where $\quad 1+a_{i}^{2}+b_{i}^{2}=a$

For large values of $w$ all terms of $u$ vanish, so $\operatorname{Re}\left[b_{i}\right]=0$. Because of three-fold planar symmetry, $a_{i}$ is purely imaginary and the general solution of equation (A5.1.11) can be written more specific

$$
u=\sum_{m=1}^{n} B_{m} \cdot \cos (3 m a) \cdot \exp \left(-w \sqrt{9 m^{2}-1}\right)
$$


As the boundary condition at the commissure level is introduced:

$$
u(w=0, a)=\frac{u_{0}}{2}\left\{\frac{27}{2} \cdot\left(\alpha-\frac{\pi}{3}\right)^{2}-1\right)
$$

where $\quad 0 \leqq \alpha \leqq \frac{\pi}{3}$

u represents the normalized deviation of the commissure point with respect to the circle with radius $\mathbb{R}_{0^{*}}$ Through Fourier analysis of equation (A5.1.13) and applying equation (A5.1.12) for the coefficients $B_{m}$, it fallows

$$
\mathrm{B}_{\mathrm{m}}=\frac{6}{\pi^{2} \cdot \mathrm{m}^{2}} \cdot \mathrm{u}_{\mathrm{o}} \text { where } \mathrm{m}=1,2,3, \ldots \ldots
$$

The circumference CIRCA of the aorta at level $w$ is

$$
\operatorname{CIRCA}(w)=2 \pi R_{0}+R_{0} \cdot \int_{\alpha=0}^{2 \pi}\left[\left\{(1+u)^{2}+\left(\frac{\partial u}{\partial \alpha}\right)^{2}\right\}^{\frac{1}{2}}-1\right] d \alpha
$$

Assuming the circumference to be constant, in order to satisfy equation (A.5.1.13) the radius $R_{0}$ must decrease, and so does the cross-sectional area $A$ according to

$$
\Delta A \cong-A \cdot \frac{1}{\pi} \cdot \int_{\alpha=0}^{2 \pi}\left\{u+\frac{1}{2}\left(\frac{\partial u}{\partial \alpha}\right)^{2}\right\} d \alpha
$$

neglecting all terms over second order in $u$. Substituting equation (A5.1.12) and equation (A5.1.14) into equation (A5.1.16) and integrating over the axial coordinate $z=\frac{1}{2} w \cdot R_{0} \cdot \sqrt{2}+h_{c}$ the change $\Delta v_{3}$ of volume of the compartment is expressed by:

$$
\Delta v_{3} \equiv \frac{-81 \sqrt{2}}{\pi^{3}} \cdot \sum_{m=1}^{\infty} \frac{1}{m^{2} \sqrt{9 m^{2}-1}} \cdot R_{0}^{3} \cdot u_{a}^{2}
$$

Applying equation (A5.1.16) to the plane w = o (equation A5.1.14) for $A_{1}\left(h_{c}\right)$ it holds

$$
\Delta A_{1}\left(h_{c}\right)=-\frac{27}{\pi} \cdot u_{0}^{2} \cdot R_{0}^{2}
$$

Substituting equation (A5.1.18) into (A5.1.17) it follows 


$$
\begin{aligned}
\Delta V_{3} & =R_{0} \cdot \Delta A_{1}\left(h_{c}\right) \cdot \frac{3 \sqrt{2}}{\pi} \cdot \sum_{m=1}^{\infty}\left[m^{2} \sqrt{9 m^{2}-1}\right]^{-1} \equiv \\
& \cong R_{0} \cdot \Delta A_{1}\left(h_{c}\right) \cdot(0.1812)
\end{aligned}
$$

By substituting

$$
\Delta A_{1}\left(h_{c}\right)=\left[[\operatorname{CIRCM}(1)]^{2} / 4 \pi-A_{1}\left(h_{C}\right)\right]
$$

and

$$
R_{0}=\{\operatorname{CIRCM}(1) / 2 \pi\}
$$

into equation (A5.1.1.9), the expression (5.31) is found. 
A5.2. ANALYSIS OF THE FORCES EXERTED BY THE LEAFLET UPON ITS COMMISSURE POINTS

The leaflet is considered to be a part of the surface of a rotational symmetric body resembling a prolate ellipsoid. The surface of the body is an infinitely thin membrane. The axis of rotational symmetry is the line of connection of the commissure points by which the leaflet is suspended (figure A5.2.1). In a plane through this axis, the radius of curvature $\rho_{e}$ of the cross-section of the surface of the body is given by

$$
\rho_{e}(z)=-\left\{\frac{d^{2} r}{d z^{2}}\right\}^{-1} \cdot\left\{1+\left(\frac{d r}{d z}\right)^{2}\right\}^{3 / 2}
$$

where $r$ is the radial coordinate and $z$ is the axial coordinate of the cylindrical coordinate system defined in figure A5.2.1. The

FIGURE A.5.2.1

Schematic representation of a surface of a body which is rotational symmetric around the axis through the commissure points. The leaflet is assumed to be part of the surface of the body. $(r, \phi, z)$ cylindrical coordinates; $p_{e}=$ radius of curvature, $\mathrm{T}_{\mathrm{e}}=$ membrane tension $\left(\mathrm{N} \cdot \mathrm{m}^{-1}\right)$ along a cross-section of the surface of the body in a plane through the axis of symmetry; $\vec{e}_{r}=$ radial direction; $\vec{e}_{z}=$ axial direction.

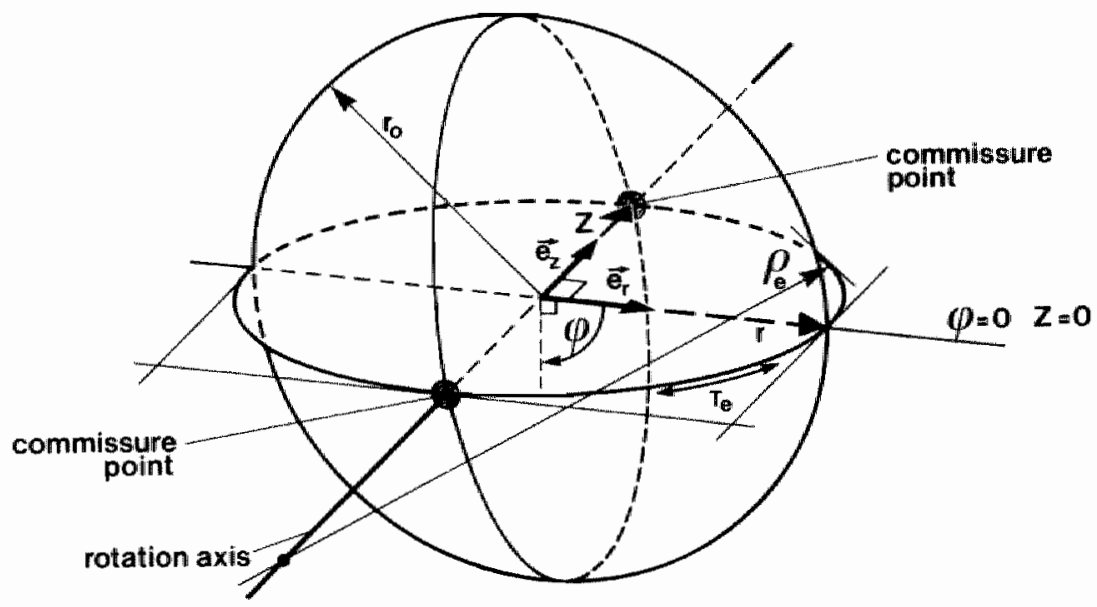


axis of rotational symmetry coincides with the z-coordinate. It is assumed, that the membrane tension $\left(\mathrm{Nm}^{-1}\right)$ along a circular cross-section of the body in a plane perpendicular to the axis of rotation equals zero. The membrane tension $\mathrm{T}_{e}$ along the crosssection of the body in a plane through the axis of rotation, is expressed as

$$
T_{e}(z)=p \cdot p_{e}(z)
$$

where $\mathrm{p}$ represents the internal pressure of the body surface with respect to the pressure outside of the body surface. The surface tension $T_{e}$ can also be expressed as

$$
T_{e}(z)=F / 2 \pi r
$$

where $F$ represents the total tensile force in the equatorial cross-section of the body surface. This tensile force $F$ equals the force exerted by the internal pressure upon the equatorial cross-sectional area. Thus it holds

$$
F=p \cdot \pi \cdot r_{0}^{2}
$$

where $r_{0}$ is the equatorial value of $r$ for $z=0$. Combining equations (A5.2.1) up to $(A 5.2 .3)$ included, it is found

$$
\frac{d^{2} r}{d z^{2}}=-\frac{p \cdot 2 \pi r}{F}\left\{1+\left(\frac{d r}{d z}\right)^{2}\right\}^{3 / 2}
$$

This second-order differential equation can be split into a set of two first order differential equations by defining $Q=d r / d z$, $\mathrm{z}=\mathrm{z} / \mathrm{r}_{\mathrm{o}}$ and $\mathrm{R}=\mathrm{r} / \mathrm{r}_{0}$ and using equation (A5.2.4):

$$
\begin{aligned}
& \frac{d Q}{d Z}=-2 \cdot R \cdot\left\{1+Q^{2}\right\}^{3 / 2} \\
& \frac{d R}{d Z}=Q
\end{aligned}
$$

The set of differential equations (A5.2.6) were solved numerical- 
Iy to satisfy the boundary condition

$$
\text { for } \begin{aligned}
z=0: Q=0 & \left(\frac{d r}{d z}=0\right) \\
R=1 & \left(r=r_{0}\right)
\end{aligned}
$$

Then the tangent of the body surface at the poles $(\mathbb{R}=0)$ existed and was equal to zero. From the solution it was found that ratio of distance between the commissure points and the radius $r_{0}$ equals 1.20 . In figure 5.3 , the radius $r_{0}$ corresponds to the line of connection of the point $S$ and the point $E$ on the base circle where $\alpha=0$. The ratio of the distance between the commissure points and the length of the line of connection of the points $E$ and $S$, was derived from data presented by Swanson and clark (1974) and Thubrikar and associates (1981). From data presented by Swanson and clark (1974; see section 5.4, table 5.1, cases 1 to 4 ) a ratio $1.28 \pm 0.21$ (mean \pm standard deviation; $n=4$ ) was derived, whereas from data presented by Thubrikar and co-investigators (1981; see section 5.4, table 5.1, case 5) a ratio 1.10 was derived. These ratios $(1.28$ and 1.10$)$ deviate less than 78 of the ratio found in the present analysis (1.20). Thus, membrane tension $\left(\mathrm{N} \cdot \mathrm{m}^{-1}\right)$ which a leaflet exerts upon a commissure point is assumed to be radially directed from the poles of the body surface (radial direction defined in figure A5.2.1). Thus, force exerted by a leaflet upon the commissure points was assumed to be directed perpendicular to the line of connection of the commissure points. 

A5.3. CALCULATION $O F$ dV $1 / d R_{c}$ AND $d V_{2} / d R_{c}:$ DETERMINATION OF sURFACE AREAS $A_{1}$ AND $A_{2}$

Let us consider a cross-section of the valve in a plane $z=$ constant perpendicular to the valve axis where $0<\mathrm{z}<$ commissure height $h_{c}$ (figures 5.1 and $A 5.3 .1$ ). The cross-sectional areas $A_{1}$ and $A_{2}$ are expressed as

$$
\begin{aligned}
& A_{1}=6 \cdot A_{11} \\
& A_{2}=6 \cdot A_{21}
\end{aligned}
$$

where $A_{11}=$ half the surface area of the sinus of Valsalva section $(\lambda<\alpha<\pi / 3)$

$A_{21}=$ half the surface area of the interleaflet trigone section $(0<\alpha<\lambda)$

$\lambda=$ value of $\alpha$ where the sinus of valsalva adjoins the interleaflet trigone.

FIGURE A5.3.1

Schematic representation of a cross-section of the aortic valve in a plane perpendicular to the valve axis. Half the surface areas of a sinus ( $A_{11}$ ) and an interleaflet $\left(A_{21}\right)$ section are denoted. $A_{11, a}, A_{11, b}=$ sub surface areas of $A_{11} ; \lambda=$ value of where sinus of valsalva adjoins interleaflet trigone; $B=$ angle of the circle segment corresponding to half the sinus section; $\gamma=$ angle of the circle segment corresponding to half the interleaflet section: $R_{i}, \mathbb{R}_{S}=$ radii of curvature of interleaflet and sinus section: $R_{\text {TRC }}=$ radius of truncated cone.

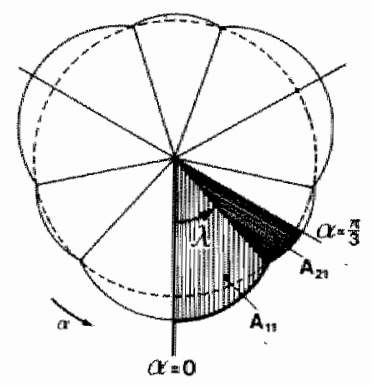

a

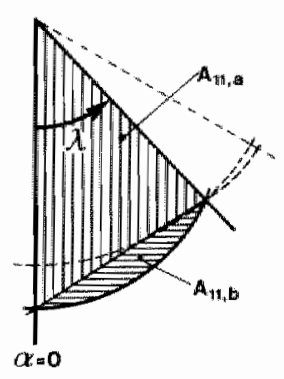

b

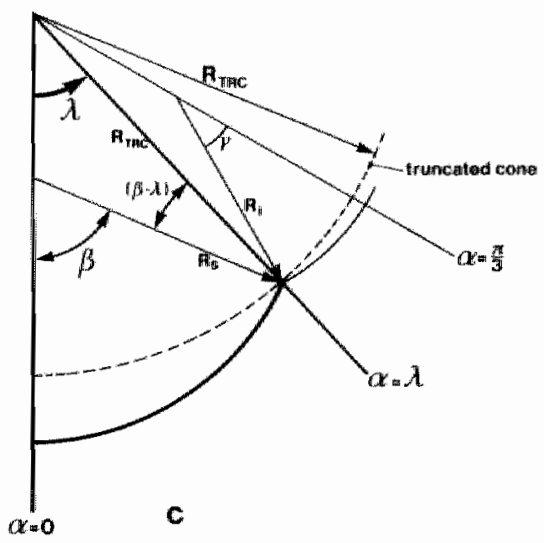


The surface area $A_{11}$ is written as the sum of two areas

$$
A_{11}=A_{11, a}+A_{11, b}
$$

$A_{11, a}$ and $A_{11, b}$ being defined in figure A5.3.1b. The surface area $A_{11}$, a can be expressed as (figure A5.3.1C)

$$
A_{11, a}=R_{T R C}\left(z_{n}\right) \cdot R_{s}\left(z_{n}\right) \cdot \sin (\beta / 2) \cdot \sin (\pi / 2-\lambda+\beta / 2)
$$

where $z_{n} \quad=$ axial coordinate normalized to commissure height $h_{c}$

$R_{T R C}\left(z_{n}\right)=$ radius of the truncated cone according to equation $(5.26)$

$\mathbb{R}_{S}\left(z_{n}\right)=$ radius of curvature of the sinus section (fig. A5.3.1c)

B = angle of the circle segment corresponding to half the sinus section (figure A5.3.1C).

The area $A_{11, b}$, which corresponds to the circle sector in figure A5.3.1b, can be expressed as

$$
A_{11, b}=\left\{R_{g}\left(z_{n}\right)\right\}^{2} \cdot\{\beta / 2-\sin (\beta / 2) \cdot \cos (\beta / 2)\}
$$

After substituting the equations (A5.3.3) and (A5.3.4) into (A5.3.2) the surface area $A_{11}$ is abtained. Combining the equations (A5.3.1a) and (A5.3.2), and using the equation

$$
\operatorname{CIRCS}\left(z_{n}\right) / 6=R_{s}\left(z_{n}\right) \cdot \beta
$$

where $z_{n}=z / h_{c}$, for the surface area $A_{1}$ equation (5.24) is found.

Analogously for the surface area $\mathbb{A}_{2}$ equation $(5.25)$ is found where $Y$ is the angle of the circle segment corresponding to half the interleaflet section (figure A5.3.1C).

The angle $\lambda$ in the equations (5.25) and (5.24) was found by equalizing the circumferential component of wall tension $\left(\mathrm{N} \cdot \mathrm{m}^{-1}\right.$ ) of the interleaflet section $\left(\mathrm{T}_{i}\right)$ to that of the sinus section 
(' $\left.T_{S}\right)$ at the junction of both sections on the truncated cone. Then, it follows

$$
\mathrm{T}_{\mathrm{S}} \cdot \cos (\beta-\lambda)=\mathrm{T}_{\mathrm{i}} \cdot \cos (\gamma-\pi / 3+\lambda)
$$

Using the equation $(5.7),(5.8),(5.18),($ A5.3.5) and the equation

$$
\operatorname{CIRCI}\left(z_{n}\right) / 6=R_{i}\left(z_{n}\right) \cdot \gamma
$$

where $z_{n}=z / h_{C^{\prime}}$ expression $(A 5.3 .6)$ can be rewritten to equation (5.27).

From figure A5.3. Ic it can be seen that

$$
R_{\operatorname{TRC}}\left(z_{n}\right) \cdot \sin (\lambda)=R_{s}\left(z_{n}\right) \cdot \sin (B)
$$

This equation can be rewritten by using equation (A5.3.5) to equation $(5.28)$.

Analogously the equation (5.29) was derived. 



\section{REFERENCES}

AKGUN, G., Layton, C.: Aortic root and left atrial wall motion. An echocardiographic study.

Br. Heart J. 39: 1082-1087, 1977.

AMBRoSE, J.A., Martinez, E.E., Meller, J., Gorlin, R., Pichard, A.D., Herman, M.V., Techholz, L.E.: Hemodynamic correlates of late diastolic posterior motion of the aortic root.

Am. Heart J. 100: 433-440, 1980 .

ARNDT, J.O., Stegall, H.F., Wicke, H.J.: Mechanics of the aorta in vivo. A radiographic approach.

Circ. Res. 28: $693-704,1971$.

ARTS, M.G.J.: A mathematical model of the dynamics of the left ventricle and the coronary circulation.

Thesis, University of Limburg, Maastricht, The Netherlands, 1978.

ARTS, M.G.J., Reneman, R.S.: Measurement of deformation of canine epicardium in vivo duxing cardiac cycle.

Am. J. Physiol. 239: H432-H437, 1980.

BELLHOUSE, B.J., Talbot, L.: The fluid mechantes of the aortic valve.

J. Fluid Mech. 35: 721-735, 1969 .

BRACENELL, R.M.: The Fourier txansform and its applications.

Tokyo, McGraw-Hill, Rogakusha, 1978.

BOUCEK, R.J., Takashita, R., Fojaco, R.: Functional anatomy of the ascending aorta and the coronary ostia (dog).

Am. J. Anat. 114:273-282, 1964 .

BREWER, R.J*, Mentzer, R.M., Deck, J.D., Ritter, R.C., Tref11, J.5., Molan, S.P.: An in vivo study of the dimensional changes of the aortic valve leaflets auring the cardimc cycle.

J. Thor. Cardiov. Surg. 74: 645-650, 1977 .

BROOKS, D.H., Whiteford, J., Berk, A.D., Bahnson, H.T.: Cinematographic studies of the interior of the actively contracting heart.

Ann. of Surg. $167: 786-790,1968$.

CARO, C.G., Pealey, T.J., schroter, R.C., Seed, W.A.: The mechanics of the circulation.

Oxford, Oxford University Press, 1978.

CLARK, R.E." Finke, E.H.: Scanning and light microscopy of human aortic leaflets in stressed and relaxed atates.

J. Thor. Cardlov. Surg. 67: 792-804, 1974.

DAVIS, P.K.B., Kinmonth, J.B.: The movements of the annulus of the mitral walve.

J. Cardilov. Surg. 4: 427-431, 1963. 
DEE, P., Crosby, I.: Fibreoptic studies of the aortic valve in dogs. Br. Heart J. 39:459-461, 1977 .

ELLIOTT, R.S.: Electromagnetica.

New York, McGraw-Hill Inc., 1966.

EENTON, T.R., Cherry, J.M., Klassen, G.A.: Transmural myocardial deformation in the left ventricular wall.

Aum. J. Physiol. 235: H523-H530, 1978.

GAMBLE, W.J." Innis, R.E.: Expeximental intracardiac visualisation. New England J. Med. 276: 1397-1403, 1967.

GREEN, S.E., POPP, R.I.: The relationship of pulmonary walve motion to the motion of surrounding cardiac structures: a two-dimensional and dual M-mode echocardiographic study.

Circ. 64: $107-112,1981$.

GROSS, L., Kugel, M.A.: Topographic anatomy and histology of the valves in the human heart.

Am. J. Path. 7: 445-470, 1931.

GUYTON, A.C.: Textbook of medical physiology. Philadelphia, W.B. Saunders Company, 1976.

HECKMAN, J.L., Ascanio, G.: A cine fluoroscope recording of aortic valve motion.

Fed. Proc. 31: 817, 1972a.

HECKMAN, J.L., Lynch, P.R., stewart, G.H.: The movement of the aortic valve.

Physiologist $15: 162,1972 \mathrm{~b}$.

HIDER, F., Taylor, D.E.M., Wade, J.D.: Action of the mitral and aortic valves in vivo studied by endoscopic cine photography.

Quart. J. Exper. Physio1. 51: 372-379, 1966.

HINDS, J.E., Hawthorne, E.W., Mullins, C.B., Mitchel1, J.H.: Instantaneous changes in the left ventricular lengths occuring in dogs during the cardiac cycle.

Fed. Proc. 28, 1351-1357, 1969.

INGELS, N.B., Mead, C., Daughters II, G.T., Stinson, E.B., Alderman, E.L.: Dynamics of the left ventricular centre of mass in intact unanaesthetized man in the presence and absence of wall motion abnormalities. In: Cardiac Dynamics, J. Baan, A.C. Arntzenlus, E.L. Yellin (eds.), The Hague, Martinus Nijhoff Publishers B.V., 1980.

LYONS, M.F.: U1trastructural organisation in the aortic valve of the dog. Anat. Res. 184: $467,1976$.

MARSBOOM, R.A., Verstraete, D., Thienpont, D., Mattheeuws, D.: The use of halo-anisone and fentanyl for neuroleptanalgesia in dogs.

Br. Vet. J. 120: 466-468, 1964 . 
MCALPINE, W.A.: Heart and coronary arteries. Berlin, Springer Verlag, 1975.

MERCER, J.L.: Movement of the aortic annulus. Br. J. Radiol. 42: 623-626, 1969.

MERCER, J.L.: The movement of the dogs aortic valve studied by high speed cine-anglography.

Br. J. Radiol. 46: $344-349,1973$.

OLSON, C.O., Van Tright, F., Rankin, J.S.: Dynamic geometry of the intact left ventricle.

Fed. Proc. 40: 2023-2030, 1981 .

ORMISTON, J.A., Pravin, Ch.B., Shan, M., Tei, C., Wong, M.: size and motion of the mitral valve annulus in man. I. A two-dimensional echocardiographic method and findings in normal subjects.

Circ. 64: $113-120$, 1981 .

PADULA, R.T." Cowan Jr., G.S.M., Camishion, Ch.B. and R.C.: Photographic analysis of the active and passive components of cardiac valvular action.

J. Thor. Cardiov. Surg. 56: 790-798, 1968 .

PRATT, R.C., Parisi, A.F., Harrington, J.J., Sasahara, A.A.: The influence of left ventricular stroke volume on aortic root motion. An echocardiographic study.

Circ. 53: 947-953, 1976 .

REID, K.: The anatomy of the sinus of Valsalva.

Thorax 25: 79-85, 1970 .

REMINGTON, J.W.: Propagation velocity of transient aortic pulses.

Am. J. Physiol. 212: 612-618, 1967.

RENMERGHEM van, R.J., Steenhoven van, A.A., Beneken, J.E.W.: The presaurevolume relationship of the aortic valve in terms of compliance.

Biomedizinische Technik 24: 281-2B1, 1979 .

RENTERGHEM van, R.J., Arts, M.G.J., Steenhoven van, A.A., Reneman, R.S.: A technique for measuring deformation of the aortic valve ring during the cardiac cycle.

The Physiologist 24: 112, 1981.

RENTERGHEM van, R.J., Steenhoven van, A.A., Dongen van, M.E.H.: A modelstudy on the relation between aortic volume flow and the rise in aortic pressure just after valve closrue.

Blomedizinische Technik 7: 57-60, 1982 .

ROUSSEAU, E.P.M., Sauren, A.A.H.J., Hout van, M.C., Steenhoven van, A.A.,: Elastic and viscoelastic material behaviour of fresh and gluteraldehyde-treated porcine aortic valve tissue.

J. Blomech.: 1983, in press. 
RUSHME, R.F., Franklin, D.L., Ellis, R.M.: Left ventricular dimensions recorded by sonocardionetry.

Circ. Res. 4* 684-688, 1956.

RUSHMER, R.F., Finlayson, B.I., Mash, A.A.: Movements of the mitral valve. Circ. Res. 4: $337-342,1956$.

SABBAH, H.W., SteĹn, P.D.: Pressure-diameter relations during early diastole in dogs. Incompatibility with the concept of passive left ventricular filling.

Circ. Res. 45: $357-365,1981$.

SANDS, M.P., Rittenhouse, E.A., Mohri, H., Merendino, K.A.: An anatomical comparison of human, pig, calf, and sheep aortic valves.

Ann. Thor. Surg* 8: 407-414, 1969.

SAUREN, A.A.E.J., KuYpers, W., Steenhoven van, A.A., Veldpaus, F.E.: Aortic valve histology and its relation with mechanics; preliminaxy report. J. Blomech. 13: 97-104, 1980 .

SAUREN, A.A.H.J.: The mechanical behaviour of the aortic valve. Thesis, Einahoven University of Technolagy, Eindhoven, The Netherlands, 1981.

SAUREN, A.A.H.J.. Rousseau, E.P.M.: A concise sensitivity analysis of the quasilinear viscoelastic model proposed by Fung.

J. Biomech.: 1983, in press.

SAUREN, A.A.H.J., Hout van, M.C., Steenhoven van, A.A., Veldpaus, F.E., Janssen, J.D.: The mechanical properties of porcine aortic valve tissues.

J. Biomech.: 1983, in press.

SEIDEL, W*, Ritz, a., Messerer, G.: Einfache Methoden zum Studium der Klappen am Schlagenden Herzen.

Langenbecks Axch. Klin. Chir. 314: 15-24, 1966.

SPIEGEL, M.R.: Advanced mathematics; Schaum's outline series. New York, MCGraw Hill Book Company, 1971.

STEENHOVEN van, A.A., Dongen van, M.E.H.: Model studies of the closing behaviour of the aortlo valve.

J. Fluid Mech. 90: 21-32, 1979a.

STEENHOVEN $\operatorname{van}$, A.A.: The closing behaviour of the aortic valve.

Theisis, Eindhoven Unlversity of Technology, Eindhoven, The Netherlands, $1979 \mathrm{~b}$.

STEENHOVEN van, A.A., Verlaan C.W.J., Veenstra, P.C., Reneman, R.S.: An in vivo cinematographic analysis of the behaviour of the aortic valve. Am. J. Physiol. 240: H286-H292, 1981.

STEENHOVEN van, A.A., Duppen van, Th.J.A.G., Cauwenberg, J.W.G., Renterghem van, R.J.: In-vitro closing behaviour of Björk-Shilley, st. Jude and Hancock heart valve prostheses in relation to the in-vivo recorded aortic valve closure. J. Biomech., in press, $1982 a$. 
STEENHOVEN van, A.A., Veenstra P.C." Reneman, R.S.: The effect of some hemodynamic factors on the behaviour of the aortic valve.

J. Biomech., in press, 1982b.

STEGALL, H.F.: Ultrasonic measurement of organ dimensions .

In: Cardiovascular applications of ultrasound, R.S. Reneman.

Amsterdam, North-Holland Publishing Company, 1974.

SWANSOM, W.M., Clark R.E.: Dimensions and geometric relationships of the human aortic valve as a function of pressure.

Circ. Res. 35: 871-882, 1974 .

THUBRIKAR, M., Harry, R*, Nolan, S.P.: Normal aortic valve function $\mathbb{A n}$ dogs.

Am. J. Card. $40: 563-568,1977 \mathrm{a}$ *

THUBRIKA.R, M*, Deck, J.D., Harry, R.R., Wolan, S.P.: Expansible nature of the base of the normal aortic valve.

Proc. on the $30 \mathrm{ACEMB}$, Los Angelos, California, $1977 \mathrm{~b}$.

THUBRIKAR, M., Nolan, S.P., Bosher, L.P., Deck, J.D.: The cycllc changes and structure of the base of the aortic valve.

Am. Heart J. 99: 217-224, 198:0.

THUBRIKAR, M., Piepgrass, W.C., Shaner, T.W., Nolan, S.P.: The design of the normal aortic valve.

Am. J. Physiol. 241: H795-H801, 1981.

TRIGHT III var, P., Bauer, B.J., Olson, C.O., Rankin, J.s., wechsler, A.S.: An improved transducer for measurement of cardiac dimensions with sonomicrometry.

Am. J. Physiol. 240: H664-H668, 1981.

TSAKIRIS, A.G., Bernuth von, G., Rastelli, G.C., Bourgeols, M.J., Titus, J.L." wood, E.H.: Size and motion of the mitral valve annulus in anesthetized intact dogs.

J. Appl. Phys. 30: 611-618, 1971 .

TEAKIRIS, A.G., Mair, D.D., Seki, S., Titus, J.C., Wood, E.H." Motion of the tricuspid valve annulus in anesthetized intact dogs.

Circ. Res. 36: $43-48,1975$.

TSIOULIAS, T.: Calibre variations in the left ventricular outflow tract. Acta Radiol. Diagn. 3: 209-217, 1965.

ZIMMERMAN, J.: The functional and surgical anatomy of the aortic valve. Am. J. Med. Sciences 5 : 862-866, 1969. 

Het onderzoek dat in dit proefschrift beschreven staat, is uitgevoerd in het kader van het samenwerkingsproject hartklepprothesen tussen de Rijksuniversiteit Limburg (RUL) en de Technische Hogeschool Eindhoven (THE). De Rijksuniversiteit Limburg was in dit samenwerkingsverband vertegenwoordigd via het onderzoekselement hartklepprothesen in het deelproject myocard, waarbij Prof. Dr. R.S. Reneman en Dr. Ir. M.G.J. Arts de begeleiding waarborgden. De Technische Hogeschool Eindhoven participeerde in het samenwerkingsverband via het interafdelingsproject hartklepprothesen waarbij Prof. Dr. P.C. Veenstra en Dr. Ir. A.A. van Steenhoven voor de begeleiding zorgden. Ik was aangesteld bij de Rijksuniversiteit Limburg in de capaciteitsgroep Biofysica terwijl mijn standplaats het interafdelingsproject hartklepprothesen van de Technische Hogeschool Eindhoven was. Gedurende de afgelopen vier jaar heb ik veelvuldig op beide instellingen mijn werkzaamheden verricht. Dat het op zo'n prettige en soepele wijze kon verlopen, is te danken aan de gastvrijheid en de uitgebreide faciliteiten die geboden werden door de capaciteitsgroepen Biofysica en Fysiologie (RUL) en de sectie Medische Techniek van de vakgroep Productietechnologie en de vakgroep Fundamentele Werktuigbouwkunde (THE). Ik heb het als een voorrecht ervaren om te kunnen werken in zo"n multidisciplinaire omgeving.

Dit proefschrift staat op naam van een persoon. De inhoud van het proefschrift kwam echter tot stand door de inzet van velen, zowel op de Rijksuniversiteit Limburg, als op de Technische Hogeschool Eindhoven als daarbuiten. Hen allen wil ik zeer hartelijk danken voor de steun die ik bij het onderzoek heb mogen ontvangen. zonder iemand te kort te doen wil ik de verdiensten van een aantal mensen met name noemen.

Het onderzoek is begeleid door Prof. Dr. R.S. Reneman, Dr. Ir. M.G.J. Arts (RUL), Prof. Dr. P.C. Veenstra en Dr. Ir. A.A. van Steenhoven (THE). Hun kritische, stimulerende en kundige inbreng was essentieel voor de uitvoering van het onderzoek. 
Eij de ontwikkeling van het inductieve meetapparaat mocht 1 k gebruik maken van de faciliteiten van het ultrageluidslaboratorium dat onder dagelijkse leiding stat van Arnold Hoeks (RUL). over electronica problemen kon ik steeds van gedachte wisselen met Arnold Hoeks, Kees Rulssen en Frans Smeets (RUL). Mede dankzij hen kon het meetapparaat in zijn uiteindelijke worm gereed komen. Eugene wintjens (RUL) heeft een belangrijk deel van het meetapparat op kundige wijze gebouwd. Het meetapparat is niets zonder spoeltjes. De spoelkerntjes werden in grote aantallen op vakkundige wijze aangemaakt door Jacques Cauwenberg (THE), terwij1 Jacques Lambregts en Theo van de Nagel (RUL) het wikkelwerk vook hun rekening namen.

Tot de realisatie van de afstandsmetingen in de aortaklep van het levende dier hebben velen bijgedragen. Dr. W. Flameng en Dr. W. Daenen (St. Rafaël klinieken, Leuven, België) leerden ons de beginselen van de benodigde open-hart chirurgische technieken. De definitieve experimenten werden uitgevoerd met ondersteuning van Ruud Kruger, Jet Beekman, Theo van de Nagel, Inger SimonsAchtenberg, Eric van de Veen (RUL) en Theo van Duppen (THE). Het blijvende enthousiasme en de inzet van deze groep waren essentieel voor het welslagen van de experimenten. Gedurende de weken dat de experimenten uitgevoerd werden was de centrale Dienst Proefdiervoorziening zwaar bellast. Huub simons zorgde ervoor dat de experimenten desondanks ongestoord konden verlopen.

Bij de verwerking van de experimenten op de computer van de Technische Hogeschool Eindhoven baande Nico Touwen (THE) het pad. De statistische aspecten van de verwerking werden op kundige wijze ondersteund door Jack Wijnen (THE).

Fons Sauren, Ed Rousseau en Tini van Hout (THE) waren fijne collega's met wie ik ten alle tijden over het onderzoek kon aiscussièren.

Dit proefschrift is zoals bij velen onder de nodige tijdsdruk geschreven. Ik aank de promotores, co-promotores en referenten voor hun snelle commentaar. Gerard van den Akker en Joop onink (THE) zorgden op korte termijn voor een goed verzorgde set figuren. Hans Rensema (RUL) dank ik voor de beschikbaarstelling van zijn aortaklep tekeningen. Leo wouters (THE) verzorgde de foto 
van het spoeltje. Rosy Borgman-Hanssen (RUL) was bereid om het proefschrift te typen naast haar werkzamheden voor de capaciteitsgroep Biofysica. Haar accurate en professionele aanpak daarbij gecombineerd met de grote inzet heb ik zeer gewardeerd. Bij de samenstelling van de eindversie van het proefschrift kon ik steeds rekenen op de steun van mijn paranimfen Ed Rousseau (THE) en Frans Smeets (RUL). Nico Touwen (THE) las het proefschrift nauwgezet na op tekstfouten.

Het schrijuen van dit proefschrift en het daaraan voorafgaande onderzoeksjaar hebben een zware claim gelegd op ons gezinsleven. Janet, deze claim werd net in een periode gelegd warin we elkaar juist nodig hadden. Vaak heb je alleen gestaan met je gevoelens en heb je het gezin in je eentje draaiende gehouden. Dat dit proefschrfit afgerond kon worden is vooral te danken aan jouw medewerking en steun. 



\section{CURRICULUM VITAE}

16 maart 1953

$1965-1970$

$1970-1978$

1 apri1 1978

1 augustus 1978

1 januari 1983
Geboren te Eindhoven

HBS-b gevolgd aan het St. Jorislyceum te Eindhoven.

Electrotechniek gestudeerd aan de Technische Hogeschool Eindhoven.

In dienst getreden als wetenschappelijk assitent van de afdeling werktuigbouwkunde, Technische Hogeschool Eindhoven.

In dienst getreden als wetenschappelijk ambtenaar van de capaciteitsgroep Biofysica van de Rijksuniversiteit Limburg, in het kader van een samenwerkingsverband tussen de Rijksuniversiteit Limburg en de Technische Hogeschool Eindhoven. De werkzamheden werden zowel aan de Technische Hogeschool Eindhoven als aan de Rijksuniversiteit uimburg uitgevoerd.

In dienst getreden als wetenschappelijk ambtenar van de afdeling kindercardiologie van de Rijksuniversiteit Nijmegen. 